\title{
Swinging industries, cycles, adjustment and performance : an empirical examination of the international paper and pulp industry
}

Citation for published version (APA):

Berends, P. A. J. (2001). Swinging industries, cycles, adjustment and performance : an empirical examination of the international paper and pulp industry. [Doctoral Thesis, Maastricht University]. Universitaire Pers Maastricht. https://doi.org/10.26481/dis.20010613pb

Document status and date:

Published: 01/01/2001

DOI:

10.26481/dis.20010613pb

Document Version:

Publisher's PDF, also known as Version of record

Please check the document version of this publication:

- A submitted manuscript is the version of the article upon submission and before peer-review. There can be important differences between the submitted version and the official published version of record.

People interested in the research are advised to contact the author for the final version of the publication, or visit the DOI to the publisher's website.

- The final author version and the galley proof are versions of the publication after peer review.

- The final published version features the final layout of the paper including the volume, issue and page numbers.

Link to publication

\footnotetext{
General rights rights.

- You may freely distribute the URL identifying the publication in the public portal. please follow below link for the End User Agreement:

www.umlib.nl/taverne-license

Take down policy

If you believe that this document breaches copyright please contact us at:

repository@maastrichtuniversity.nl

providing details and we will investigate your claim.
}

Copyright and moral rights for the publications made accessible in the public portal are retained by the authors and/or other copyright owners and it is a condition of accessing publications that users recognise and abide by the legal requirements associated with these

- Users may download and print one copy of any publication from the public portal for the purpose of private study or research.

- You may not further distribute the material or use it for any profit-making activity or commercial gain

If the publication is distributed under the terms of Article $25 \mathrm{fa}$ of the Dutch Copyright Act, indicated by the "Taverne" license above, 


\section{Swinging Industries}

Cycles, adjustment and performance

An empirical examination of the international pulp and paper industry 


\section{Swinging Industries}

Cycles, adjustment and performance

An empirical examination of the international pulp and paper industry

\section{PROEFSCHRIFT}

ter verkrijging van de graad van doctor aan de Universiteit Maastricht, op gezag van de Rector Magnificus, Prof. Dr. A.C. Nieuwenhuijzen Kruseman, volgens het besluit van het College van Decanen in het openbaar te verdedigen op woensdag 13 juni om 16.00 uur door

Pieter Albert Johan Berends

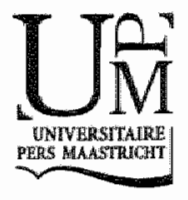


Promotores:

Prof. Dr. A. van Witteloostuijn (Rijksuniversiteit Groningen) Prof. Dr. A.G.L. Romme (Katholieke Universiteit Brabant)

Beoordelingscommissie:

Prof. Dr. J.G.A.M. Lemmink (voorzitter)

Prof. Dr. W.F.J. Buijink

Prof. Dr. S.W. Douma (Katholieke Universiteit Brabant)

(C) Peter Berends, 2001

ISBN 90-5278-310-1

Cover: Jori Spaa 


\section{Acknowledgements}

I wonder whether or not the pile of paper (i.e., this thesis before going to press) lying in front of me is the result of purposeful work or that it is merely the by-product of a transformational process of the last four years. Certainly, this thesis is the result of long and enduring labor. However, it would not have been possible without the help and support of many, many other persons to whom I am greatly indebted.

First of all, I survived the "AiO-struggle' because I was lucky to have been in frequent contact with three people that I consider being masters in their fields. Arjen van Witteloostuijn, Gerard Endenburg, and Yvo van Orshowen all influenced me in significant ways in the choices I have made and serve as important examples of how to live.

This thesis could not have been completed without the support and help of my supervisors Arjen van Witteloostuijn and Sjoerd Romme. It is due to the latter, by the way, that I embarked in 1996 on this thesis trip. I am indebted to both of them for the meticulous reviews of my chapters and the helpful suggestions for improvement. I am grateful to Martin Carree and Martin Wetzels for their help on econometric matters. Specifically, the former Martin has been of great help with his technical knowledge and also by putring the techniques into perspective. I would allso like to thank Jos Lemmink, Willem Buijink and Sytse Douma for evaluating the final version of this document.

The research that is part of this thesis has been greatly facilitated by the easy access to substantial data sources. I am grateful to Marion de Groot from Sappi and Heide Matussek from PPI for allowing me into the archives of their companies. Rob van Well and Piety van der Nagel are highly appreciated for the data entry and construction of the early data set. Furthermore, I am grateful to Susan Roggen for helping me out with, and improving the English of the final version; to Jori Spaa for, first of all, designing the cover and, secondly, for doing so with eyesmashing speed.

Then, many people played important roles in the social environment of the university who invariably lightened up the path to travel. I would like to mention a few people, and, at the same time, to apologize to those who I forget here. They are Sjoerd Romme, my 
roommate Vera Bröcheler, Nicole and Wenco, Annelies and Hans, Marielle, Jeroen and Marc, my literature society fellows Christiane, Ruth and Boris, the colleagues from the department of Organization Studies and those from the Strategy department.

I am grateful to my family, especially to my parents and brother, for installing in me the genes and the wir, for offering a place to go, and for their unconditional listening; to my grandfather for trying to explain, when I was eight years of age, the concept of a 'stochast'. My father deserves a special word of thanks for providing funds (and a lot of them) when I was doing my studies, even after I decided to start studying again at 26. I still have the letters that accompanied the weekly support.

My greatest thanks, however, go to Mayke, for supporting me during my personal troughs and celebrating my peaks with me; for patiently putting up with me during the past four years; for being my muse; for daring to challenge my views. It is to her that I dedicate this book.

Peter Berends

Maastricht, April 2001 
To Mayke 


\section{Contents}

\section{List of tables \\ List of figures}

\section{Chapter 1}

\section{INTRODUCTION}

1.1 Guiding question

1.2 Conceptuall framing of the thesis

1.3 Overview of the chapters/ outline of this study

\section{Chapter 2}

INDUSTRY, SAMPLE AND METHOD 7

2.1 Choice of industry and sample description 7

2.1.1 Choice of the industry 7

2.1.2 The size of the samples in the different examinations 8

2.13 Method of data collection 9

Firm data 9

Industry data 10

2.2 Structure, conduct and performance in the paper and pulp industry $\quad 11$

2.2.1 Structure of the paper and pulp industry 11

2.2.2 Conduct in the paper and pulp industry 14

2.2.3 Performance in the paper and pulp industry 17

2.3 A note on the use of simulation techniques in this thesis 18

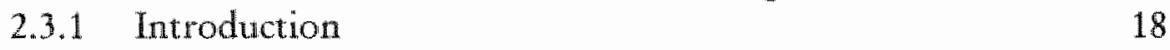

2.3.2 Definition: what is simulation? 20

2.3.3 Systems thinking and simulation 23

2.3.4 Validation of a system dynamics model 24

2.3.5 Examples 26

2.4 Methods: A short note on other methods used 29

Chapter 3

\section{AS THE WORLD TURNS}

Cyclicality of capital intensive industries 31

3.1 Introduction 31

3.2 Sinulation and System Dynamics 33 
3.3 Cyclicality of the paper and pulp industry 34

3.4 Starting point: Meadows' model 36

3.5 Modeling the paper and pulp industry $\quad 40$

3.5.1 Validation of the model: price determination 41

3.5.2 Validation of the model: capacity determination 42

3.5.3 The influence of new process technology 43

3.6 Conclusion and discussion 45

Chapter 4

GOOD TIMES, BAD TIMES

Symmetric or Asymmetric Adjustment to Cycle Movements $\quad 48$

$\begin{array}{lll}4.1 & \text { Introduction } & 49\end{array}$

4.2 Theory and hypotheses $\quad 54$

4.2.1 The influence of macro cycles 54

4.2.2 The influence of meso cycles 55

4.2.3 The influence of micro cycles 57

4.3 Data and methods $\quad 59$

4.3.1 Motivation for industry choice $\quad 59$

4.3.2 The sample 60

4.3.3 Variables and measurement 60

4.3.4 Method 68

4.4 Results $\quad 69$

4.5 Discussion 76

Chapter 5

THE (B)HOLD AND THE BEAUTIFUL

Sticky Downsize Routines with an Inert vs. Versatile nature $\quad 80$

$\begin{array}{ll}5.1 \text { Introduction } & 81\end{array}$

5.2 Theory and hypotheses 83

5.2.1 Two seemingly opposing theoretical frameworks:

Darwin versus Lamarck $\quad 83$

$\begin{array}{ll}\text { 5.2.2 Downsizing studies } & 84\end{array}$

5.2.3 Change and inertia studies 85

5.2.4 Propositions and hypotheses 88

5.3 Data and methods $\quad 89$

5.3.1 Research setting $\quad 89$

5.3.2 Variables and measurement 90 
5.4 Results 100

5.4.1 Key findings 100

$\begin{array}{lll}5.4 .2 & \text { Robustness tests } & 102\end{array}$

5.4.3 Performance of the routines over time 104

$\begin{array}{ll}5.5 \text { Discussion } & 107\end{array}$

\section{Chapter 6}

\section{CONCLUSION}

6.1 Problem statement and methodology review 109

6.2 Summary of findings and contribution to the literature 111

6.3 Limitations of the studies

6.4 General conclusions and recommendations for further research

6.4.1 General conclusions

6.4.2 Future research

\section{Appendices}

A. Stock-flow diagrams and equations for models used in Chapter 3

B. Data for US paper and pulp industry

C. Detailed report of OLS-transformation steps for GLS-results presented in Chapter 5

D. Clarification of the split-up procedure followed In Chapter 5

References 


\section{LIST OF TABLES}

1.1 This study and organization science

2.1 Overview of per-capita consumption, total consumption and human development index for selected Western countries

2.2 Density and concentration in the sample

2.3 Degree of similarity between expectation in year $t$ and result for year $t+1$

2.4 Simulation research in organization (related) studies

3.1 Summary of the assumptions made by Zhang et al. (1993) and Meadows (1970)

3.2 Effects of decreasing delay and inventory coveragte on cycle amplitude and cycle time

4.1 Cycles at different levels of aggregation

4.2 Adjustment to cycle stages

4.3 Cycle stages

4.4 Causes of inertia

4.5 Description of this study's variables.

4.6 Overview of growth and decline per indicator variable

4.7 Descriptive statistics

4.8 Correlations

4.9. Testing the influence of macro-cycles 70

4.9 b $1975-1985$ versus $1986-1997$ in the U.S. 70

4.9c 1975-1990 versus. 1991-1997 in Europe 71

4.10 Influence of stages over the industry cycle on divestment and measurement

4.11 Testing for the influence of meso cycles

4.12 Testing for the influence of micro cycles 75

4.13 Summary of the results 77

5.1 Hypothesized effects of covariants on profitability 94

5.2 Description of the variables used in this study 95

5.3 Routine boundaries and their descriptives 96

5.4 Correlations 97

5.5 Descriptive statistics 98

5.6 Correlations (all variables) 99

$\begin{array}{lll}5.7 & \text { GLS coefficients } & 101\end{array}$ 
5.8 Descriptives: group membership under original and adjusted boundary settings

5.9 Test results

6.1 Overview of the main propositions, variables and conclusions

B.1 Data used for model validation

C.1 Rough OLS coefficients

C.2 Coefficients of the most important partial regression

C.3 Partial regression results on a random sample of 100 cases

C.4 Test results corrected for multicollinearity

D.1 The process dimension of downsizing

D.2 Possible downsizing positions of a firm in the sample

D.3 Unpooled and pooled GLS results

D.4 Firms and their routine combinations

D.5 Mean profitability for the firms holding different routine combinations

\section{LIST OF FIGURES}

1.1 Framework of this thesis

2.1 Sample and industry paper and board production

2.2 Overview of simulation techniques

3.1 Capacity utilization and return on assets of the top-150 producers in 1978-1996

3.2 Causall loop structure

3.3 Observed versus simulated price $\quad 42$

3.4 Observed versus simulated capacity 43

3.5 Causal loop structure adjusted for direct demand influences

4.1 Schematic overview of the examination

4.2 Relative frequencies of asset and workforce growth for the continuous covariants

4.3 Cycle stages of capacity utilization with $87 \%$ as demarcation point 
5.1 Nature, process and content of downsizing and the influence on performance

5.2 Development of mean paper sales rank per year for the contemporaneous asset downsizing groups

5.3 Development of mean paper sales rank per year for the Contemporaneous workforce downsizing groups

5.4 Development of mean paper sales rank per year for the delayed asset downsizing groups

5.5 Development of mean paper sales rank per year for the delayed workforce downsizing groups

6.1. Framework of this thesis

6.2 Adjusted framework of this thesis

A.1 Stock and flow representation of the basic model

A.2 Stock and flow representation of the extended model

C.1 Plot of squared residuals on the predicted $Y$

C.2 Plot of squared residuals on diversification

C.3 Plot of squared residuals on the number of countries

C.4 Plot of squared residuals on the capital to sales ratio

C.5 Plot of the unstandardized residuals on their one-period lagged values

C.6 Plot of the standardized residuals on their one-period lagged values 



\section{Chapter 1 INTRODUCTION}

This introductory chapter consists of three sections. Section 1.1 introduces the questions that have guided the series of three studies of this thesis. Then Section 1.2 locates the thesis in the broader context of the organization sciences at large and argues why it may be interesting to take notice of this work. Finally, Section 1.3 gives a short outline of what is to come in the following chapters.

\subsection{Guiding question}

What determines the performance of firms? This is perhaps the most examined question in organization studies. In the organization sciences, a wide range of factors, both external and internal to the firm, are studied in relation to individual firm performance. Ultimately, the purpose of this study is to examine factors that might explain the relationship between economic cycles (at three levels of aggregation) and firm performance, particularly profitability. Moreover, this thesis also examines if and how the phenomenon of the industry cycle can be explained by examining firm behavior. It explicitly recognizes the reciprocal influences from industry dynamics to firm behavior and vice versa, so stepping in the footsteps of a long tradition in economic studies. This thesis thus deals with economic cycles, the adjustment behavior of firms and the resulting organizational performance in a 
dynamic context. The dynamic context implies that we consider worldwide industry movement over a period of 25 years. The international pulp and paper industry is chosen as the research setting of this thesis.

The research questions in this thesis arise from an amazement about the huge and sustained dynamics in the paper and pulp industry. For one thing, the paper industry is one of the oldest industries of our society. Additionally, it cannot be disputed that the industry is a typical example of a mature industry, characterized by low growth. Why is an industry that is so old not in a kind of equilibrium? And, given the dynamics of the industry, how can an individual firm best perform in such a state of permanent flux? These two statements of wonder gave rise to the research questions of this thesis. More specifically, this thesis seeks to contribute to an understanding of the following three, related, questions:

What causes industrial cycles in mature capital-intensive industries?

How do cycles at the micro, meso and macro level influence firm behavior?

How does the nature of the firms' reactions to cyclicality infuence their performance?

\subsection{Conceptual framing of the thesis}

The number of fields that can be covered by a student of business administration or business economics is vast. Due to their multidisciplinary nature, these fields of research can leave one in disarray as to what belongs to what. In order to determine the scope of this study, we will locate this thesis within a framework adopted from Van Witteloostuijn (1994 and 1996), which categorizes branches of organization studies on the basis of the level of aggregation and disciplinary perspective or background. This current study approaches one industry from both an economic and a sociological perspective. The economic aspect originates in industrial organization and strategic management, while the sociological part relates to organization ecology. Table 1.1 pictures the framewrork, and indicates where to position this thesis. 
Table 1.1: This study and organization sciences

\begin{tabular}{|c|c|c|c|}
\hline \multirow[t]{2}{*}{ Aggregation level } & \multicolumn{3}{|l|}{ Disciplinary perspective } \\
\hline & Econiomics & Psychology & Sociology \\
\hline Sociely & Whroeconomics & Macro Psychoby & Maph Sorroloy \\
\hline Muluple indusines & \multirow{2}{*}{$\begin{array}{l}\text { ndustral Orgarizalon and } \\
\text { Strateglo Managentent }\end{array}$} & - & \multirow{2}{*}{ Organization Ecology } \\
\hline Single industry & & Neso Psychology & \\
\hline Fim? & \multirow{2}{*}{$\begin{array}{l}\text { Ecowomic Theory of intemal } \\
\text { Organization }\end{array}$} & 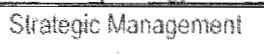 & \multirow[t]{2}{*}{ Organtration Snowh } \\
\hline$\frac{\text { Tean }}{\text { Inowidual }}$ & & Onternational Behawot & \\
\hline
\end{tabular}

Adopted from Van Witteloostwizn (1994).

Within the defined framework of the industry study, the focus is on economic cycles and firm behavior. An understanding of what drives cyclical movements will greatly influence the actions taken by the firms that face the cycle. Studying the history of an industry offers a profound insight into what reactions to cyclical movements are performance enhancing, and what strategies are not. This question can be examined both from a societal position and from a business perspective. It might even be that specific organizational behavior is beneficial for both society and the firm. Thus, this thesis hopefully makes for interesting reading for both policy makers within governmental bodies and business strategists of firms that operate within mature capital-intensive industries.

\subsection{Overview of the chapters and outline of this study}

This section briefly describes the contents of this thesis. Roughly, the thesis comprises general chapters (Chapters 1,2 and 6) and empirical chapters (Chapters 3, 4 and 5). The empirical chapters are all written as stand-alone essays around the general theme of this work. They can thus, by and large, be read without knowledge of the previous or subsequent chapters. This design was deliberately chosen, as each examination demanded its own approach, in theoretical content as well as in the methods applied. Definitions of key terms can hence be found in each separate examination.

Chapter 2 provides an introduction into and an overview of the paper and pulp industry and the research sample as well as a note on the methods used in this thesis. It provides an insight into why the paper and pulp industry was chosen, and it introduces the sample and data used. The chapter also describes the industry in terms of structure, conduct and performance, and shows why it is interesting to study 
mature capital-intensive industries. Additionally, arguments are provided as to the choice of the research methods for the following chapters. Finally, descriptive statistical information about the sample has been added (i.e., concentration ratios and sample coverage).

Chapter 3 is the first empirical chapter of this thesis, dealing with the causes of industry cyclicality. Cyclical behavior of economies and industries has attracted attention from scholars ever since the establishment of economics as a science, but particularly since the early 1930 s when a large part of the Western world was hit by a severe depression. The course of firms and industries is, almost by definition, accompanied by times of prosperity and times of downfall. The following pattern emerges at an aggregated industry level: if times are good, the dominant wisdom is to invest in capacity; if times are bad, rationalizing is the strategy commonly followed. Rationalizing goes, more often than not, hand in hand with the layoff of a large part of the labor force, which imposes huge costs on society. This underlines the importance of studying economic cycles, in order to understand their emergence and remedy their consequences. The prevailing literature on causes of and remedies for business cycles typically approaches cyclicality from an external angle, attributing causes to forces outside the industry. Chapter 3 aims at answering the following, related, questions from an industry-internal perspective: Why is over-capacity such a persistent factor in the pulp and paper industry?; What drives firms to invest while knowing that adding extra capacity undermines industry profitability?; How can we gain a deeper understanding of the processes leading to the cyclicality of the paper and pulp industry and what is the influence of technological development on the emergence and sustained nature of economic cycles? The chapter seeks to explore these questions with the use of simulation techniques. The chapter first explains why simulation methods and, more specifically, the system dynamics perspective are used here. Then, the industry under study the pulp and paper industry - is described. Third, it briefly reviews the relevant models found in the literature, and explains why a model developed by Meadows is selected as our starting point. Subsequently, the original model will be adjusted and validated. Finally, the influence of new process technology on industry cycles is explored with the adjusted and validated model.

Chapter 4 extends the idea of economic cycles and how they influence investment behavior of firms. More specifically, it distinguishes three different levels of cyclicality, all associated with 
stages of rise and decline that influence the adjustment behavior of firms. This chapter looks at macro or business cycles, meso or industrial cycles and micro or firm cycles. It examines whether or not companies adjust their positions in relation to the stage of a cycle the firm is facing. The position of the firm is defined in terms of the composition (or vector) of its resources. In this examination we focus on the assets base and the number of employees as two important components of the position of a firm. We assess the influence of macro and meso cycles on alterations in firm positions. At a micro level, we study the influence of profit decline, particularly whether or not a firm responds to this decline by downsizing its position. In the organization sciences, decline is normally associated with a phase in the life cycle of an industry or of a firm (Miller and Friesen 1984; Klepper 1997). This chapter focuses instead on regularly returning phases of decline in the macro cycle, in the meso cycle, and in the micro cycle. Hypotheses are formulated so as to test the relationship between the different cycle stages and the position adjustment patterns (in assets and workforce) of individual firms. Chapter 4 first defines the concept of cycles at the different aggregation levels. Then, the idea of symmetric and asymmetric adjustment is introduced. Third, hypotheses are derived from existing literature. Finally, these hypotheses are subsequently tested employing a logistic regression technique.

Chapter 5 probably examines the most frequently asked research question within organization studies as it focuses on explaining the (financial) performance of firms. Within the confines of this question, the current study concentrates on the effect of downsizing on performance, particularly profitability. 'Thus, Chapter 5 builds on the results of Chapter 4 by looking at the performance effects of the reactions of firms that face declining resources. This examination adds to the existing downsizing literature by testing the relationship between downsizing routimes and organizational performance. Specifically, the model developed in this chapter answers the question as to what downsizing routine yields the highest performance. It proposes the idea that downsizing routines are sticky over time, and defines two routines that differ in nature. Chapter 5 first develops the idea that routines are sticky over a prolonged period of time. Then, a theoretical framework is proposed that looks at downsizing from a three-dimensional framework: the nature, content and process of a downsizing operation. Thirdly, we define two competing propositions as to what type of downsizing routine yields the highest performance. 
The hypotheses are tested using the generalized least squares method. Chapter 5 devotes special attention to the robustness of the results.

Chapter 6, finally, wraps up the whole thesis, summarizes the chapters and gives a short overview of the hypotheses tested and the results obtained. Suggestions for further research are also proposed here.

Figure 1.1 provides a scheme that shows how the different empirical chapters are interrelated.

Fugure 1.1: Framentork of this thesis

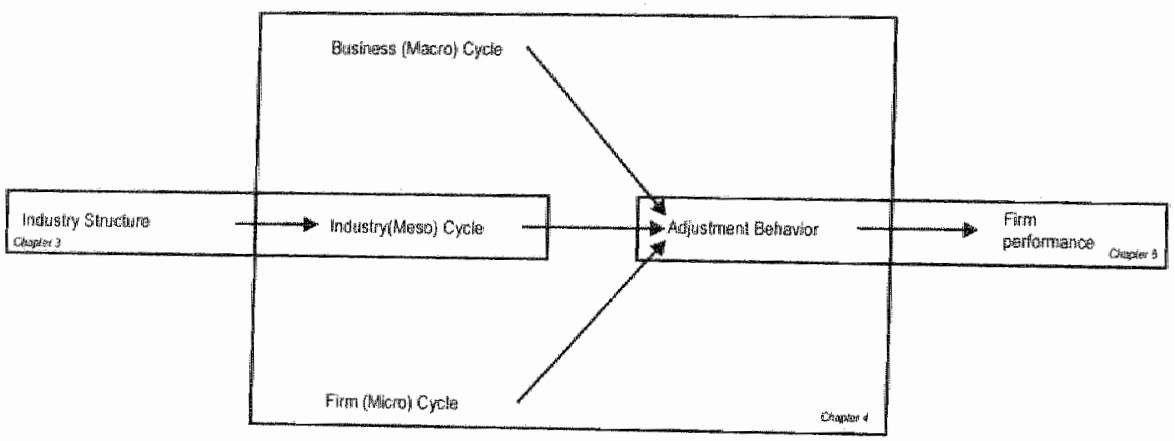

As explained above, Chapter 3 describes how firms in an industry cause their own industrial cycle. A simulation technique is used to gain an insight into the endogenous dynamics of industry cyclicality. Furthermore, the model is validated, which provides extra support for our viewpoint. Taking cycles for granted, Chapter 4 deals with the issue of whether or not firms try to establish a fit between their internal positions and the external resources. As an indicator for contracting or expanding external resources, we look at stages of economic cycles at different aggregation levels. So, Chapter 4 shares its theme with Chapter 3: firm behavior and economic cycles. Chapter 5, then, focuses on the patterns of firm adjustment as found in Chapter 4. Three patterns or routines are proposed, and their influence on firm 


\section{Chapter 2 \\ INDUSTRY, SAMPLE AND METHOD ${ }^{1}$}

This chapter provides an overview of the paper and pulp industry, the research sample and a note on the methods used in this thesis. Section 2.1 offers an insight into why the paper and pulp industry was chosen, and introduces the sample and data used. Section 2.2 describes the industry in terms of structure, conduct and performance, arguing why it is interesting to study mature capital-intensive industries. Next, Section 2.3 gives an extensive argumentation and endorsement for the simulation method used in Chapter 3. Section 2.4, finally, devotes a word or two on the other methods employed in this thesis. These methods are more common and therefore require less elaboration. Moreover, these methods are all dealt with at length in the empirical chapters that employ them.

\subsection{Choice of industry and sample description}

\subsubsection{Choice of the industry}

The research setting of this thesis is the international pulp and paper industry over the period 1974-1997. The reason for selecting this setting is fourfold. First of all, many scholars have pointed at the obvious relevance of doing in-depth industry specific research to form and test

\footnotetext{
${ }^{1}$ Part of this chapter is based on Berends and Romme (1999).
} 
theories on the evolution of industries and conduct of (groups of) individual firms (cf. Sutton 1991). In this context, the paper and pulp industry has received relatively little attention in the organization/economic literature [exceptions are Nehrt (1996) and Calori and Ardisson (1988)] other than in production technology related publications. Secondly, the industry is very old, going back to at least the end of the 18th century, and it is characterized by low growth, high capital intensity and notoriously cyclical behavior. These features make the setting very appropriate in the context of our interest in boom and bust cycles, specifically in their causes (Chapter 3) and in the influence on organizational change (Chapter 4). A third reason for selecting this industry is that it was possible to accumulate data on many firms over a fairly long period (24 years) over several worldwide regions. On average, the firms in our data set account for 60 to 80 percent of yearly paper and pulp production. The variety of firms in our data set together with the range of parameters observed enable us to examine different hypotheses and their validity in different contexts. Additionally, the length of the observation period provides good opportunities to study firm and industry dynamics. Fourthly and finally, the availability of detailed industry yearbooks and an annually published ranking of paper-related firms made the data relatively easily accessible. The choice to restrict the observation period to 24 years was induced by the unavailability of fine-grained data on this wide range of firms before 1974.

\subsubsection{The size of the samples in the different examinations}

It is important to mention that the empirical studies in this thesis differ in sample size. This was caused by the different study-specific data demands, availability of the data in the different study-specific periods and different study-specific sets of dependent variables. The examinations required differing modifications of the data set, the procedures of which are described in the respective chapters. In each case, the maximum number of observations was included in the samples, which is reported with the test results. In order to be able to correct for multicolinearity and autoregression, twenty outliers were removed for the test in Chapter 5. However, the results without this correction are also reported here.

Chapter 3 covers a simulation study with a validation exercise that exploits other data. To compare the simulation results with a yardstick, we used data as compiled and reported by Zhang and 
Buongiono (1993), whose research question bears close resemblance to the one put forward in Chapter 3: How are boom and bust cycles generated endogenously in capital-intensive industries?

Firms are selected based on the number of data points available. Firms were excluded from all samples if no earnings, sales, assets or workforce information was reported. For examinations in Chapter 4, firm data over at least two consecutive years was needed. Each first observation of a series of reported firm-years was thus dropped.

\subsubsection{Method of data collection}

All data was collected from Paper and Pulp International (PPI) sources, a publisher of industry journals and compendia. ${ }^{2}$. The firm-level data were extracted from the top 150 that the industry journal publishes each year. The industry level data were derived from their industry yearbooks. Furthermore, to gain insights into the dynamics of the industry and to test our ideas informally, we conducted four open unstructured interviews with industry insiders.

\section{Firm data}

Data were collected on 287 individual firms over a time span of 24 years (1974-1997). The rough data set includes 2941 firm-year observations, implying that we have, on average, 10.2 observations per firm only. 35 Firms were present in the industry's top 150 during the whole period of observation, for 104 firms the data set contains 10 to 23 observations (mean: 14.3) and for the other 148 firms we have 1 to 9 observations (mean: 4.2 ).

From home-country information we can conclude that 287 firms are spread over the various worldwide regions as follows: Europe with 130 firms and 1210 observations; North America with 86 firms and 1047 observations; Asia with 43 firms and 443 observations; and South America with 13 firms and 103 obserwations. Fifteen remaining companies include 147 observations.

The data collected per firm comprised the following accounting data: total sales (in US \$), paper-related sales (\$), net earnings (\$) and total assets ( $\$$ ). Further information was collected on market pulp production (tons), paper production (tons), converted products (tons), workforce (number fo employees), nationality of the firm's

\footnotetext{
2. We thank Heide Matussek of PPI and Marion de Groot of Sappi, who both
} generously made sources available for this research project. 
headquarters and $C E O$ replacement events. Nor all companies reported all data for each year. Specifically, data on production numbers appeared to be unreliable. In each empirical chapter, only full cases (i.e., without missing values) were used to estimate the models. Due to the different nature of the tests, different numbers of observations were used, which are reported with the test results. Furthermore, assets were not reported for any firm from before 1975 .

\section{Industry data}

Next to firm-level data we collected industry information. Of the huge amount of data found, we predominantly used capacity (tons), consumption (tons) and production (tons). These figures are reported per country. Data on capacity is only available for the 1978-1996 period. Figure 2.1 shows the development of world paper and board production, together with sample paper and board production. The figure clearly reveals that the sample used covers most production, producing similar dynamics over time.

Figure 2.1: Sample and industry paper and board production

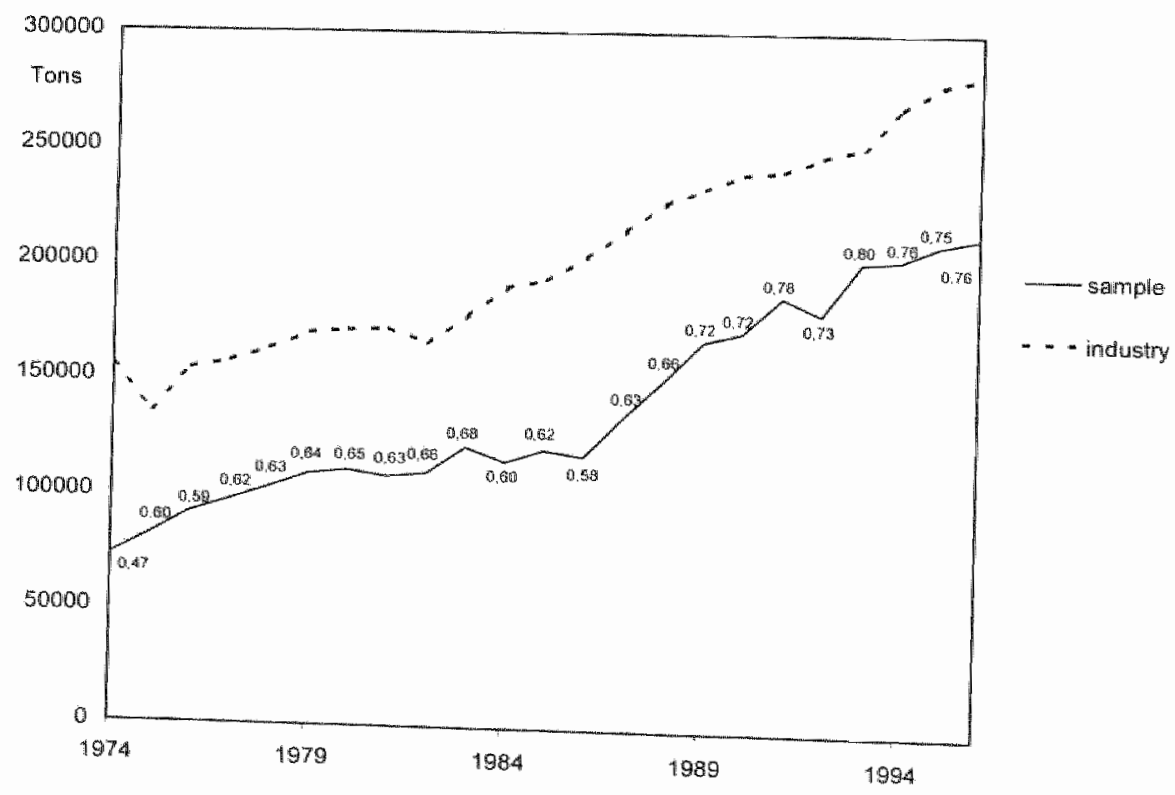

* Numbers in the chan indicate percentages of sample coverage. 


\subsection{Structure, conduct and performance in the paper and pulp industry}

\subsubsection{Structure of the paper and pulp industry}

The paper and pulp industry is part of a business system (cf. Zavatta 1993, Lilja et al. 1992) that starts with forestry and waste paper collection, and ends via intermediate chains (pulp production, production of paper, and conversion of paper products) with sales to a wide variety of end-users. The 'paper and pulp industry' refers to a broad range of activities such as the production and conversion of paper, board and pulp.

It is interesting in the context of this thesis that capacity utilization and profitability of the firms in the paper and pulp industry show a cyclical pattern. Moreover and surprisingly, they seem hard to predict. The cyclical character of the industry is surprising because the demand of paper has risen steadily over the past forty years and is projected to grow even further in the future. Consumption per head of the population still diverges widely, even in the Western world, which provides a basis for continued growth. Table 2.1 provides an overview

Table 2.1: Overview of per-capita paper consmmption, total consumption and buman development index for selected Western countries

\begin{tabular}{lccc}
\hline & $\begin{array}{l}\text { Per capita consumption } \\
\text { (kghead) }\end{array}$ & $\begin{array}{l}\text { Total } \\
\text { consumption } \\
\text { (000 tons) }\end{array}$ & $\begin{array}{l}\text { Human development } \\
\text { indeg }\end{array}$ \\
\hline Finiand & 319.5 & 1638 & 94.0 \\
lialy & 144.1 & 8250 & 92.1 \\
Netheriands & 204.2 & 3181 & 94.0 \\
Poland & 40.0 & 1544 & 83.4 \\
Poitugal & 85.2 & 836 & 89.0 \\
\hline
\end{tabular}

3 Population data are from staristics provided by United Nations over 1996, and the

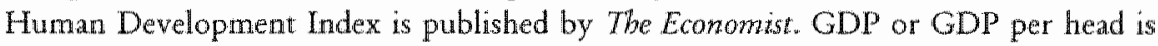
often taken as a measure of how developed a country is, but its usefulness is limited as it refers to economic welfare only. In 1990, the UN Development Program published its first estimate of a Human Development Index, which combined statistics on two other indicators -adult literacy and life expectancy- with income levels to give better, though still far from perfect, indicator of human development. In 1991, average years of schooling was combined with adult literacy to produce a knowledge variable. The index shown there is scaled from 0 to 100 ; countries scoring over 80 are considered to have high human development and those under 50 to have low human development. 
of per-capita consumption, total consumption and the United Nations Human Development Index (HDI) for selected European countries in 1996.

The idea that growth rates will be persistently positive for years to come rests on two assumptions. First of all, that paper consumption per head is strongly associated with welfare (here HDI), implying that if welfare in a country increases, the amount of paper used will also rise. Interestingly, the impressive rise of the use of computers seems to have had only stimulated the usage of paper instead of substituted for it. The second assumption is that welfare across Europe will keep on growing with a tendency to converge to the level of the richest countries.

An explanation of the cyclicality in the paper and pulp industry can be found in the combined effects of two structural characteristics of this industry:

1. Capital intensity. The production of pulp, paper and board is highly capital-intensive due to the vast amounts of money needed for investments in production facilities. This follows directly from the advantages that can be gained through large scale. It is interesting to note that the average paper production capacity of facilities in Scandinavia is about three times larger than the capacity on the European continent.

2. Investment delay. The delay between the decision to invest and the materialization of this decision is significant. This delay amounts from three to five years (Nehrt 1996) between the investment decision and the first usable paper that is produced. The decision to divest is also characterized by delay, albeit shorter (one to two years) than the investment-construction-materialization delay. Additionally, common practice in the industry is to "mothball" machinery, but it usually takes some time to plan for the mecessary personnel implications.

The dynamics of the industry are caused, to a certain extent, by a 'prisoner dilemma', which is well grounded in the game-theoretical literature. Its complex operation is determined by the inability of paper producers to co-ordinate their actions, predominantly because of the fairly low degree of concentration, the geographical dispersion and the
delay structure that has been described above.

Concentration in the paper and pulp industry is measured using a $\mathrm{Cn}$ ratio. This measure indicates the combined market shares (sales) of 
the $n$ largest producers. Our sample $\mathrm{C}_{n}$ ratio development provides a good proxy of total industry concentration development because of the industry coverage of our sample. Table 2.2 reports sample $\mathrm{C}_{4}$ and $\mathrm{C} 8$.

Table 2.2: Density and Concentration in the sample

\begin{tabular}{rrll|rrrr}
\hline JAAR & \multicolumn{1}{c}{$N$} & $C_{4}$ & $C_{8}$ & JAAR & $N$ & $C_{4}$ & $C_{3}$ \\
\hline 1974 & 94 & 0.16 & 0.28 & 1986 & 97 & 0.17 & 0.28 \\
1975 & 100 & 0.15 & 0.25 & 1987 & 99 & 0.17 & 0.27 \\
1976 & 100 & 0.16 & 0.27 & 1988 & 1.49 & 0.15 & 0.24 \\
1977 & 100 & 0.15 & 0.27 & 1989 & 150 & 0.15 & 0.25 \\
1978 & 100 & 0.15 & 0.25 & 1990 & 150 & 0.16 & 0.27 \\
1979 & 99 & 0.14 & 0.24 & 1994 & 150 & 0.16 & 0.26 \\
1980 & 97 & 0.13 & 0.23 & 1992 & 150 & 0.16 & 0.28 \\
1981 & 100 & 0.14 & 0.24 & 1993 & 150 & 0.16 & 0.26 \\
1982 & 98 & 0.14 & 0.24 & 1994 & 150 & 0.16 & 0.27 \\
1983 & 99 & 0.14 & 0.25 & 1995 & 150 & 0.17 & 0.28 \\
1984 & 95 & 0.15 & 0.27 & 1996 & 150 & 0.18 & 0.29 \\
1985 & 90 & 0.17 & 0.28 & 1997 & 150 & 0.18 & 0.29 \\
\hline
\end{tabular}

Firms are susceptible to economic cycles for the prices that they are able to ask. In troughs it appears to be exceedingly difficult to attain a profitable position, while during peaks the whole industry blossoms. Following growth projections, firms tend to make an investment decision if their cash flow predictions allow them to do so. Given the common influence of the cycle, firms tend to invest at the same time, thus causing a surge in productive capacity after the three to five year delay. So, the situation of overcapacity occurs through a selfreinforcing process of high prices, profit margins, investments in new capacity, and after three to five years, extensive capacity that depresses prices. Because prices decline, cash flow dries up, which leads to divestments. When demand catches up with supply, the cycle starts all over again. The cyclical character of the industry shows strong similarities to so-called hog cycles, based on the processes that are visible in many livestock industries. The processes are similar, albeit that the livestock industry is characterized by (i) a shorter investmentdelay structure and (ii) higher degrees of freedom as to the choice of quantity.

The end of the 1980 s is a case in point. This period was characterized by a wave of new investments that materialized between 
1991 and 1993, after which both prices and profitabilities started to gain momentum again. Although the cyclical pattern seems to be rather smooth and regular, it is apparently very difficult to predict the phase of the cycle and its impact on the individual paper producer. An analysis of the former KNP-BT annual reports (1970-1996) illustrates this unpredictability (see Exhibit 2.1).

Public policy influences the paper and pulp industry in two ways. On the one hand, many national governments protect their paper and pulp industry. Because of the unification of Europe, these protective measures were gradually abolished in the European Union, which in some cases led to little dramas. For instance, facing the unification measures, the paper and pulp industry of Ireland discovered in the early 1980 s that it made the same paper grades as Scandinavian producers, but 12 times more expensive. Several times especially in Europe at the end of the 1970 - governments tried to save their national industries. On the other hand, a strong sentiment toward environmentally neutral production has induced a spur of antipollution legislation. Obviously, the production of paper is inherenty polluting, mainly due to the necessity to bleach the pulp and the enormous amounts of water (hence the positioning of paper plants next to rivers) and energy needed. Needless to say, this whole process infringed huge obligatory costs upon the industry. However, Nehrt (1996) suggests that a firm can enhance its profitability by a timely invesment in new pollution-reducing technologies.

\subsubsection{Conduct in the paper and pulp industry}

A large body of literature describes the phenomenon of macroeconomic (or business) cycles whereas an equally impressive strand of literature deals with product or industry lifecycles. While both have common themes (i.e., a distinguishable up-and-down pattern over time), the business cycle literature is related to the aggregated movement of national or global economic data. The lifecycle idea focuses on distinguishable stages in the life span of a product or an industry (birth, growth, mature and decline). The paper and pulp industry is undeniably in its mature stage (Calori and Ardisson 1988, Nehrt 1996), and has been for decades. Interestingly, economic indicators like the industry's Return on Investment (ROI) show a regular, recurring pattern that can be described as a cycle.

Despite little industry level growth, high capital intensity produces barriers to exit (Porter 1985), which induce incumbents to stay in the 
market. Moreover, transparency of available production techniques (Calori and Ardisson 1988) and near minimum efficient scale size of individual plants (Scherer and Ross 1990) make it difficult to distinguish oneself from the other paper producers. Small size of potential competitive advantage and few sources of differentiation characterize 'stalemate' industries (Calori and Ardisson 1988). A closer look at the paper and pulp industry (sources: Pbillips Paper Directory and PPI International Pulp and Paper Directory) reveals that in 1994 about 450 different paper grades were produced, from acoustic paper to X-ray interleaving paper. This suggests that the market consists of many different segments that can be exploited separately and in conjunction. The number of producers per grade (segment) ranges from one to several dozens and most firms produce multiple products. However, besides in exotic grades niches, within a segment the product seems to be rather homogenous, so that the earlier remarks hold true.

The standard strategic options in the face of stalemate markets would be to acquire competitors, form cartels, delocalize (i.e., centralize production) and withdraw from the industry altogether. Merger and acquisitions abound right now, though the concentration level within the industry still is moderately low. Next, although cartel formation is forbidden, countries do try to restructure or save the industry by price-setting, tariff raising, etcetera (a case in point is the attempt of the Dutch government to restructure the strawboard overcapacity in the late 1970s). Besides, cartel formation seems to work well in favorable times (high usage of capacity) but appears to be highly unstable and thus ineffective if the industry's economic health is hampered (Gallet 1997). Finally, delocalization and withdrawal are associated with both financial and social barriers to exit, and are not really considered as viable options by most producers (Calori and Ardisson 1988).

Several authors have examined sources of competitive advantage in the paper and pulp industry. Competitive advantage can be obtained from increasing customer satisfaction by enhancing quality (printability and resistance) and timely delivery (Calori and Ardisson 1988) or by providing customers with client relevant information that competitors cannot (Dutton 1992). Other strategies, cited in the literature, focus on improving the internal composition and use of 
Exhibit 2.1: Predictability in the paper and pulp industry, KNP-BT

By comparing the projections in year w with the materialized results in year $t+1$ we can assess the limited predictability of results in the paper and pulp industry. The extent of similarity was arrived at via comparing subsequent annual reports that spanned a period of 25 years (1970-1995). A three-way label was used to indicate the degree of similarity: 1 being good, 2 bad and 3 not possible (if no clear statement was issued about the expecred results for a next year).

The results of this coding process are summarized in Table 2.3 . In total the degree of similarity was assessed 22 times of which 3 times were coded as 'undetermined", 10 times as 'good' and 9 times as 'bad'. These results are all the more surprising because the executive letter from which the information was taken, is prepared in the year following the accounting year. The prediction thus covers a period that is considerably shorter than one year. The results suggest that KNP-B'T was not able to predict year results, even for a relatively short period.

Table 2.3. Degree of similarity between expectation in year $t$ and result for year $t+1$

\begin{tabular}{|c|c|c|}
\hline Year & Expentation & Similatity \\
\hline $1970-71$ & In 1972 mo improved circumstances & $\mathrm{Bad}$ \\
\hline 1972 & $?$ & Undetermined \\
\hline 1973 & $?$ & Undetermined \\
\hline 1974 & Sad time, due to declining economy & Good \\
\hline 1975 & Good based an 04 results of ' 75 .' & Bad \\
\hline 1976 & Bad & Good \\
\hline 1977 & Good & Bad \\
\hline $1978-79-80$ & in 1981 great investment plans & Undeternined \\
\hline $1901-82$ & Falding board continusaly good: papar bad & Bad \\
\hline 1983 & Good & Good \\
\hline 1984 & Good: & Good \\
\hline 1985 & Modest & Bad \\
\hline 1986 & Good: paper sales 440 o due to new capacity & Gond \\
\hline 1987 & Good & Good \\
\hline 9988 & Good & Bat \\
\hline 1989 & Less than last year but still good & Bad \\
\hline 1990 & Results depressed due to over-gapacity. & Good \\
\hline 1994 & Over-capacily will depress the results in 92 and 93 & Good \\
\hline 1992 & Merger with Bühman Tetterode and WRG: results will ameliorate & Bad \\
\hline 1993 & Rationalization in KNP-Leykam will improve overall company results & Good! \\
\hline 1994 & mproving economic conditions: good & Good \\
\hline 1995 & $\begin{array}{r}\text { Good } \\
\end{array}$ & Bad \\
\hline
\end{tabular}


resources (Administrative Management 1982), improwing the forecasting system and method (Alibaig and Iilly 1999), implementing state-of-theart management information systems (Truman and Draghi 1999, Ledbetter 1993) and taking care of intensive education of skilled employees (Penn et al. 1992). Nehrt (1996) suggests that the timely investment in pollution-reducing technology (i.e., before competitors do or before regulation is imposed) enhances performance relative to lacking rivals due to first mover advantages.

\subsubsection{Performance in the paper and pulp industry}

Performance in an industrial organization context is concerned with issues of efficient allocation of resources, technological progress, full employment of resources (especially human resources) and equitable distribution of income (Scherer and Ross 1990). Free competition and profit maximization are currently regarded as schemata (as opposed to in the 1970s) that should automatically lead to the efficient allocation of resources and the stimulation of technological progress. Additionally, the tax system must regulate the income distribution. We will cover these aspects only briefly because a full examination of the performance in the paper and pulp industry deserves a separate study. The argument below can thus be regarded as an indication of performance in the paper and pulp industry only. Additionally, this argument is included to argue in favor of the social need for studies in the area of mature capital-intensive industries.

The increasingly important drive of stock-listed firms to maximize shareholder value has led to two contemporary trends in managerial praxis. The first is the widely used instrument of downsizing to reduce costs (cf. Gordon 1996, McKinley et al. 2000) and the second is the wridespread use of share option plans for the higher echelons (cf. Van Witteloostuijn 1999). The first has induced massive lay-offs in the industry, and the latter has stimulated the introduction of widely divergent remuneration schemes between workers and management (as option plans are normally not available to everybody). These processes are further said to have induced a break-up of the social structure in many societies, not only due to the downsizing hype but also due to an increasing 'class consciousness' between those who fire and those who are fired (Gordon 1996). This, in turn, increases the need for extra personnel control mechanisms and thus costs. This argument suggests that resources are allocated sub-optimally and that income is not distributed equitably. Moreover, as Gordon (1996) notes, 
although firms are increasingly "mean" they fail to be 'lean', suggesting that operations are not designed to enhance full employment of resources. Presumably, these factors hamper technological progress as well.

Van Witteloostuijn (1999) points out that regional differences exist in corporate governance and managerial routines. In our case, the Scandinavian paper and pulp industry seems to be an exception to the above-sketched rule. First of all, due to the vast amount of key resources (soft wood) and the availability of water, the paper and pulp industry has developed into one of the most important industrial sectors, making up ten percent of GNP in Finland and Norway (Zavatta, 1993). Secondly, Scandinavian societies are known for their social attitude. The paper and pulp industry in the region is characterized by a huge expenditure on paper-processing education, research and development, being the technological 'Mecca' of the paper and pulp industry. It seems that the Scandinavian institutional system nourishes better performance compared to the rest of the world. Chapters 4 and 5 deal with downsizing adjustment routines and the influence of such adjustment patterns on firm profitability, also taking account of different regions.

\subsection{A note on the use of simulation techniques in this thesis}

\subsubsection{Introduction}

Above, we described the industry and the sample. This section deals with one of the methods applied in this thesis, specifically the simulation technique of Chapter 3. The method of simulation has gained a robust status in econometrics at large and in the more technical areas of economics (such as operations research). However, organization researchers, particularly those who study business and organization systems as social rather than technical or mechanical entities, still rarely use simulation. This section explores the question why this is the case and provides an introduction into a simulation methodology that is (1) applied in Chapter 3 and (2) promises useful applications in social sciences. In this context, the validation issue in

\footnotetext{
Notwithstanding, of course, important examples such as garbagewan simulation (Cohen et al. 1972) and evolutionary economics (Nelson and Winter 1982).
} 
simulation research and severall examples of good simulation practice within the system dynamics methodology are discussed.

The invention and further development of the computer have stimulated the widespread use of simulation methods and tools in such disciplines as engineering, medicine and physics. Medical researchers and surgeons are increasingly trying out operating techniques on a virtual patient before testing or using them on real patients; navigation and flight simulators are used to test complicated maneuvers by ships or airplanes; preliminary designs of complex machines, products and processes are tested with three-dimensional simulation software, and so forth.

By contrast, the enormous increase in information-processing capabilities of computers has not produced similar developments in the social sciences. Although user-friendly simulation software has been available for social scientists for about twenty years, social scientists and organization researchers in particular do not appear to use simulation tools frequently. Table 2.4 illustrates this observation. It shows the number and percentage of articles using simulation methods which appeared in ten major journals over the past 12 years. With the exception of Management Science and European Journal of Operational Research, all the journals we looked at publish no or very few articles using simulation methods. ${ }^{5}$ Moreover, there is clearly no significant trend towards increased usage of simulation techniques in the reported period.

The exceptional high number of entries reported for Management Science and European Journal of Operational Research suggests that the use of simulation is largely restricted to operations research, dealing with optimization problems in manufacturing and logistical systems, which tend to be similar in nature to optimization problems in the technical sciences.

\footnotetext{
"A search in the major sociological outlets Sociology, Annual Review of Sociology, American Journal of Sociology and International Sociology resulted in a zero count of articles using simulation in the reported years. Also note that highly specialized journals such as Simulation and System Dynamics Review have been excluded from this examination.
} 
Table 2.4: Simwlation research in anganization (related) studies, (percentage of total articles [bold] and number of anticles in indicated year)

\begin{tabular}{|c|c|c|c|c|c|c|c|c|c|c|c|c|c|}
\hline & 1966 & 1987 & 11988 & 1989 & 1090 & 1991 & $\sqrt{1092}$ & 1993 & 1994 & 1995 & 1996 & 1997 & 1998 \\
\hline ASQ & 023 & 023 & 0.24 & 123 & 1023 & 021 & 025 & 049 & 0.49 & 043 & 058 & 154 & 1063 \\
\hline 64 & 133 & 044 & 057 & 050 & 151 & 1064 & 161 & 057 & 1163 & 051 & 068 & 165 & 070 \\
\hline AMIN & 051 & 1047 & 148 & 040 & 039 & 145 & 047 & 065 & 071 & 0162 & 264 & 065 & 045 \\
\hline QRs & 021 & 018 & 024 & 025 & 022 & 1023 & 027 & 028 & 1034 & 089 & 089 & 085 & 064 \\
\hline Mol & 8116 & 7117 & 13117 & 8104 & 7105 & 9109 & 14109 & 10121 & 5119 & 10144 & 9126 & 9124 & 13144 \\
\hline EMI & ma & na & na & $\mathrm{Na}$ & na & 062 & 061 & 057 & 053 & 063 & 185 & 080 & 078 \\
\hline E10 & 18260 & 23129 & 14.202 & 15204 & 13215 & 6207 & 25270 & 14290 & 2138 & 20394 & 23388 & 18252 & 11228 \\
\hline Ma & 27504 & 30378 & 28472 & 24446 & 21455 & 16531 & 40600 & 24667 & 27770 & 30946 & 35878 & 29725 & 24692 \\
\hline
\end{tabular}

ASO Administrative Science Quarterly

SMJ Strategic Management Journal

AMU Academy of Management toumal

CRS Organization Studies

MCl Marnagement Science

EMJ European Management Journal

EsO European Joumal of Operational research

Organization researchers, particularly those who study business and organization systems as social rather than technical entities, still rarely use simulation methods. This section focuses on system dynamics as a sophisticated simulation approach that is currently available for social scientists. First, an overview of simulation methods and tools is given. Subsequently, a closer look will be presented at the system dynamics tool and the important issue of validation. Next, we will give an overview of three applications of system dynamics simulation in organization and institutional research, and finally, explore why simulation is not used much in organization studies.

The focus here is on computer simulation research, rather than on other applications of the simulation idea such as rolle-playing, gaming and micro-worlds. The purpose of the latter applications tends to be training and teaching of people, which falls outside the scope of this thesis.

\subsubsection{Defintion: what is simulation?}

The simulation methodology as a social science research tool is defined by Dawson (1962) as the construction and manipulation of an "operating" model, that is, a physical or symbolic representation of all or some aspects of a social or psychological process. For the social 
scientist, simulation leads to building a model of individual or group processes and experimenting with the replication of these processes by manipulating the variables and their interrelationships within the model. By developing a model, the components and relationships, which are hypothesized as crucial, are abstracted from reality. Here, the methodology relies heavily on mathematical modeling techniques without, however, the demanding test to solve the model (fully) analytically.

Simulation tools permit the experimenter to study processes in ways that nature prohibits, because the simulation can be run many times with the values of the parameters modified between runs, subsequently observing the changes in output. The possibility to experiment with variables that can be manipulated is particularly useful in organization research because moral and physical factors often prohibit experimenting with real people, systems and organizations.

Different forms of the simulation methodology can be distinguished, each of these being used in certain scientific communities. We distinguish the following types and applications that are depicted in Figure 2.2. The most basic distinction in simulation approaches is that of physical versus mathematical simulation. Physical simulation entails experimenting with real objects that act as models of a subset of reality. Examples include building models for pllanes and ships, whereas in the social sciences one could think of role playing experiments. In matbematical simulation techniques, the relations of a system are expressed in mathematical formulas, which can be done in two ways: analytical and numerical. In the case of analytical simulation, on the one hand, the modeller will be able to reach solutions by applying optimization methods. Game theory is an example of this kind of simulation (cf. Fudenberg and Tirole 1991). Numerical simulation, on the other hand, deals with the typical behavior of systems and not so much with optimal solutions (Forrester 1961).

There are two kinds of numerical simulation methodologies. Deterministic numerical simulation entails fixing the values of parameters, whereas stochastic numerical simulation uses some kind of distribution function as input for the variables. Monte Carlo simulation is an example of the stochastic approach in which the simulation will use a scheme of random values with a uniform distribution. Apart from being well grounded in the literature, Monte Carlo simulation allows the modeler to perform robustness tests. Most spreadsheet simulations can serve as an example of the deterministic 
approach. System dynamics modeling is an example of numerical simulation in which both deterministic and stochastic modeling is possible.

Many numerical simulation techniques are relatively free from complex mathematics, making them more widely comprehensible than other more complex systems of formal mathematical analysis. Malcolm (1962) stresses that simulation is easily understood, relatively free of complex mathematics and often quite superior to mathematical methods that may be too complex or even not available. Moreover, Forrester (1961) asserts that a mathematical or analytical solution to problems with more than five interrelated variables becomes impossible. This observation is still not far from the truth, even after about 40 years (cf. Sterman 2000).

Another issue in simulation research is the required balance between parsimony and complexity of the model. In general, the social sciences attempt to develop and test models that explain as much as possible of the social system under study with the least possible number of variables. Put differently: the more parsimonious, ceteris paribus, the more preferable a model is ${ }^{6}$.

Figure 2.2: Omervieze of simwlation tedmiques (adapted from: Guetzkowe 1962)

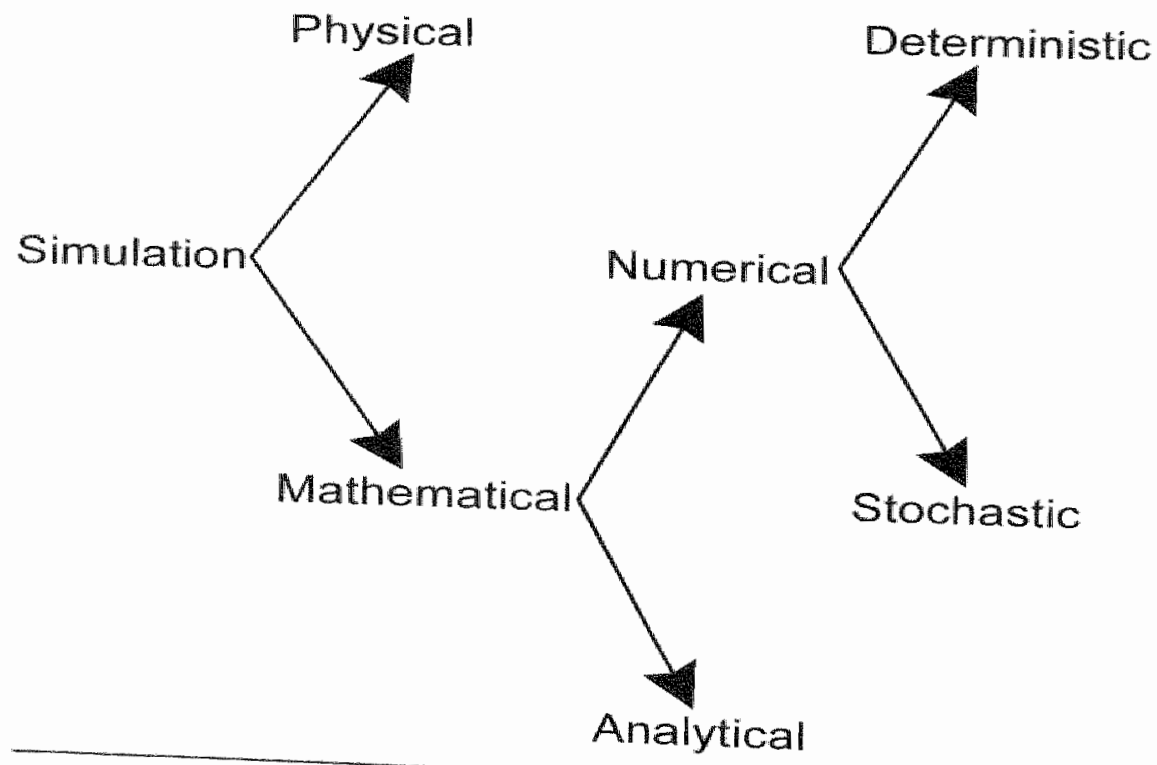

\footnotetext{
"Incidentally, this is what the KISS-credo boils down to: Keep It Simple, Stupid! (or
other variations).
} 
This approach tends to result in elegant, parsimonious models that greatly simplify the complex and dynamic interactions that any social system characterizes.

The use of simulation offers researchers the possibility to build dynamic models in which the value of many variables is determined endogenously. Especially the system dynamics method makes it tempting (because of its user friendliness) to build models that are too large. The danger here is that too many variables and relationships are taken on board. The result may be that the model is too complex to provide any understanding of the real system being modeled. This means that the simulation method, as any other, should be used in a way that creates a balance between parsimony requirements and the complexity of the system modeled.

\subsubsection{Systems thinking and simulation}

Systems thinking often involves building models to facilitate understanding and communication at the level of both the individual and the larger group. As individuals we all view the world differently. This is to be expected since we are conditioned over time by different cultural traditions, personal experiences and educational backgrounds (Stacey 1993, Argyris et al. 1985, Forrester 1961). While such diversity has a latent value, it can also be a source of misunderstanding and increased complexity in our social systems because of the assumptions we unwittingly make in communicating with fellow workers and citizens. We are referring here to the 'soft' dimensions of the workplace - the complex web of value systems, mutual understanding and human relationships that forms the 'real' organization (social systems).

Social systems are composed of people living, playing and/or working together in a shared environment. This includes people having thoughts, articulating these thoughts, communicating them to others, listening to the communication, trying to understand it and responding appropriately. People in social systems are observers of the very system they operate in; they engage in conversations through the use of a shared language. It is this ability to share language that might lead to shared mind-sets, values and beliefs. Systems thinking enriches this ability for language and problem-solving which, in turn, may lead to more effective teamwork, empowerment and participative management (Senge 1990, Checkland and Scholes 1990, Morecroft and Sterman 1994). 
A rypical output of systems thinking is a model or series of models that attempt to explain the workings of the system under investigation. Accepting the principle that there is generally no single linear cause-and-effect sequeace, the value of these models lies in their ability to help us view complexicy from the position of numerous inter-linked cause-and-effect situations (Forrester 1987). As a consequence, we may perceive unintended effects of our actions or strategies that are often counter-intuitive. This is frequently the source of significant personal and organizational learning brought about by the sharing of mental models.

Of course, this recognition of the importance of multiple causeand-effect responses is not unique for systems thinking. However, this very recognition of complex linearities and interactions underscores the usefulness of simulation techniques, which are much better equipped to deal with such complexities than 'traditional' mathematical or natural language methodologies.

\subsubsection{Validation of a system dynamics model}

Simulation research emphasizes the similarities in dynamic patterns between the simulation 'world' and the real system under study, rather than focusing on the absolute comparison between systemic behavior and simulated results. Nevertheless, validation of simulation models is necessary if we want to apply simulation models in a scientific context and if we want to gain a real understanding of the system under study. Although it is basically possible to use as many variables as one likes, the individual relationships must be tested in order to validate the conjectured linkages. In general, the rule is that the more relationships are modeled, the more elaborate the validation procedure should be. Thus, as is true for other scientific models as well, simulation models should be guarded against too high a number of relationships and variables.

Most system dynamics scholars agree that testing the relationships in a simulation model econometrically greatly increases its potential impact and acceptance (Hall 1976, Senge and Forrester 1980, Barlas 1989, Homer 1997). Hall (1976:186) notes that "a model is a theory. Acceptance of a computer program as 'good' social theory is

\footnotetext{
A study with a major consultancy that applies both hard (ne, empirically validated) and soft (informal) modeling in client projects found that hard modeling leads to mone satisfaction with the clients (Sterman 1998).
} 
dependent upon one's acceptance of the responsible theorist and his assumptions. It is important to know both". Among system dynamics practitioners a well laid-out framework exists which modelers can use to enhance refutability and thus reliability of the model (Barlas 1989, Gujarati 1988, Hall 1976, Ford and Sterman 1998, Forrester and Senge 1980).

The validation framework roughly consists of two phases that should be followed consecutively. To start with, a researcher should check whether the model complies with common sense of the actors within the system under study. This first phase is called structural validation. In this respect, Lane and Oliwa (1998) offer a taxonomy of current practices to elicit models from system insiders, in which the authors recognize that a system dynamics intervention influences the environment of the participants in the modeling effort. This approach boils down to analyzing the different worldviews that the participants hold by a technique also known as enquiry (cf. Argyris et al. 1985). The authors then suggest to develop the formal relationships of the system in such a way that differences in mental models of the participants are incorporated.

The second phase, called behavioral validation, involves two steps. First, the assumed relationships should be tested empirically. This step involves estimation of parameters and establishing validity of the relationships. A problem that frequently occurs, is the unavailability of data to measure assumed relationships directly. Two common methods are suggested to go around this barrier: the first method is to find good observable proxies for the unobservable ones (Gujarati 1988), and the second method boils down to checking the importance of the variables in the relationships via complex sensitivity analysis (Graham 1980). If, on the one hand, a variable is of critical importance to the model, data are needed. If, on the other hand, the variable is of no critical importance to the model, calibration (Gujarati 1988) could generate the plausible values for the parameter. This technique changes the value of parameters automatically until the simulation results best approximate the reference 'real world' behavior of the system. Of course, one should always test for sensitivity of the

\footnotetext{
Basically, this is what happens in much non-simulation quantitative empirical work in the sacial sciences, too. That is, in 'orthodox' applied 'social' econometrics many' unobservable theoretical constructs must be operationalized intelligently by creatively arguing in favor of obserwable variables that could serve as plausible proxies for the underlying theorevical structures.
} 
model to changes in the parameter values. The final check is whether the patterns of the model comply with the patterns found in the real system. The R-square (or adjusted $\mathrm{R}^{2}$ ) is a commonly used statistic to evaluate the performance of the model.

\subsubsection{Examples}

A widely cited example of good simulation practice is the study of the demise of the Saturday Evening Post by Hall (1976). Hall's paper relies heavily on the system dynamics methodology. A model is built in which it is important to set feasible boundaries to the system under study. As Hall (1976:188) puts it: "The system dynamics view of a company and its environment leads to the notion that the structure of the system accounts for a large part of the company's own peculiar growth and development". Hall constructs the model from several subsystems within the company, which are first separately tested empirically and subsequently connected in a later stage of the modeling process. This procedure is commonly used if a system is too complex to model at once. In Hall's case, the model comprises a management information system (accounting information flow), a remuneration structure, a set of controllable levers with which management tries to control the business (particularly involving price-setting), and a set of variables which depict the relationship with the environment. The validation of the model was conducted through estimation of the parameters in the equations via a least-squares regression. Furthermore, theory formed the basis of the primary assumptions that proved valid after testing. Simulation of the model, finally, generated behavior that was similar to behavior in the real system, gaining a $\mathbb{R}^{2}$ of at least .95 (Hall 1976: 192).

Traditional explanations for the demise of newspaper have included competition with other media, a sharp rise in postal and printing costs, substantial increases in the costs of acquiring additional readers, lost touch with readers, erratic and unpredictable behavior of advertisers, and mismanagement. Instead, Hall (1976) found that the deterioration of the newspaper was induced by a reinforcing feedback loop in which management tried to take corrective measures by increasing the subscription rate -a measure that proved successful in an earlier period-, thus loosing regular subscribers. Further diminishing profits made management realize that subscription rates should be lowered again. Instead, advertising rates were increased. Hall concludes: "unfortunately, the rate of increase in readers did not match the rate of 
increase in the advertising rate, which rose $25 \%$ per page per thousand readers and thus induced advertisers to exit." Findings of the study support the idea that structure induces behavior, in the sense that locally rational and sensible actions by management produce an uncontrollable situation. This kind of process and its unintended outcome is characterized by delays between action and its effects and difficulty to grasp interconnections between the subsystems.

Sterman (1989), who has applied the system dynamics methodology to the area of decision-making, has published another well-known study. His pioneering work deviates from traditional literature on decision-making in that it tries to model how people make decisions without theorizing on how people should make decisions. He conducts an experiment in which individually 'sound' decision-making in a simple situation with four people produces patterns of undesired results for all four individuals involved. Sterman (1989) uses simulation techniques in two ways. Firstof all, in order to monitor 'real' decisionmaking he uses a gaming structure, the so-called Beer game, which is based on a simple model of a production-inventory chain (cf. Senge 1992). Secondly, he employs a computer simulation model to test different modes of decision-making. That is, given the information available to the individual actors and given different theories on decision-making, he tests what mode individuals actually use and wherher or not this mode is universally applicable over the different subjects $(\mathrm{n}=40)$. Econometric methods are used to estimate parameters, robustness and variance explained by the model.

Sterman (1989) finds that individuals consistently use a decision rule that is sensitive to adaptation and relative to an anchoring point of some desirable property of the individual state. Both the way in which individuals form their expectations and the extent to which they are sensitive to a gap between the desired state and the current state is highly individualistic. Nevertheless, Sterman models this heterogeneous behavior using the same generic heuristic. The results of the study indicate that people employ simple heuristics when deciding on actions. Individuals tend to misperceive the feedback and delay structure in which they act, even in the presence of rich information on structure, interrelationships between actors and exogenous factors. This study therefore shows that the "efficacy and robustness of decision strategies lies not only in the availability of outcome feedback, but depends crucially on the nature of action feedback between decisions and 
changes in the environment which condition future decisions" (1989: 338; emphasis in original).

Our final example is Homer (1993) who conducted a study into the use of cocaine in the United States where drug policy decisions have been taken for many years on the basis of national survey data giving an indication of national drug use. These survey data show that cocaine use leveled out in the 1982-1996 period, where until 1982 the population of drug users grew substantially. Critical in Homer's model is reporting reliability, or the likelihood of honest reporting of an individual. Homer argues that the reporting rate dropped as a consequence of changes in categories of users, image of the drugs (social desirability) and the prevalence of crack in the mid-1980s. Analogous to Hall's (1976) study, Homer constructed two models that were later coupled to assess systemic behavior. The first model deals with reporting probability and the second is a user-estimation model based on the data that were widely available, such as historical initiation rate, drug price, police reports, drug arrests and accompanied amount of drug seizures. Unable to measure the variable directly, he thus exploits proxy data so as to compare historical relationships with current relationships.

After simulation of the total model Homer found that the simulated reporting rate matched that of the real reporting rate (number of persons that reported drug use). In addition, the simulated actual drug use rate showed a dramatic gap between estimated use by means of the survey and estimated use by means of the simulation. Additional investigations also have suggested that the simulation results are more likely to have predicted actual use better than the surveybased estimations. The implications of this study are twofold. Firstly, it indicates that presumed success of anti-drug policies cannot be validated based on the survey instruments used; and, secondly, it suggests that rigorous simulation modeling offers the opportunity to gain powerful insights in a system, as compared to verbal reporting stories about the system.

The examples given in the previous section illustrate the added value of simulation, particularly for complex social systems in which structure in terms of the pattern of relationships between variables- induces behavior. The studies described in the previous section illustrate that simulation techniques are especially worthwhile when a (industrial or corporate) system is studied as a whole. Moreover, the examples also 
show that simulation is best used in combination with econometric research tools, for validation and other purposes. Simulation as a research tool therefore requires an emphasis on all-round craftsmanship, rather than specialization, in training and educating management researchers. Evidently, the prevalent emphasis on specialized training and ditto career systems in the field of organization research is a major barrier for the diffusion of simulation as a research tool.

This section explored why management researchers, particularly those who study business and other systems as social rather than technical or mechanical entities still rarely use simulation. In doing so, we focused on system dynamics as a sophisticated and promising simulation approach currently available for social scientists. We looked at the validation issue in simulation research and at several examples of good simulation practice.

\subsection{A short note on other methods used}

Chapters 4 and 5 make use of other, more traditional methods. As mentioned above, these methods are more common in the organization studies domain, so they need no real in-depth coverage here. Moreover, these methods are all dealt with in far more detail in the empirical chapters that employ them.

Chapter 4 employs a logistic regression technique. There, the dichotomous nature of the dependent variable rules out standard least square estimation methods, thus forcing us to choose from other techniques. Fortunately, the literature offers many methods that can be applied to these cases. First of all, the roughest method to test hypotheses in this context is to compare classes of events via nonparametric tests (Chi-square, Mann-Whitney, Kruskall-Wallis, etcetera). Statistics derived from these tests reveal whether or not a significant difference exists between the observed and the expected distribution of the observations. This process generally produces statements about differences between classes of observations. Obviously, these tests offer some broad 'colloquial' insight but cannot lead to deeper conclusions about the nature of the difference. Rather, non-parametric tests offer a first step in analyzing the data.

After the execution of non-parametric tests, the results suggested that further analysis of the data set would be sensible. As indicated above, a dichotomous dependent variable violates an 
important assumption conditional for the application of normal least squares regression, which is that the dependent variable should be normally distributed; obviously, this is not the case with a dichotomous variable. Of course, mathematically it is possible to apply a least squares method, but the results cannot be interpreted. Having said this, several methods are specifically designed to properly deal with dichotomous dependent variables, including logistic regression (logistic because the logistic distribution function is used). Logistic regression differs in two ways from least square methods. First of all, the dependent variable is transformed into an odds ratio (see Chapter 4). Secondly, instead of calculating the value of the estimators via clear-cut formulas, with logistic regression this value is computed using an optimization method: maximum likelihood estimation.

Finally, Chapter 5 employs the generalized least squares (GLS) estimation technique. Generalized least squares is comparable to ordinary least squares (OLS), but the GLS-label is given to all classes of models that embody extra information. In our case, the OLS results were adjusted for multicollinearity and autocorrelation. Although some software packages automatically return GLS results, we have chosen to transform the model "manually" after the interpretation of the OLS results. Appendix C provides an outline of the procedure followed with regard to the results of Chapter 5 . 


\section{Chapter 3}

\section{AS THE WORLD TURNS}

Cyclicality of capital-intensive industries

This chapter provides a view on the cyclicality of capital-intensive industries that could add considerably to our understanding of how cycles in prices, profits and capacity come about. Previous studies of business cycles focused on macro-economic systems or on the agricultural sector. Causes for fluctuations are typically believed to be mainly exogenous in nature. We seek to extend the existing literature on industrial cycles by developing a model which incorporates endogenously generated cyclicality. A simulation model of the paper and pulp industry will be developed, and validated on the basis of data from the US paper industry.

\subsection{Introduction}

Cyclical behavior of economies and industries has attracted attention from scholars ever since the early 1930s when a large part of the Western world was hit by a severe depression. Business cycles can be described as "rhythmical alternations of prosperity, crisis, depression and revival" (Mitchell 1950, p. ix), invoking a picture of music with a regular beat. Traditionally, studies of cycles focus on macro-economies or on agricultural commodity sectors (Kydland 1995, Meadows 1970). This study intends to expand the literature by focusing on capitalintensive industries. 
The course of firms and industries is, almost by definition, accompanied by times of prosperity and times of downfall. As such, problems of cyclicality were already acknowledged in ancient times. The traditional cure has been to save resources during good times in order to survive the bad times. Although this recipe still holds for an individual producer of say pulp and paper, the following pattern emerges on an aggregated industry level: if times are good, the dominant wisdom is to invest in capacity; if times are bad, rationalizing is the strategy commonly followed. Rationalizing more often than not goes hand in hand with the lay off of a large part of the labor force, which imposes costs on society. This underlines the importance of studying cycles in order to understand their emergence.

Moreover, the metaphor of "the seven good and the seven bad years" appears to characterize the dominant way of approaching cyclical problems: the people involved are not to blame for the downfalls. Instead, it is some incomprehensible or external power that causes them. The prevailing literature on causes and remedies for business cycles has therefore approached cyclicality from an external angle, attributing causes to forces outside the industry. Fluctuations in demand and prices of raw materials are considered as the major external causes. However, causes external to the industry merely provide a partial explanation. For example, the international paper and pulp industry currently suffers from a downturn in profitability while most other industries boom. In addition, from annual reports of companies in this industry, it becomes clear that most executive boards also adopt an external focus when explaining the situarion to the public. For example, the following statement is taken from the annual report of a major European paper producer: "The paper industry was confronted with an unprecedented serious down cycle in the second half of 1995 , as a result of which demand decreased and paper prices fell dramatically" (KNP-BT, annual report 1997). This so-called attribution error is well-known from organizational behavior studies (Buchanan and Huczynski 1997).

Historically, demand for paper rises with increasing prosperity (and both demand and production have risen in recent years), so obviously other factors are contributing to the industry's current performance. In this respect, over-capacity is generally blamed for slumps in the pulp and paper industry. A few interesting questions can now be raised: Why is over-capaciry such a persistent factor in the pulp and paper industry? What causes firms to invest while knowing that 
adding extra capacity undermines industry profitability? How can we gain a deeper understanding of the processes leading to over-capacity? What is the influence of technological development on cycles? We think that an answer to these questions from the paper and pulp industry can be generalized to other capital-intensive industries as well.

This chapter seeks to explore these questions with the use of simulation. Recent developments in social sciences suggest that simulation is a viable technique that can deal with the complexities of these questions in a more comprehensible way than more linear-like research methods. Specifically, growing computer power and userfriendly software with easy to understand symbol-steered-language make simulation feasible for practitioners in the social sciences that would normally not consider simulation as an analytical tool.

This chapter is organized as follows. First of all, we explain why simulation, and the system dynamics perspective especially, is used here. Then, the industry under study -the pulp and paper industry- is described. Thirdly, we will briefly describe the models found in the literature and explain the choice of a model developed by Meadows as our starting point. Subsequently, the original model will be adjusted and validated. Finally, the influence of new process technology on cycles is explored with the model.

\subsection{Simulation and system dynamics}

The main arguments for using a simulation technique, developed in the field of system dynamics, are as follows. First of all, systems thinking appears to enrich the ability to communicate meaning by the use of symbols that picture relationships between the most important elements in a system (Checkland and Scholes 1990, Morecroft and Sterman 1994, Senge 1990).

Secondly, simulation allows the researcher to test a hypothesis quantitatively in a way that mathematical methods do not allow for, due to analytical complexity that increases if the number of relationships in a model increases (Forrester 1961, Roberts et al. 1980). Of course, econometric methods are used in estimating parameters in relationships. Specifically, system dynamics simulation offers a powerful tool that allows for multiple layer simulation in a way that is very user-friendly; moreover, it keeps the parts of the system and the way they are connected visible (Roberts et al. 1980, Sterman 2000). 
Finally, system dynamics rests on two assumptions that make it a useful tool for our research purpose. The first assumption is that behavior is caused by the underlying structure of the system in which the behavior takes place and thus the unit of analysis should be the structure rather than the behavior itself. Secondly, one should try to understand behavior in a systemic way due to interactions between several parts of the system that cause the behavior. This understanding can only be gained by studying the whole of relevant parts and their connections within a system (Forrester 1961, Sterman 2000). The last argument is in itself not enough to justify the application of simulation rools from a system dynamics perspective. It merely adds to the previous two arguments. As with any other form of simulation, the outcomes of a simulation study should be evaluated in terms of the plausibility of its outcomes and within the confines of the theoretically driven assumptions underlying the model.

\subsection{Cyclicality of the paper and pulp industry}

Our main interest is in understanding the forces that drive cyclicality in capital-intensive industries. The paper and pulp industry serves as a good example of the industry cycle phenomenon because it is regularly hit by severe depressions. The paper and pulp industry is part of the broader forestry industry system that starts with forestry and ends with different buyers from stationary retailers to printing and packaging firms. The customer base of most segments in the paper and pulp industry involves professional buyers who evaluate the products on quality and price. Because quality is rather homogeneous across a broad range of different suppliers, price is the main decision criterion. The paper and pulp industry, as defined here, also includes the production of pulp and board. Profitability and capacity utilization in the international paper and pulp industry show strong cyclical tendencies that are found to be weakly predictable. This aspect of the industry seems contradictory because aggregate production as a proxy for demand rises steadily over the years (Berends and Romme 1997).

The population in the Western world has grown with about 5\% over the period 1978-1997, while paper consumption (in the Western world?) has increased with about $50 \%$ over the same period (source: PPI). Figure 3.1 shows the development of capacity utilization and profitability of the international paper and pulp industry. It shows 
that profitability, in terms of the average return on assets of the 150 largest paper and pulp producers, goes up and down with the operating rates. The instability of the return on assets (ROA) is a reason for concern for the actors in this industry.

Figwe 3.1. Capacity wilization (left $Y$ wais) and retarn on assets of the top 150 producers in 1978.1996 (source: PPI)

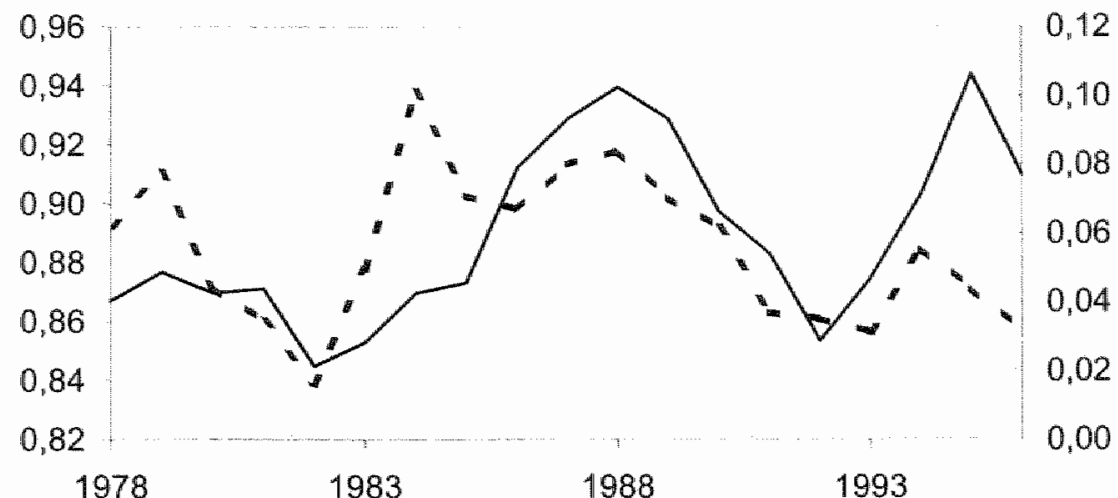

- - Operating rates (prod/cap) — Return on assets (top 150)

Apparently, these cycles are supply driven and aggravated by demand fluctuations. That is, too much production capacity enters the market in batches after periods of relative profitability, because producers tend to make capital investment decisions approximately at the same time. Evidently, the fact that most actors decide to invest simultaneously is not a sufficient condition to explain cyclical behavior. Zavatta (1993) argues that producing paper goes with large economies of scale, meaning that the decision to invest implies a certain minimum size for a plant. That is, investment costs per unit of output decline markedly with size, mainly as a result of indivisible resources (e.g. computerized control equipment). The economies of scale differ somewhat depending on the paper grades produced. Specialty paper, for example, benefits less from scale economies than newspaper paper because customized orders are mostly smaller than an efficient machine run (Zavatta 1993). Thus, producers collectively invest more than is justified by growth in demand, feeling forced to invest when a competitor does so. Then, due to the highly capital-intensive nature of the industry, individual companies will do their utmost to 'keep the machines running'. Hence, 
in times of over-capacity, paper producers try to sell their products with prices going down until they barely cover the variable costs. The buyers, of course, are aware of this situation and are very price sensitive; apparently, there are no major differences in paper grade quality between producers.

Two structural features of the industry therefore appear to drive a pattern of collective behavior that tends to be destructive. Firstly, as we have seen, producing pulp and paper in a competitive manner requires significant scale economies and thus large amounts of invested capital. Secondly, the industry is characterized by delays of three to five years between the investment decision and the moment the new capacity is available for actual production. These two structural features constitute a prisoner's dilemma situation: individual firms may be well aware of the industry's structure, but feel trapped or forced to continue their investments, fearing that not complying to the 'rules' will lead to even more severe future losses. Moreover, due to the delay between the investment decision and actual capacity increase, cause and effect are often difficult to address and thus easily misunderstood (Forrester 1961, Sterman 1989a).

Concentrating market power by integrating individual businesses has been regarded traditionally as an interesting solution for these cycles in performance in a fragmented capital-intensive industry. In this respect, market power in the worldwide paper and pulp industry has indeed become more concentrated in the last decade: the Cia, the market share of the ten largest producers among the top 150 producers (covering approximately 60 percent of world sales in the paper and pulp industry), has been increasing from .29 in 1988 to .32 in 1993 and .34 in 1997 (source: PPI). The largest paper firm -born from a recent takeover of US-based Champion by International Papercurrently has a market share of about six percent of the total sales of the 150 largest producers. These figures also show that overarching market power of a few producers is presently absent, which basically impedes any attempt at market co-ordination.

\subsection{Starting point: Meadlows' model}

Traditional cycle research has focused on the macro business cycle (Black 1987, Kandill 1997, Lucas 1981, Kydland 1995, Mitchell 1950, Zarnowitz 1985). These studies focused on time series of real and 
monetary data. The basic idea is that the cycle originates in discrepancies between exogenous supply and demand of factor inputs (capital and labor). Another strand of literature (Forrester 1976, Haxholdt et al. 1995, Mosekilde and Rasmussen 1986, Sterman 1985, Sterman 1989a, Sterman 1989b) deals with modeling an economy and attributing the existence and proliferation of cycles to, for example, instabilities of ordering behavior (information delay structure), the bounded rationality of the decision makers, and misperception of the physical feedback structure. These models basically consist of two or more interlinked sectors, and can explain the phenomenon without exogenous shocks. Shocks do exist, but they merely aggravate the cycle rather than induce it.

Few studies have been published in the area of industry cycles. Zhang and Buongiorno (1993) explain the addition of capacity in the pulp and paper industry by referring to Tobin's q-theory on what drives investment. Zhang and Buongionno's article starts from a neoclassical view on investment, seeking for proxies of complete markets. The drawbacks of this model are that, firstly, depreciation of capacity is endogenously determined, leading to economic life spans of four years to infinity, and that secondly, no interaction between the productive and consumptive sector takes place.

Meadows (1970) developed a model that explains cycles and investment decisions in agricultural commodities. Meadows' work is a basis for other system dynamics market models (e.g. Butler et al. 1998, Roberts et al. 1980). Meadows' work departs from a system dynamics viewpoint, taking a more behavioral perspective than is typically done in the neoclassical literature. The model of Meadows (1970), however, was not developed for capital-intensive industries but for agriculture. Other drawbacks are that the model assumes fixed consumption per capita and its investment function is based on an expectation of price only.

The model of Meadows (1970) was nevertheless chosen as a starting point for our study because the assumptions in this model are much richer than those made by Zhang and Buongiono (1993), whereas the drawbacks of Meadows" model can probably be overcome. Table 3.1 summarizes and compares the key assumptions made by Zhang and Buongiorno (1993) and Meadows (1970). More specifically, the advantages of Meadows' model in the context of this study are as follows: 1) the parameters that drive investment behavior are directly 
observable, 2) less exogenous inputs are required, and 3) the model allows for alternative policy testing.

Table 3.1. Summary of the assumptions made by Zbang et al. (1993) axd Meadorss (1970)

\begin{tabular}{lll}
\hline Assumptions & Zhang and Buongiomo (1992) & Meadows (1970) \\
\hline Inwestment & Based on projected cash flowsitobin's q & Based on expectation of prices \\
Price & Exogenous to the model & Endogenous \\
Consumption & Exogenous & Dependent on needs per capita and price \\
Priceidemand effects & Not accounted for & Reirforcing cyclical effects \\
\hline
\end{tabular}

The remainder of this section gives a more detailed description of Meadows' model, with several extensions and references to more recent literature. The following two assumptions, which are well grounded in economic theory, are at the heart of Meadows' model. Firstly, producers are motivated to maximize profit, and their decisions to invest are guided by this principle. The producer focuses on expected prices as a predictor of profits, and as a predictor of desired capacity. Secondly, consumers are believed to need a certain amount of the product, but tend to look for substitutes as prices get higher; they will fill up extra stock or substitute other products with paper products if prices get lower (Meadows 1970).

The general causal structure of Meadows' model is depicted in an informal way in Figure 3.2, using the notation conventions of system dynamics. 'This figure clearly shows that the system consists of a producer, a market and a clearing mechanism. Producers deliver their products to one central distributor that tries to maintain the balance between inventory level and consumption by adjusting the price level so that inventory coverage the amount of inventory to expected consumption-satisfies its criteria to be able to deliver promptly (this process is Walrasian in nature). The market buys an amount of the products at a certain price; if the model is in equilibrium, the amount consumed per capita is equal to the equilibrium per capita consumption.

A key element in Meadows" model are delays. Delays arise because it takes time for data in the form of indicators to be transformed into information that can be used for decision-making. Delays operate both in technical and in social systems. These delays have been incorporated in the model in places where one could expect such delay structures. 
Figure 3.2: Catusal loop structure

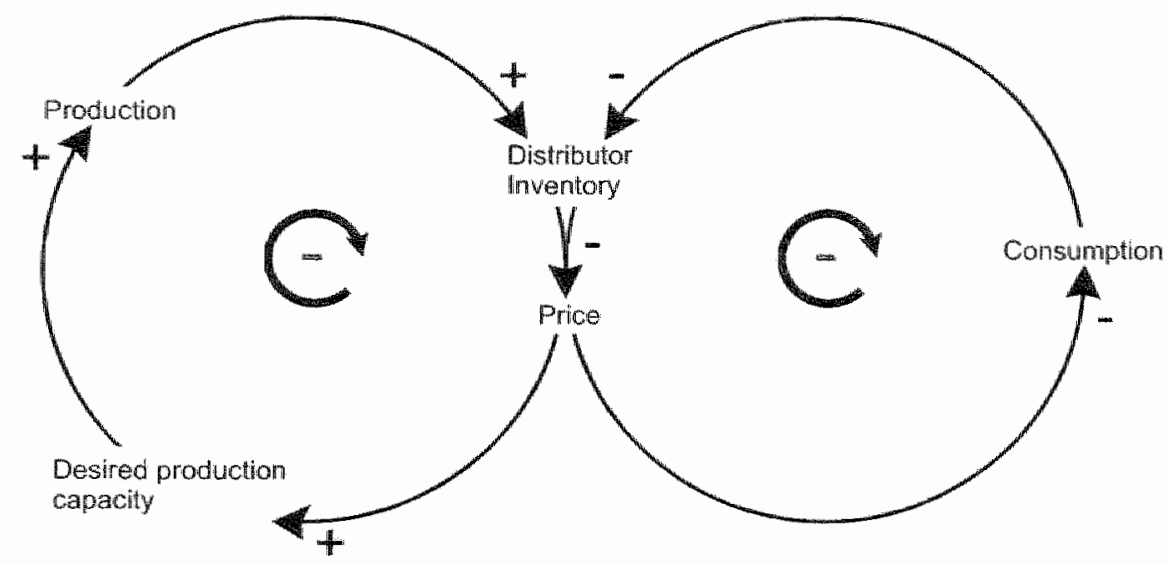

Working from any wariable chosen as the stating point, the polarity of the shown loop is establisbed by tracing through the effects of each ink watil a circuit is completed If the net effert of is to reinforce an initul change in the wariable wosen as the siaring point, the loop is positive" and is denoted by " + ", whereas the effect is connteracted, the loop is "negative' and is denoted by $\because$ The arrows linking variables are defined formally as' $x \rightarrow+y \Rightarrow \partial y / \partial x>0$ and $v . w$.

Meadows uses several curvi-linear functions that have the form of (inverted) S-curves in determining price, per capita consumption and desired capacity. This means that the functions are of a monotonically increasing or decreasing nature. The logic for the form of these curves is highly similar and therefore only the "per capita consumption requirements" will be highlighted as an example. Economic theory suggests that consumption is a decreasing function of price: the higher the price, the lower the amount consumed. We are thus used to graphs that display only the linear parts of this relationship and we take this linearity for granted for computational reasons. There is nothing wrong with this assumption of linearity as long as we are conscious of the fact that this linearity only holds for a certain range of prices. Generally, the relationship between price and consumption is as follows. Certain amounts of products will always be bought, no matter how high the price is. Conversely, a maximum amount of products will be taken no matter how low the price is.

Expectations of certain key indicators play an important role when taking decisions. In Meadows' model, the inventory holder makes projections of the amount of consumption in the next period. 
Likewise, producers try to estimate demand or prices for some future time in order to adjust production and investment. The expectation functions used have been tested both empirically (Meadows 1970, Senge 1990) and experimentally (Sterman 1989a, Sterman 1989b, Van Witteloostuijn 1990). These studies found that the adaptive expectation form was the specification that best fitted the data. An adaptive expectation means that the projected value of the indicator is a combination of its past values in which the most recent ones get the highest weight. Put formally, the expected price at time $t$ is defined as:

$$
\bar{P}_{t}=b P_{t-1}+(1-b) \bar{P}_{t-1}, 0 \leq b \leq 1
$$

In line with the system dynamics literature, Meadows (1970) uses a certain symbolic language that has been developed to represent systems. This language involves so-called material stocks and flows and informational flows. An overview of Meadows' model is given in Appendix $A$, using the stock and flow language where flows of goods are represented by double line arrows, flows of information by single line arrows, and containers (stocks) by rectangles.

\subsection{Modeling the paper and pulp industry}

This section contains a validation process in which we seek for anomalies in the results and correct them by adding apparently more viable heuristics (c. Barlas 1989, Forrester and Senge 1980). Note that this process is very similar to searching for falsifiable explanations of reality. Our basic hypothesis in this process is that the model is able to reproduce reality well. Rejecting the hypothesis leads to examining the assumptions and where needed, plausible adjustments should be looked for.

A minor adjustment to the original model has been made as to the consumption function. Meadows argued that consumption cycles around a stable per capita consumption (Meadows 1970). This is quite plausible for food products. There is, for example, simply a maximum amount of grain that a person can consume. However, per capita consumption of paper and pulp has risen $2 \%$ annually over the past 40 years, (source: PPI). Moreover, given the high current growth in per capita paper consumption for Eastern and Southern Europe and the 
Asian continent - which are expected to remain high for the next 10 years- the overall growth rate can be assumed to be around $2 \%$. We therefore included a $2 \%$ growth factor influencing per capita consumption requirements in the model.

Another adjustment should be made in the area of investment decisions. The investment decision for agricultural production is a recurrent one, that is, investment decisions are taken every three to six months: land produces crop once or twice a year. In the paper and pulp industry, it takes roughly three to five years to construct a papermaking machine, in which huge amounts of capital are invested. This has implied an increase of the transfer delay between the initiation of new capacity and the actual capacity change from 3 to $36-60$ months, with regard to Meadows" original model. Additionally, we will introduce an economic life span of the machinery, which is estimated to be around 25 years (source: $P P I$ ).

\subsubsection{Validation of the model: price determination}

We now have a model that is extended and adjusted in three ways: 1) an exogenous growth factor for per capita consumption has been included, 2) an increase of the delay between initiation of new capacity and actual capacity increase has been adjusted for, and 3) an economic life span has been introduced. We have used the same data as Zhang and Buongiorno (1993) used in our attempt to validate the model. These data are for the USA only, gathered from the Bureau of Census (see Appendix B).

The simulated price can be compared with actual price development when using the real capacity development to drive the simulation. Figure 3.3 shows the results. Until 1974 (year 16), the year after the sudden surge in oil prices, the simulated and observed prices move nicely together. After 1974, however, a pattern emerges that cannot be explained by the model. The paper and pulp industry also suffered from this more or less exogenous macro-economic shock, as almost all industries faced a jump to a higher price level due to the effects of the oil crisis (Beijdorff et al. 1982). We used OLS regression to determine to what extent the observed data could be explained by the simulated data, taking the oil crisis into account by means of a dummy variable. The adjusted $\mathrm{R}^{2}$ of .75 between observed price and simulated price (using OLS) suggests that this part of the model provides a good foundation for further exploration of the model. 
Figwe 3. Observed price os sintalat price

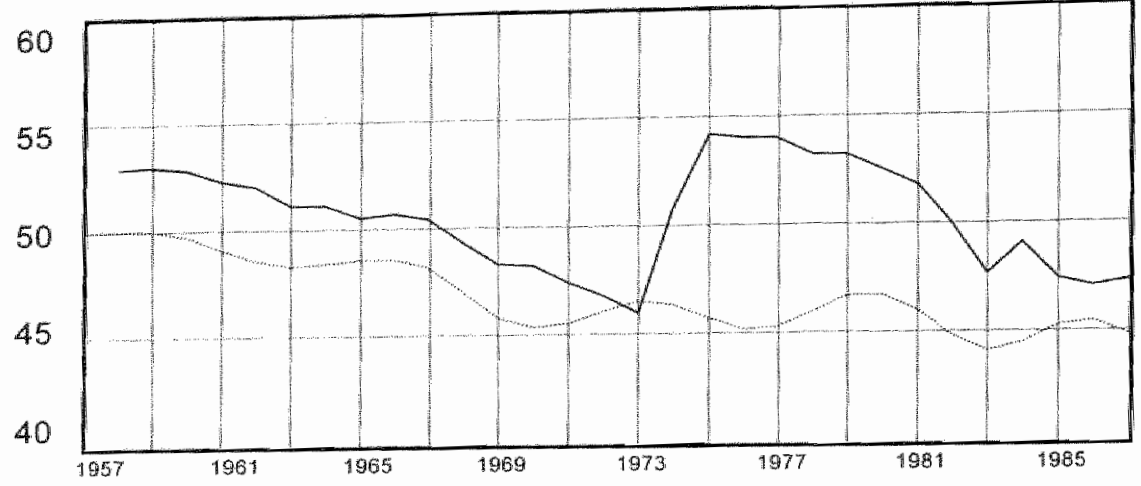

Observed price:

Simulated price:

\subsubsection{Validation of the model: capacity determination}

Meadows' investment function only deals with a prediction of the price level and the accompanying level of desired capacity. These heuristics are built around the idea that a gap between desired and actual capacity triggers decisions to add capacity. The investment decision function takes into account current capacity, capacity under construction (capacity being transferred) and desired capacity, and is subject to the construction time and the time to take the decision (see Appendix A). For the paper and pulp industry, the construction time is estimated to be between three and four years, and the time to take the decision is assumed to be between one year and eighteen months (due to the massive required funds allocated to new capacity).

Initial simulation runs, in which we used observed price as an input to drive the simulation (of capacity determination sector of the model), resulted in simulated capacity which increasingly diverged from the observed capacity. This initial result can be explained from the fact that the original investment function does not take into account growth of per capita demand (see Appendix A). We might infer from these findings that in a (slow) growth market, price is not the only factor directly determining investment in new capacity. In addition to the expected price level, demand expectations (predictions) may be fueling investment (Butler et al. 1998). We therefore assume that the desired production capacity is determined by the expected 
consumption and the difference between the expected price and an equilibrium (break-even) price, on the basis of which the producer generates (or fails to generate) investment funds for new capacity. Figure 3.4 gives the simulation results on the basis of observed price as input. The adjusted $R^{2}$ of .996 suggests that the extended investment segment of the model explains the observed capacity development rather well.

Figure 3.4: Observed capacity us simulated capacity

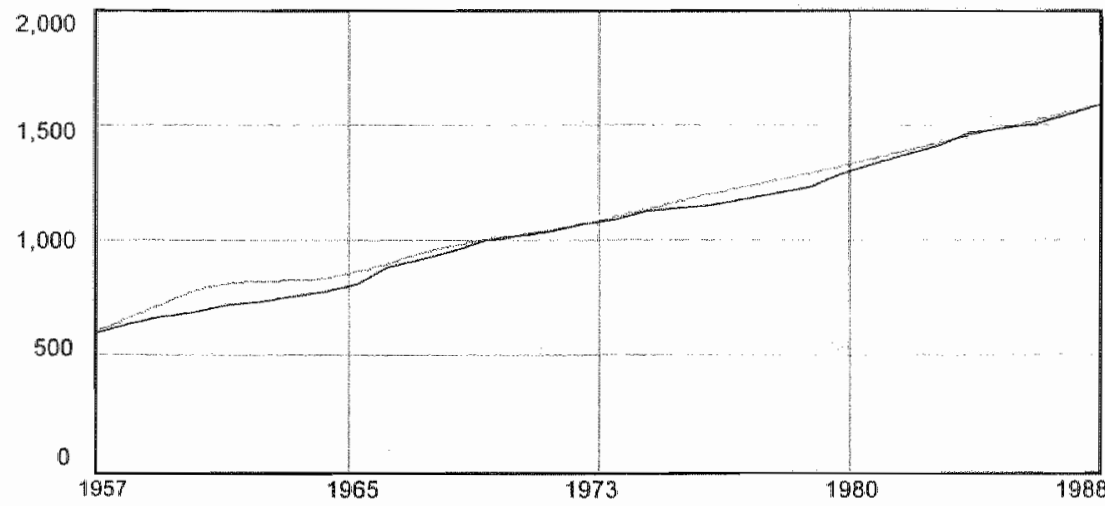

Observed capacity

Simulated capacity

\subsubsection{The influence of new process technology}

The model can now be used to determine in what way technological change affects the vollatility and the duration of cycles in the paper and pulp industry. Particularly, the introduction and diffusion of new process technology, such as CAD/CAM and Just-In-Time (JIT) inventory management, have been influencing cyclicality in all likelihood in the paper and pulp industry. But how exactly? The model developed in the previous section will be used to find (preliminary) answers to this question. 
The introduction and diffusion of new process technologies particularly affects two model elements in the context of the extended model for the paper and pulp industry (for details see Appendix A):

- Capacity transfer delay (CT): this is the delay between the investment decision and the moment the new capacity actually becomes available for production. This delay can be assumed to have decreased in the last 10 to 15 years, particularly as a result of new design and development technologies (such as CAD), used by suppliers of pulp processing and paper production machinery,.

- Desired inventory coverage (DIC): basically, this is the rate of inventory to consumption coverage that the producer prefers to maintain. The gradual diffusion of (JIT) on-line information systems between producers, distributors and retailers can be assumed to have decreased the inventory/demand coverage, also because smaller inventories reduce cost per unit. The development of e-commerce and e-business tools will probably reinforce this trend in the nearby future.

A number of simulations has been executed in order to determine what the influence is of (gradually) decreasing these parameters, from their respective base values (DIC $=10 \%$ and $\mathrm{CT}=2.5$ years). The value of one of these parameters was gradually decreased in the simulation runs. The results are summarized in Table 3.2. Shortening the capacity transfer delay (CT) leads to smaller average amplitude but shorter cycle times. Decreasing the relative inventory level that the producer wishes to maintain (DIC) reinforces the amplitude of cycles and also shortens
cycle time. Table 3.2: Effects of decrearing delay and inventory coverage on cycle amplimde and
cycle time

\begin{tabular}{lll}
\hline Capacity transfer delay (CT) & Cycle Amplitude & Cycle time \\
Desired inventory coverage (OIC) & Decreasing & Shortening \\
\hline
\end{tabular}

The results for CT suggest that investments in technologies such as CAD/CAM can decrease cyclicality, because it allows producers to adapt their production capacity more quickly (less delays as a result of time lost in building machines, plants, etcetera). The results for DIC confirm the intuitive wisdom that technological developments tend to destabilize capital-intensive industries. No individual producer can 
withdraw from investing in this area because competitive forces impose the diffusion of new logistic technologies. But at the same time, these technologies reinforce cyclicality.

\subsection{Conclusion and discussion}

The conventional way of looking at cycles in capital-intensive industries has been to attribute these cycles to mainly external causes, such as raw material prices and demand fluctuations. We propose to change this perspective towards attributing causes internal to the industry. On the basis of a model developed by Meadows (1970) for the agricultural industry by means of systems dynamics modeling techniques, an adjusted and extended simulation model for the (capitalintensive) paper and pulp industry was developed. The most important adjustments were regarding: 1) the (much longer) delay between investment decisions and the moment new capacity becomes available for production, and 2) the rolle of demand expectations in investment decisions. The general causal structure of the extended model is depicted in Figure 3.5 (compare with Figure 3.2).

Figure 3.5: Causal loop strwcture adjusted for direct demand influences

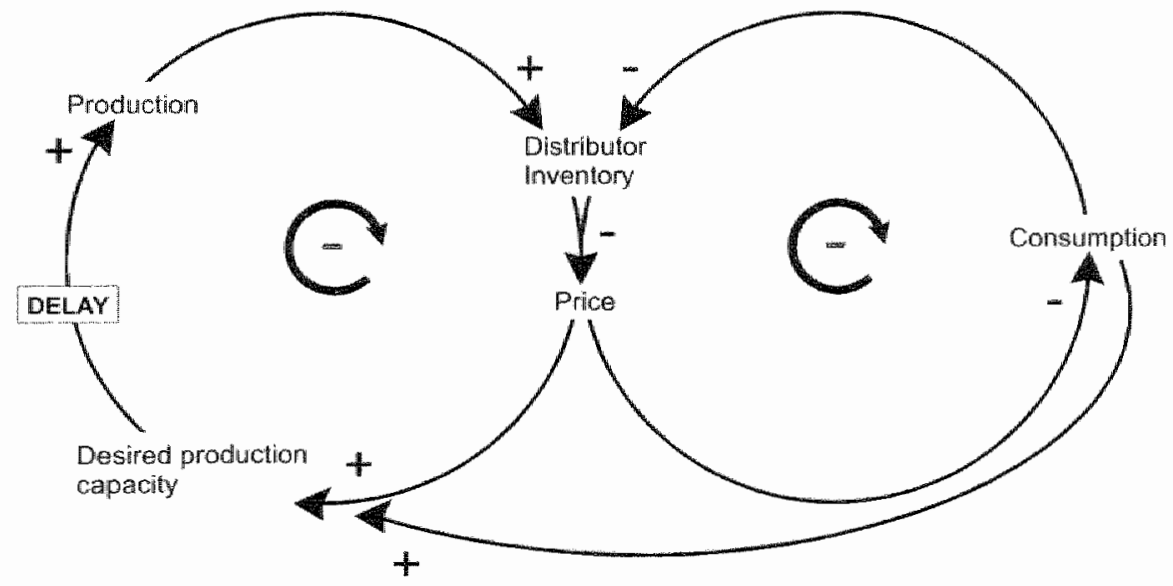

The model was validated with data from the US paper industry, first of all, for the price determination sector of the model, and secondly, for the capacity determination sector. Overall, the results of these 
validation processes were good. Finally, the influence of the introduction of new process technologies was simulated by means of the validated model. These simulation runs showed that certain technologies tend to reinforce cyclicality in capital-intensive industries, in terms of both the amplitude and the period of cycles, whereas others do not.

These results should be assessed in the context of the limitations of the model. For example, a perfect supply-side monopoly was assumed. Another limitation arises from the assumption that capacity maintenance is similar up and downwards. In practice this process will probably be asymmetric: capacity will be more easily added than decreased because capacity once built requires little maintenance. Instead, individual producers will vary capacity utilization to buffer price differences. It might thus be useful to regard capacity as defined in this model as capacity in use.

A more fundamental limitation of this model arises from the nature of any model as a limited, simplified representation of the real world. Thus, some authors argue that validation or verification of models, in the sense of establishing the truth, is impossible (Forrester 1961, Greenberger et al. 1976, Sterman 2000). Regardless of whether one agrees with this position, models seem to be most useful when they are used to challenge existing formulations, rather than to validate or verify them (Oreskes et al. 1994).

Overall, this study resulted in a model that describes and simulates how capital-intensive industries generate their own volatility. Thus, this study provides a challenging view on industrial cyclicality, possibly implying other than traditional cures to business cycles. The implications for industry policy have not been discussed in detail in this article. One clear implication is that governmental agencies stimulating the application of new process technology should do so with caution, because our model suggests that certain kinds of technology reinforce cyclicality in capital-intensive industries, whereas others do not.

Cyclicality of other capital-intensive industries can be examined in future studies. In this respect, industries such as chemicals, primary metals and civil aviation have a similar structure (significant scale economies, delay structures) and also suffer from cyclicality, regardless of the high concentration ratios in some of these industries (Butler et al. 1998, Gallet 1997, Mills 1990). Two questions could guide further research for capital-intensive industries: 1) to what extent should 
concentration of supply rise in order to have a dampening effect on price volatility, and 2) what other strategies can be applied by producers when influential coordination cannot be attained? These questions can be explored in the same manner, by means of simulation modeling, as was done in this study. 


\section{Chapter 4 \\ GOOD TIMES, BAD TIMES}

Symmetric and asymmetric adjustment to cycle movements

Divestments and reorganizations are downsizing strategies to (re)establish a fit between the firm and its environment. These actions can have severe consequences for both societal welfare at large and the personal well-being of individuals involved in such processes. A negative alteration in a business position (through an assets or workforce reduction) is often presented to the outside world as an inevitable action caused by unfavorable external forces such as industry over-capacity. The central question in this examination is whether or nor firms adjust their internal position (assets and personnel) to changing environmental munificence of resources in a symmetrical or asymmetrical way. We distinguish three levels of indicators of changing resources: (1) the stage of the macro cycle of the economy at large, (2) the stage of the industrial or meso cycle, and (3) changing firm profitability or micro cycle stage. We have found evidence of symmetrical adjustment to macro, meso and micro cycles. The results provide evidence for influences of all cycle movements on adjustment patterns in the paper and pulp industry. However, the profitability position of the firm (micro level) itself seems to be of more importance than the macro or meso cycle stage. 


\subsection{Introduction}

This examination adds to the existing literature in that it examines the "why' of firm-level change by locating antecedents at three different levels: (1) the impact of the macroeconomical stage of the cycle, (2) the influence of the cyclical condition of the total industry, and (3) the effect of firm characteristics and micro-level cycles (movement in profitability). This chapter examines whether or not companies adjust their resource positions in response to the stage of a cycle that influences the firm. The position of the firm is defined as its composition (or vector) of resources. We have regarded the assets base and number of employees as two important components of the composition of a firm's resource portfolio. Both asset stock and workforce size receive by far the most attention in the literature (Hammermesh and Pfann 1996).

The influence of macroeconomic cycles and meso (industrial) cycles on alterations in firm positions has been assessed; at the microlevel, we look at the influence of profit decline. The key question is whether or not a firm downsizes its position in response to declining (cyclical) conditions. Cameron et al. (1991) define decline as a situation in which the availability of resources in the environment decreases. Normally, decline is associated with a phase in the life cycle of an industry or a firm (Miller and Friesen 1984, Klepper 1997). This examination focuses instead on regularly returning phases of decline in the macro cycle, in the meso cycle, and in the micro cyclical movement of profitability of individual firms within those industries. Hypotheses are formulated as a stepping stone for testing the relationship between the different cycle stages and the position adjustment patterns (in assets and workforce) of individual firms. We define an adjustment as (a) symmetric if a firm does (not) downsize in reply to or as a result of a decline stage of a cycle, or does (not) increase its position because of an upturn. Surely, our main interest focuses on the downsizing actions because of their societal consequences.

As a first step, cycles should be defined in order to develop an understanding of what we mean and how we deal with cycles. The literature on cycles is quite substantial and prominent scholars spent large volumes on the subject, among them Schumpeter (1939), Mitchell (1950) and more recently Kydland (1995). Their main focus is on macro cycles and their causes. Work on industrial or meso cycles bears some similarity with the ideas developed on hog cycles (cf. Meadows 1970). 
This body of literature reveals that several possibilities exist to define a cycle. In general, a cycle is the abbreviated term for a pattern in the behavior of a certain parameter that moves around a baseline (whether this is a trend line or a fixed benchmark) over time with some regularity. This concept of cycles is very old and deeply ingrained in our culture. The oldest references can be found in writings of old Greek poets, but also in the bible - in which cases it was referred to as periods of fortune and misfortune that follow each other naturally. Macroeconomies tend to move in cycles, as do individual industries.

This takes us to the next point, which concerns the issue of different aggregation levels. Table 4.1 gives an overview of cycles at the macro, meso and micro levels of aggregation. Basically, macro-level research deals with the causes of macroeconomic cycles, taking the meso or the industry-level cycle as given input. Likewise, meso level or industry cycles are constructed by aggregating individual firm results, which are defined as micro cycles.

Table 4.1: Cycles at different levels of aggregation

\begin{tabular}{|c|c|c|}
\hline $\begin{array}{l}\text { Aggregation } \\
\text { level }\end{array}$ & & Definitions \\
\hline Macro & $\begin{array}{l}\text { Long wave (Kondriateff) } \\
\text { Business cycle (cf. Schumpeter } \\
1939 \text { ) }\end{array}$ & $\begin{array}{l}\text { The long-term deviation from a trend of a } \\
\text { counthy's GDP } \\
\text { - The short-term movement of a country's GDP }\end{array}$ \\
\hline Meso & $\begin{array}{l}\text { Industrial cycle (cf. Meadows } \\
1970 \text { ) }\end{array}$ & $\begin{array}{l}\text { The movement of an industry's profitability } \\
\text { The movement of an industry's operating } \\
\text { rates (l.e. production to capacity) }\end{array}$ \\
\hline Micro & Firm cycle & $\begin{array}{l}\text { The movement of profitability of ar individual } \\
\text { - Thempany } \\
\text { - The movement of an individual firm"s capacily } \\
\text { utilizalion or operating cales }\end{array}$ \\
\hline
\end{tabular}

Cycles invoke the notion of dynamism in the sense that individual firms in period $t$ cause aggregate results in period $t$, or are effected in period t by period t's cyclical movement. It is plausible that these aggregate results also influence an individual firm's decisions in period $t+1$. This circularity is omnipresent in economic sciences, and is well grounded in feedback thought literature (Forrester 1961, Richardson 1991, Sterman 1989).

In this chapter we ignored the influence that decisions of individual firms have on the cycles, but rather monitor the influence of a cycle phase on the position adjustment of a firm. Furthermore, it is 
not the aim of this examination to explore the nature of cycles; this chapter takes cycles for granted, as we are interested in relationships between cycle movement and industrial or individual firm behavior. Besides, De Wit (1994) notices that surprisingly little work has been done in the area of cycles at the industry level. We too were not able to locate pieces of research, although we tried to find literature in the area of micro cycles (or similar ideas) and the influence on decisions that affect positions of the firm, outside the domains of production management and operations research.

This study builds on an earlier examination of (a)symmetric adjustment by Van Witteloostuijn (1998). Van Witteloostuijn argues that the integration of behavioral (organization studies) and economic models leads to interesting hypotheses for empirical testing in the area of the impact of organizational inertia on firm behavior and performance. Specifically, combining industrial organization (IO) economics (cf. Tirole 1988, Scherer and Ross 1990, Pindyck and Rubinfield 1992) with organization science (OS) theory (cf. Penrose 1959, Cyert and March 1963, Hofstede 1991) could lead to a more satisfactory explanation of specific real world observations in industries. Within the OS field, organization ecology (OE) studies (ct. Hannan and Freeman 1993, Carroll 1988, Baum 1995) take a relative new and interesting position in this context, and the attempt to combine $\mathrm{IO}$ and $\mathrm{OE}$ is very promising (cf. Boone and Van Witteloostuijn 1995). Van Witteloostuijn (1998) argues that companies invest or divest in ways that cannot be understood by mainstream economic theory alone. He finds, for example, that chemical industries retain certain inefficient plants while it could be expected that firms abolish inefficient plants in times of a downturn, or if profits are falling. Van Witteloostuijn proposes three reasons for this behavior by applying both organizational inertia ideas (originating in organization ecology) and strategic choice notions (originating in industrial organization). First of all, companies do not divest inefficient assets because they are inert; secondly, companies do not divest inefficient plants during downturns because they want to maximize their market share; and thirdly, profit-maximizing firms could be at a disadvantage if their rivals blindly pursue sales maximization. The next paragraphs give a short overview of existing literature that relates to the topic of this chapter. Specifically, the concepts of adjustment, downsizing, strategic fit and decline are briefly explained below. 
The adjustment literature is broad as this issue has received considerable attention from several scholars over the past two decades. Most literature focuses on the effects of change. Organization ecology (Hannan and Freeman 1993, 1984) looks at change from a sociological stance. They predict that change, overall, leads to a greater risk of failure due to resistance to change from internal and external forces that the firm faces. These ideas have spun off a great body of literature that examines the effect of, for example, geographical location and geographical changes (Baum and Korn 1996, Ingram and Baum 1997, Baum and Haveman 1997), changes in legislature influencing industries (Haveman 1993), and core-business changes (Delacroix and Solt 1988, Delacroix and Swaminathan 1991, Greve 1999, Greve 1998). For illuminating literature overviews we refer to Carroll (1988) and Baum (1995).

Strategic choice theory claims that a firm can and must achieve a fit between the resources in its environment and its own position. This fit can be achieved by the strategies employed by the firm (cf. Porter 1985). A wide variety of empirical studies has been performed to assess the relationship between firm and industry characteristics on the one hand, and strategy and performance on the other [see Miller and Cardinal (1994) for a meta study on this subject]. This contingency approach is still one of the most important paradigms in the organization sciences (but see Porter 1991, Mintzberg 1994, Stacey 1995, Stacey 2000). These studies have focused mainly on one of the steps in the strategy process, such as environmental scanning, assessment of the internal position or establishment of a strategy-action planning process (cf. Lynch 2000). An example of a multi-contingency study can be found in Heijlties (1995).

The literature on the effects of downsizing is quite extensive too, and examines such broad topics as the effect of downsizing on organizational structure (McKinley et al. 1992), reactions of survivors of downsizing mediated by levels of trust, empowerment and justice (Mishra and Spreitzer 1998, Moser Illes 1995, Allen et al. 1995), the composition of social networks in organizations (Shat 2000), the learning capacity of organizations (Reynolds-Fisher and White 2000), and the meager effect -if any-on financial performance (Cascio et al. 1997, Gordon 1996, Huber and Glick 1993). McKinley et al. (2000) compare three theoretical perspectives on downsizing: 1) the economic - implicit or explicit link to performance, 2) the institutional - focusing on isomorphism or mimetic behavior to gain legitimacy, and 3) the 
sociocognitive - examining the 'why' of the effectiveness-of-downsizing idea. They offered an excellent review of the downsizing literature as well. Cameron et al. (1987a, 1987b) examine the effects of the business or industry life cycle decline phase on organizational atributes (e.g., scapegoating, turnover and increased conflict). In another article (Cameron et al. 1991), six 'best' practices to downsize are proposed. These studies all have in common that they look at the effects of the downsizing change on organizational features and performance.

The present chapter focuses on the adjustment patterns of companies to perceived (lack of) environmental munificence. So, we deal with the antecedents of firm-level change, particularly the association between cycle features and firm adjustments. Hence, this study shares the interest in firm-level changes and especially downsizing behavior with the literature described above. Furthermore, it explores the dichotomous nature of adaptation versus inertia. It is assumed that the perceived availability of resources follows a cyclical pattern that features several stages. Adjustments made in the business cycle could happen with respect to sales, assets, human resources or any other strategic variable that makes up the position of a firm. As mentioned above, we look at changes in the asset and workforce base. Furthermore, we distinguish between symmetric and asymmetric reactions to a decline or expansion stage of the cycle under examination. Following this logic, we define four possible situations. Table 4.2 gives an overview of cycle stages and the associated firm adjustment pattern classification.

Table 4.2: Adjusment to cycle stages

\begin{tabular}{l|cc}
\hline $\begin{array}{l}\text { Perceived } \\
\text { environmental } \\
\text { resoufces }\end{array}$ & \multicolumn{2}{|c}{ Position adjustment: } \\
\cline { 2 - 3 } $\begin{aligned} \text { Expanding } \\
\text { Declining }\end{aligned}$ & Upsizinglinvesting & Downsizingldivestment \\
\hline
\end{tabular}

As indicated above, the influence of the macro, the meso and the micro cycle on adjustment patterns of individual firms will be examined below. We will also assess the influence of the individual characteristics of a firm like mere size, extent of diversification and home country origin. Schematically, this examination explores the relationships depicted in Figure 4.1. 
Figure 4.1: Sobematic owerview of the examination

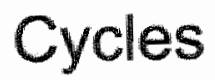

MACFO MESO

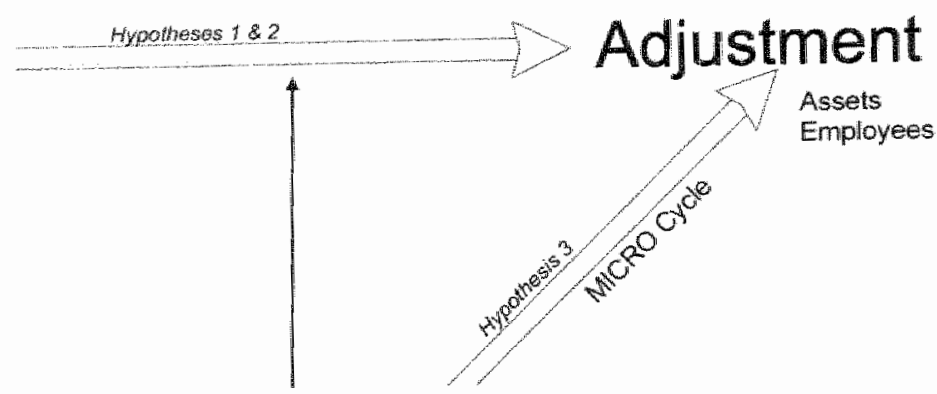

Firm Characteristics

Size

Profitabinity

Regional membership

\subsection{Theory and hypotheses}

\subsubsection{The influence of macro cycles}

Abrahamson (1997) examines the effects of the economic long wawes or Kondratieff cycles on the inclination of an individual firm's managernent to downsize in order to adjust for performance gaps. His argument is built upon the emergence of different management theories -i.e., a rationalist versus a normative rhetoric paradigm. The rationalist rhetoric paradigm embodies the idea that downsizing during contracting periods is the proper way to survive. The normative rhetoric says that established resources should be used to guarantee employee loyalty and satisfaction, which means that employee wellbeing should be guarded in times of downturn, too. The interesting idea behind Abrahamson's examination is that the different paradigms follow the phases of the long cycle. He suggests that a new rational rhetoric emerges around the onset of each long-term expansionary upswing of the long wave, whereas a new normative rhetoric gains dominance around the onset of a long-term contractionary downswing (1997: 493).

Abrahamson (1997) found evidence for an upswing accompanied by a rationalizing rhetoric in the period 1944-1971, and for a downswing accompanied by a normative rhetoric in the period 1972-1992. Thus, the inclination to downsize in the first phase of the wave was higher than in the second phase. According to this logic, we 
should find evidence for a lower tendency to divest up to 1992 (the normative rhetoric period) compared to the period following 1992 (the rationalizing period in our data set) if Abrahamson's argument holds in the paper and pulp industry. The following hyporhesis can thus be formulated.

H1a. The probability that a firm downsizes, is bigher in the period 19921997 compared to the period 1975-1991.

Van Witteloostuijn (1999) proposes yet another period shift in downsizing activity caused by the shareholder value maximization paradigm, which became fashionable in the US in the mid-1980s and in Europe in 1990. Firms are increasingly pre-occupied with enhancing shareholder value at the cost of organizational slack, which might, in the end, endanger the very survival of the firm. The slack-cutting activities in favor of higher stock prices certainly have been stimulated by the fact that management of many stock exchange listed companies are partly remunerated with stock options. This leads us to formulate two hypotheses (for the US and Europe, respectively) with differing period cut-off points.

H1b. The probability that US firms downsize, is higher in the period 1986-1997 compared to the period 1975-1985.

H1c. The probability that European firms dorwnize, is bigher in the period 1991-1997 compared to the period 1975-1990.

\subsubsection{The influence of meso cycles}

Mascarenhas and Aaker (1989) observe that firms adjust their strategies differently and asymmetrically over business cycle stages according to their strategic-group membership. Strategy is formulated as investing or divesting in capital production goods. The authors define four stages in 'industry-idiosyncratic' cycles, based on the utilization level of current capacity, in addition to looking at the (macro) long wave only (Abrahamson 1997). We will use this measuring stick for the paper and pulp industry, too. Accordingly, we distinguish the four phases or stages that are depicted in Table 4.3. 
Tablo 4.3. Cycle stages (adjusted from: Mascarenhas and Aaker 1989:201)

\begin{tabular}{l|l|ll}
\hline \multirow{2}{*}{ Cuycle stages } & Previous year \\
\cline { 3 - 4 } & Up & Down \\
Cuprent year & Up & Stage 1 & Stage 2 \\
& Down & Stage 3 & Stage 4 \\
\hline
\end{tabular}

Interestingly, Mascarenhas and Aaker (1989) do not look at relative change from year to year, but at the deviation from a demarcation point. This means that the authors define an 'up' ('down') year as a year in which capacity utilization lies above (below) 90\%. We needed a yardstick in order to define the cycle stages for the international pulp and paper industry. A possible cut-off threshold could be the industry's break-even point in capacity utilization, which lies around $80 \%$ (Romme 1994). However, as break-even production implies the generation of no extra cash flow, the real demarcation point is likely to be above this ratio. Glass (1997) estimates that the ratio is $90 \%$ for the graphical paper industry. We will let the data decide (see below) which demarcation point corresponds best to the theory deployed here.

We expect that downward adjustments will be postponed in hope for better times. Dixit and Pyndyck (1995) argue that the practice of investment in capital goods can be understood better if traditional investment theory (i.e., invest if the net present vallue for a project is above zero) takes into account the value of the decision not to invest. This option-to-wait can be compared with a call option and the value of this option should be added to the cost of the investment. More uncertainty about future states increases the value of the option-to-wait and thus the costs of the project. People tend to experience a certain inertia in making projections of these future states: recent experience will dominate future expectations (cf. Sterman 1989), culminating into a linear extrapolation of the most recent states. As a counter force, firms in capital-intensive industries are limited in their ability to discard of expanded capacity, which depresses the value of current capital. This cost, in turn, should also be accounted for in investment decisions (Abel et al. 1996). All this leads us to formulate the following hypothesis:

12. The probability that a firm downsizes, increases per capacity utilization stage in increasing order from stage 1 to stage 2 to stage 3 to stage 4. 


\subsubsection{The influence of micro cycles}

The idea of organizational inertia plays an important role within the field of organization ecology. Hannan and Freeman $(1984,1993)$ argue that organizations are inert in nature, which means that they face difficulties in adjusting or changing their resource position. More specifically, they assume that organizational change is not impossible, but merely that "any radical change is sure to encounter stiff resistance" from many stakeholders that value stability. Organizational inertia arises from two complementary societal demands that an organization faces, and that justify its very existence: reliability and accountability. These features are highly valued in uncertain environments, especially in times of organization building, because of investor demands (Hannan and Freeman 1993). Both internal and external forces can explain inertia. Inertial forces are hypothesized to vary positively with both organizational age and organizational size (Baum 1995). This means that the bigger or the older a firm is, the more difficulties it will face to adjust or change. Table 4.4 summarizes the internall and external forces. The present study mainly focuses on internal forces that influence firms in their adjustment patterns.

\section{Table 4.4: Camses of inertia}

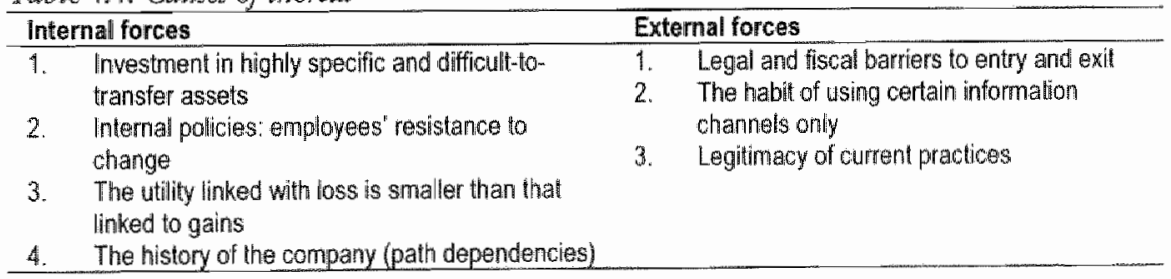

Firms can differ due to a different mix of inertia-enhancing factors. For example, the proximity to and the availability of resources influence the degrees of adjustment freedom a firm has. Van Witteloostuijn (1998) finds four closely related arguments as to inertia in the existing literature:

1. Organizational routines or habit formation in human actions;

2. Biased environmental expectations and resistance to change;

3. Escalation of commitment; and

4. Organizational slack. 
A key argument in the literature is that such inertia-increasing forces are positively correlated with firm age and size. Baum (1995) found limited support for age dependency and strong support for size dependency in his literature overview. This means that bigger companies face a larger probability of failure after change, whereas firm age tends not to have any effect.

What does the idea of inertia mean for our examination? First of all, capital-intensive industries invest heavily in highly specific assets that have little or no value outside their dedicated industry. This makes it hard to adjust downwards. Dixit and Pindyck (1995), as explained above, formulate similar arguments when exploiting the option theory to understand investment decisions. Secondly, bigger companies are probably more reluctant to divest as larger firms experience stronger inertia forces in their external environment. Thus, firm size decreases the probability of downsizing in poor years. It is likely that firms holding other assets than the industry-specific ones, have more degrees of freedom to adjust, assuming that the other holdings are less restrictive (put differently: embodying assets that can be more readily bought or sold in the appropriate factor markets). Firms, then, that are diversified face less restrictions to adjust downwards. These arguments induce the two hypotheses that follow next.

H3a. The size of a firm bas a negative effect on the probability that it downsizes in profit decline years.

H3b. The degree of diversification of a firm bas a positive effect on the probability that it downsizes in profit decline years.

Still another possibility exists if firms face a need to take investment and divestment decisions. That is, past profitability might well influence the growth and decline of assets. This conforms to the rationalist argument that the firm's ultimate objective is to maximize profitability (Van Witteloostuijn 1998). We thus expect that in decline years past profitability has a negative influence on the decision to divest. This argument bears close resemblance to the thought developed above on extrapolation of past experience.

H3c. Past profitability will have a negative effect on the probability that a company downsizes in profit decline years. 
Van Witteloostuijn (1999) argues in his work on organizational anorexia that companies in Anglo-Saxon countries (and the US specifically) are more prone to divest in order to enhance profitability than firms from other regions, as a result of their corporate governance rules. Similarly, Gordon (1996) claims that 'downsizing' was the strategy most proposed by consultancy firms to corporations in the US. He found evidence for these short-term strategies, especially in the area of human resources (the most atomized and least specific asset). Firms will adjust the size of their workforce during downturns more easily because they can fairly easily fire employees, more than they can divest fixed dedicated assets. We formulate the following hypothesis related to regional differences, and expect to see the strongest effect for workforce adjustment.

H3d. US firms bave a bigher probability of downsizing in profit decline years than their Asian and European counterparts.

\subsection{Data and methods}

\subsubsection{Motivation for industry choice}

We chose the international pulp and paper industry for the following reasons. First of all, the sample is fairly homogenous. We refer to strategic group research suggesting that the effect of competitive strategies depends on the specifics of the industry context (Boone et al. 1996, McGee and Thomas 1986). The choice of a sample from one industry enhances internal validity, but at the same time decreases external validity of the results found. However, we prefer increasing internal validity to increasing external validity because this provides richer results; similar studies performed in other contexts should contribute to external validity (cf. Cooper and Emory 1995). Secondly, the pulp and paper industry is notoriously cyclical in nature, which gives us a proper setting to study hypotheses as to at what level of cycle features influence the adjustment of firm positions. Besides, the industry is relatively stable regarding the main players as entry is very costly, and the key assets are very knowledge specific. Thirdly, it was rellatively easy to obtain data on a large sample of pulp and paper firms. In total, our data set contains information on 100-150 paper and pulp producers per year from 1974-1997. This group of manufacturers together account for $60-75 \%$ of total industry output. Although the 
sample is biased toward size, the sample itself guarantees sufficient size variation.

Basically, the data were collected from one source (PPI's annual top 150), and thus should be regarded as a secondary data set. In total, we have approximately 3000 firm-level observations on total sales, paper-related sales, earnings, total assets, amount of pulp, paper and converted products production, workforce and the number of countries in which a company has production facilities (numbers are in US \$ or units). Moreover, we chose this data set because of its firmlevel richness and longitudinal availability. Limitations of the use of secondary data in doing organizational research apply to our examination as well, of course. However, we feel that given the topic of interest (adjustment to cycles), this data set passes the tests of prudence. In our setting, the mode of adjustment (cf. plant closures, sellouts, overall personnel reductions, etcetera) all are results of decisions to downsize or rationalize costs. Thus, we deem the acting more important than its possible form, though we distinguish between personnel and asset adjustments.

\subsubsection{The sample}

The sample consists of yearly observations at firm level (firm/years). Data have been collected from 1974 through 1997, leading to a total of approximately 3100 firm-year observations. However, we had to reduce this original set due to reporting gaps. We lost two year (i.e., all firm-years for two years) observations (1974 and 1975) since data on assets were only reported from 1975 on, and due to the fact that we consider changes from year to year. In total, our data comprise 2039 observations of 181 firms of which 31 are present over 22 years $(N=$ 682), 60 over $10-21$ years $(\mathbb{N}=823, \bar{X}=14$ years) and 90 over $2-9$ years $(\mathrm{N}=534, \bar{X}=6$ years). The observations cover all regions in the world, the most important ones being Europe $(\mathrm{N}=791)$, US $(\mathbb{N}=$ 623) and Asia ( $=292)$.

\subsubsection{Variables and measuremont}

The dependent variable is the adjustment of a firm's resource position. Position adjustment is operationalized in terms of a change in the asset ${ }^{1}$

\footnotetext{
We assume that increases or decreases in assets imply investments or diwesitments, respectively. However, as stated in the method secrion, assets are reported total assets and thus include fixed but also current assets. Current assets might dilute the
} 
or workforce base in two subsequent years. This results in two dichotomous dependent variables (for assets and employees) which are used for Hypotheses 1 and 2. For Hypothesis 3 we only regarded years in which profitability was lower compared to the preceding year. For the sake of clarity, we constructed two extra dependent variables to account for this situation. The rationale is similar to the logic applied above. Downward symmetric adjustment is defined as the occasion in which a fall in profits is accompanied by a downward change of a firm's position; this process also leads to two dependent variables for Hypothesis 3. The next paragraph describes in more detail what procedures were followed.

We define the variable $I_{p}$ (profitability $(P)$ growth) as follows:

$$
I_{p}=1 \text { if } \Delta P_{t} \geq 0 ; I_{p}=0 \text { if } \Delta P_{r}<0
$$

Furthermore, we choose to assign a ' $O$ ' in each year in which profitability was negative. None of the cases studied showed equal profitability in two subsequent years, so either profitability grew or fell. We then defined changes in the position-adjustment variable $r_{j}$ ( $i=$ assets; workforce) by basically using the same heuristic, the advantage being that we did not have to adjust for negative values because these cannot occur. The data were transformed as follows:

$$
I_{r_{3}}=1 \text { if } \Delta r_{i} \geq 0 ; I_{r_{s}}=0 \text { if } \Delta r_{i}<0
$$

We coded the phases as indicated in Table 4.5 in order to examine the influence of macro (long-wave) and meso (industry-level) cycles, and subsequently assessed whether or not the estimated parameter was significant. This study examined cases in which $I_{p}=0$ for micro

properness of our measure. We dealt with the lack of information in our data set in two ways. First of all, we left out the amount of growth but assigned the value " 1 " to growth and the value " $O$ ' to no growth or decline. Secondly, we assessed annual reports of a random sample from the data set to check whether the direction of change of reported total assets correlated with a change in fixed assets position. This correlation is very high (0.9), so we think that taking up reported asset change as an indicator for fixed asset change serves as a good proxy. Furthermore, closer examination of the individual firm-level data reveals that for cases in which total asset change not correct in predicting direction of change, the relative change over two years was very small $(<0.005)$. 
(firm-level) cycle influence, implicitly assuming that a fall in profitability can be considered as a decline phase. We deliberately chose this cut off point because our null-hypothesis states that a certain cycle stage should be accompanied by a fall in the magnitude of the variable (and not a status quo).

The independent variables vary somewhat per hypothesis tested; the independent variables used for Hypothesis 3 are used in Hypotheses 1 and 2 as covariants, but the relevant theory is developed in the paragraph relating to Hypothesis 3 . The following information is available for every firm in our sample.

Past profitability

Workforce

\section{Diversification}

Non-US

1975-1991 versus $1992-1997$

1975-1985 versus $1986-1997$

1975 . 1990 versus $1991-1997$

Stages
Return on assets (net profits in US dollars divided by the asset base) of one year preceding the year of observation. The number of employees of a firm. In the tests, we used the natural logarithm. This variable serves as a proxy for firm size.

Paper-related sales in US dollars divided by total sales (in US \$). Basically, this variable indicates the degree of 'related' versus 'unrelated' diversification.

Dummy variable that indicates that a firm has its headquarters outside the US. Period dummy used in Hypothesis 1a. Period dummy used in Hypothesis $1 \mathrm{~b}$. Period dummy used in Hypothesis $1 \mathrm{c}$. Capacity-utilization stage based on capacity utilization in the year of observation as defined below, which is used for examining Hypothesis 2. Capaciry utilization is measured as world paper production divided by world paper capacity. A dummy variable is defined for each stage. Due to unavailability of the capacity data in early years, information on this variable was obtained from 1978 till 1996. 
Additionally, the next two covariants were defined for the present study:

Firm

Year

A dummy variable was coded for each firm.

A dummy variable was coded for each year which is used only in the test of Hypothesis 3. The other hypotheses use the time dummies as described above.

Table 4.5 gives a summary of the variables used, as well as their codes and values.

Table 4.5: Description of this study's mariables

\begin{tabular}{|c|c|c|c|}
\hline Code & Name & Used in model: & Values \\
\hline ASSGT & Asset growth & $\begin{array}{l}1,3,5 \text { and } 7 \text { as } \\
\text { dependent }\end{array}$ & $\begin{array}{l}0=\text { decline } \\
1=\text { growth }\end{array}$ \\
\hline WFGT & Workforce growth & $\begin{array}{l}2,4,6 \text { and } 8 \text { as } \\
\text { dependent }\end{array}$ & $\begin{array}{l}0=\text { decline } \\
1=\text { growth }\end{array}$ \\
\hline DNSYMWF2 & $\begin{array}{l}\text { Downward symmetric adjustment } \\
\text { of workforee }\end{array}$ & $\begin{array}{l}10 \text { as } \\
\text { dependent }\end{array}$ & $\begin{aligned} 0= & \text { no downsizing in case of profit } \\
& \text { decline } \\
1= & \text { downsizing in case of profit } \\
& \text { decline }\end{aligned}$ \\
\hline DNSYMAS2 & $\begin{array}{l}\text { Downward symmetric adjustment } \\
\text { of assets }\end{array}$ & $\begin{array}{l}9 \text { as } \\
\text { dependent }\end{array}$ & $\begin{aligned} & 0= \text { no downsizing in case of profit } \\
& \text { decline } \\
& 1= \text { downsizing in case of profie } \\
& \text { decline }\end{aligned}$ \\
\hline LAGIROA & Past profitability & all & $\begin{array}{l}\text { Scalar; one year lagged Relum on } \\
\text { Assets (ROA) }\end{array}$ \\
\hline LNWF & Workforce & all & $\begin{array}{l}\text { Sealar; nalural ilog of workforce } \\
\text { (H employees) }\end{array}$ \\
\hline PERCPAP & Diwersification & all & $\begin{array}{l}\text { Scalar; percentage of sales in } \\
\text { paper-ralated activities to toral } \\
\text { sales. }\end{array}$ \\
\hline US2 & Non-US origin & $1,2,7,8,9$ and 10 & $\begin{array}{l}0=\text { US.based firms } \\
1=\text { Other }\end{array}$ \\
\hline DH12 & $1975-1991$ versus $1992-1997$ & 1 and 2 & $\begin{array}{l}0=1975-1991 \\
1=1992-1997\end{array}$ \\
\hline USPER & $1975-1985$ verstus $1986-1997$ & 3 and 4 & $\begin{array}{l}0=1975-1985 \\
1=1986-1997\end{array}$ \\
\hline EURPER & $1975-1990$ versus 1991.1997 & 5 and 6 & $\begin{array}{l}0=1975-1990 \\
1=1991-1997\end{array}$ \\
\hline STAGE & $\begin{array}{l}\text { Capacity ulilization stages } \\
\text { as defined in Table } 3\end{array}$ & 7 and 8 & $\begin{array}{l}1=\text { stage } 1 \text { (up-up) } \\
2=\text { stage } 2 \text { (up- down) } \\
3=\text { stage } 3 \text { (down-top) } \\
4=\text { stage } 4 \text { (dowm-down) }\end{array}$ \\
\hline
\end{tabular}

Some variables need extra explanation. The natural log of workforce was used here as the indicator of size. We chose the log transformation to adjust for the size distribution (cf. Gujarati 1988). Normally, size is distributed somewhat exponential, thus we used a logistic 
transformation of the size variable. The advantage of positive transformations is that the interpretation of the estimators is then straightforward. We expect that this measure gives a realistic estimation of firm size given that our data covers at least $60 \%$ of total industry sales. The measurement of diversification, and the possible effects on company and industry performance, is a topic that received considerable attention in the strategic management literature (for an illuminating overview see Ramanujam and Varadarajan, 1989). Several indicators have been developed to measure the degree of diversification and the relatedness of the different diversified activities within a firm. Two well-known examples of such measuring sticks are Rumelt"s (1974) classification scheme and Berry and Jacquemin's (1979) entropy definition of diversification. However, the researcher needs information on both the relatedness and the sales share of the activities to calculate these proxies. We took shelter in a measure that simply indicates the degree of relatedness, as our data only provide information on paper-related sales versus other sales. That is, diversification (D) is measured as

$$
D=\frac{\text { Sales }_{\text {paper }}}{\text { Sales }_{\text {torat }}}
$$

The degree of diversification is thus dependent on the amount of paperunrelated versus related sales. A higher value of the index indicates more concentration on paper-related activities.

Table 4.6 gives an overview of the relative frequencies of growth or decline for the individual indicator independent variables. Tables 4.7 and 4.8 show the descriptives for the variables used in this chapter.

Table 4.6. Overwew of growth and declime per indicator wariable

\begin{tabular}{|c|c|c|c|c|c|c|c|}
\hline & & \multicolumn{2}{|c|}{ Whole sample } & \multicolumn{2}{|c|}{ US } & \multicolumn{2}{|c|}{ Europe } \\
\hline \multirow{3}{*}{ Assets } & & $1975-1991$ & $1992-1997$ & $1975-1985$ & 19861997 & $1975-1990$ & $1991-1997$ \\
\hline & Decline & 0.24 & 0.40 & 0.18 & 0.22 & 0.28 & 0.48 \\
\hline & Growth & 0.76 & 0.60 & 0.82 & 0.78 & 0.72 & 0.52 \\
\hline \multirow[t]{2}{*}{ Workforce } & Decline & 0.54 & 0.52 & 0.58 & 0.51 & 0.56 & 0.65 \\
\hline & Growth & 0.46 & 0.38 & 0.42 & 0.49 & 0.44 & 0.35 \\
\hline
\end{tabular}


Table 4.6 continued

\begin{tabular}{|c|c|c|c|c|c|c|c|}
\hline & & \multicolumn{2}{|c|}{ Regional } & \multicolumn{4}{|c|}{ Meso cycle stage $(t, t-1)$} \\
\hline & & US based & Other & 1: up-up & 2: up-down & 3: down-up & $\begin{array}{l}\text { 4: down } \\
\text { down }\end{array}$ \\
\hline \multirow[t]{2}{*}{ Assels } & Decline & 0.20 & 0.33 & 0.15 & 0.29 & 0.20 & 0.45 \\
\hline & Growth & 0.80 & 0.67 & 0.85 & 0.71 & 0.80 & 0.55 \\
\hline \multirow[t]{2}{*}{ Workforce } & Decline & 0.54 & 0.58 & 0.46 & 0.55 & 0.58 & 0.67 \\
\hline & Growth & 0.46 & 0.42 & 0.54 & 0.45 & 0.42 & 0.33 \\
\hline
\end{tabular}

Figure 4 pictures the relative frequencies for the continuous covariants.

Figure 4.2: Relative frequencies of asset and workforce growt for the continuows covariants
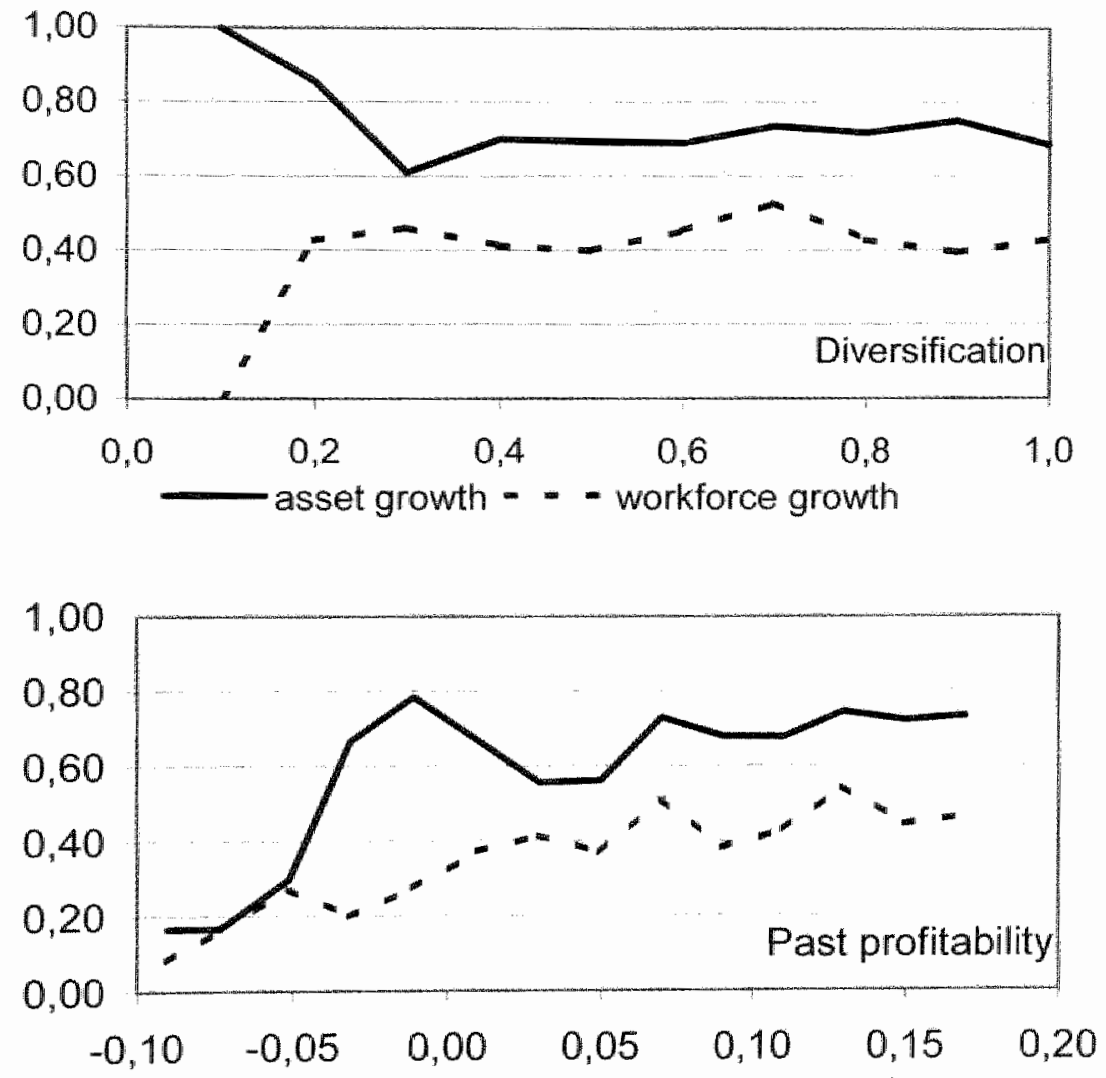

- assel growth - - - workforce growth 
Figure 42 continued

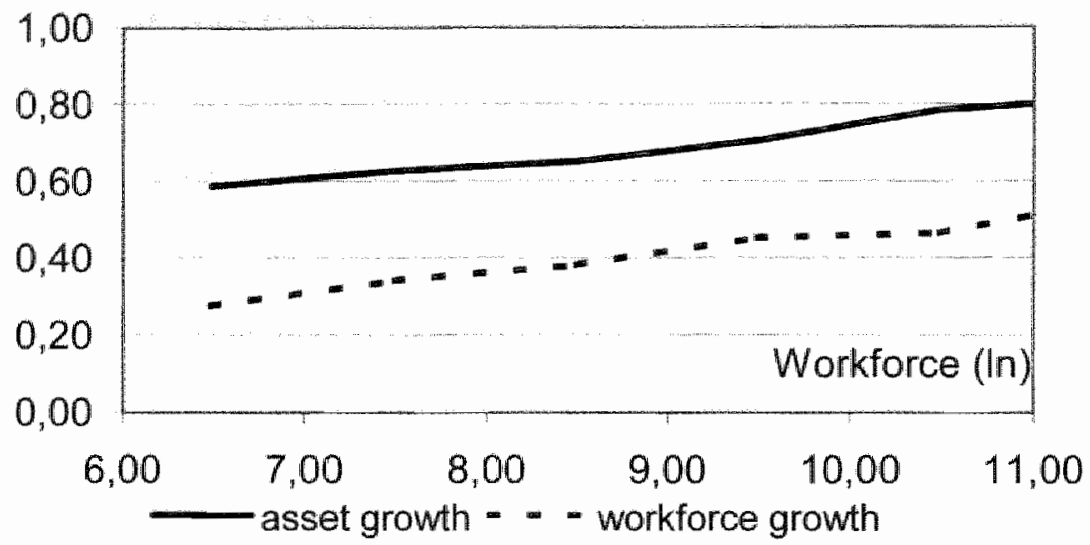

Table 4.7: Descriptive statistics ${ }^{2}$

N Minimum Maximum Mean Std.

\begin{tabular}{|c|c|c|c|c|c|}
\hline & & & & & Deviation \\
\hline Diversification index & 2028 & 0.0847 & 1 & 0.7909 & 0.2139 \\
\hline Past profitabilly & 2007 & -0.5024 & 1.1222 & 0.0584 & 0.0721 \\
\hline Workforce & 2028 & 0 & 87000 & 11395 & 12014 \\
\hline Non-US firms & 2039 & 0 & 1 & 0.6945 & 0.4607 \\
\hline 1975.1991 vs. $1992-199 ?$ & 2039 & 0 & 1 & 0.3237 & 0.4680 \\
\hline $4975-1985$ vs. 4986.1997 & 2039 & a & 1 & 0.5875 & 0.4924 \\
\hline $1975-1990$ vs. $1991-1997$ & 2039 & 0 & 1 & 0.3811 & 0.4858 \\
\hline Asset growth & 2007 & 0 & 1 & 0.7085 & 0.4546 \\
\hline Workforce growlin & 2013 & 0 & 1 & 0.4312 & 0.4954 \\
\hline Downward symmerric adjustment of asseis & 1048 & 0 & 1 & 0.2758 & 0.4471 \\
\hline Downward symmetric adjustment of worllforce & 1034 & 0 & औ & 0.5938 & 0.4914 \\
\hline Slage 1: wp up & 1696 & 0 & 1 & 0.1138 & 0.3177 \\
\hline Stage 2: down-up & 1696 & 0 & 1 & 0.3461 & 0.4759 \\
\hline Stage 3: up-down & 1696 & 0 & 1 & 0.1840 & 0.3876 \\
\hline Stage 4: down-down & 1696 & 0 & 1 & 0.3561 & 0.4790 \\
\hline
\end{tabular}

${ }^{2}$ 'The number of cases varies per variable. In the tests, all cases with missing values have been deleted. The value of ' $O$ ' with "workforce' indicates missing data. A better picture of this variable can be obtained by regarding mean value and standard deviation. Note also that we use the natural log transformation on workforce in the tests. 


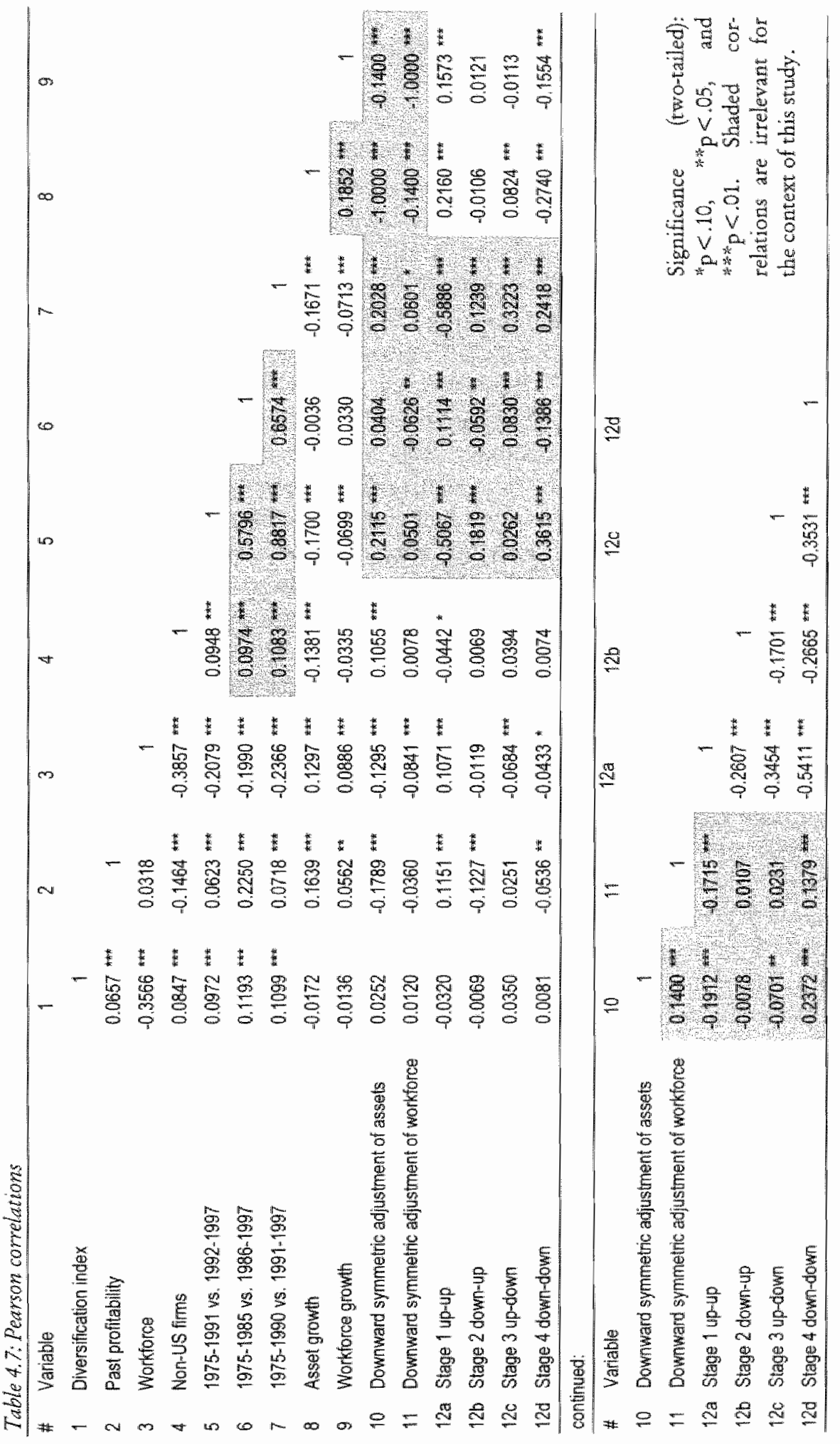




\subsubsection{Method}

Logistic regression was chosen to test the hypotheses. First of all, we could not apply normal regression techniques like OLS due to the dichotomic nature of our dependent wariables. We could resort to a form of discriminant analysis in dealing with categorical variables. However, we prefer the logistic regression method since the results of a logistic regression can be interpreted like the coefficients of a normal linear model, and because logistic regression requires fewer assumptions on the distribution of the individual variables, (Hair et al. 1998). Furthermore, logistic regression is very flexible because it suffers less from 'the plagues' of ordinary least squares techniques due to the binominal distribution of the error term (following from the fact that the dependent variable only takes on the values $[0,1])$. Of course, observations should be independent from each other (Hosmer and Lemeshow 1989), and multicollinearity between variables can make the prediction interval larger, leading to less significant predictors. An OLS estimation among the regressors showed a moderately significant functional relationship between size and diversification. We offer two argiments why we did not correct for this incidence of multicollinearity. First of all, although multicollinearity tends to decrease the significance levels of parameters (Gujarati 1988), our tests without the size variable yielded similar results in both directions and significance levels of the parameters. Secondly, we did not find it appropriate to delete one of the variables from our analyses because we explicitly use both size and diversification in our theory. Our model would have suffered from a far more serious error: model misspecification, if we would have done so.

A logistic regression model has the general form:

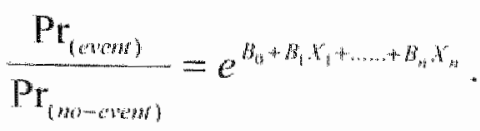

The first part of the equation is formally known as the odds ratio and compares the probability of the occurrence of an event to its nonoccurrence probability. Logistic regression is very flexible in that the independent variables can be metric or categorical. The interpretation of the estimators of the equation is similar to that of metric regression methods. The estimators should be transformed following Formula (4) to assess their influence. In stead of reporting standard errors, we chose 
to report the Wald statistic, which follows a Chi-square distribution. The Wald statistic for a likelihood estimator yields the same results as the likelihood ratio test between two models if only this variable is added (cf. Hosmer and Lemeshow 1989). The significance level of each estimator indicates whether or not the estimator differs from 0 . The likelihood value reveals individual model fit, with the difference between likelihood values of two or more nested models following a Chi-square distribution. Significance of the Chi-square statistic indicates an increase in explanatory power between models. Additionally, pseudo $R$-square statistics can be calculated, which are reported to indicate goodness of fir.

In total we have constructed three logistic regression tables because the testing of several hypotheses asked for a transformation of the year indicators. Models 1-6 (the influence of macro cycles) include a period indicator (Hypothesis 1 and Table 4.9). Then, Models 7 and 8 (the influence of meso cycles) are estimated with year-capacity indicators (Hypothesis 2 and Table 4.11). Finally, Models 9 and 10 (the influence of micro cycles) are run after introducing an indicator for each year (Hypothesis 3 and Table 4.12). All regressions exploit fixedeffect models using a dummy for each firm present in the data set to correct for unobserved firm heterogeneity. Besides, the total number of firm-years was reduced considerably in testing Hypothesis 2 because we did not have information on capacity utilization before 1979 .

\subsection{Results}

We find strong support for Hypothesis 1a (Models 1 and 2). Both estimators are in the expected negative direction (the dependent variable is growth, while the theorized direction is decline). 
Talle 4.9. Testing for the influence of macracycles

\begin{tabular}{|c|c|c|c|c|}
\hline 19751991 ve $1992-1997$ & $\begin{array}{l}\text { Assset gr } \\
\text { Mode }\end{array}$ & & $\begin{array}{l}\text { Workforce } \\
\text { Mode }\end{array}$ & $\begin{array}{l}\text { growth } \\
2\end{array}$ \\
\hline $\begin{array}{l}\text { Pand A: Control variables (") } \\
\text { Variable } \\
\text { Constant }\end{array}$ & $\begin{array}{r}B \\
-34340 \\
\end{array}$ & $\begin{array}{r}\text { Wald } \\
24358\end{array}$ & $\begin{array}{r}B \\
-111.6747 \\
\end{array}$ & $\begin{array}{c}\text { Wald } \\
27.3978^{*}\end{array}$ \\
\hline $\begin{array}{l}\text { Panel B: Independent variables } \\
\text { Diversification index } \\
\text { Pasi profitability } \\
\text { Workforce } \\
\text { Non-US firms } \\
1975 \text {-1991 } 45 \text {. 1992-1997 }\end{array}$ & $\begin{array}{r}-1.2096 \\
8.8567 \\
0.3504 \\
0.7325 \\
-1.0005 \\
\end{array}$ & $\begin{array}{c}4.4286 \\
48.5629 \\
4.4274 \\
0.2874 \\
50.2389\end{array}$ & $\begin{array}{r}0.2763 \\
0.2449 \\
1.1488 \\
-0.4175 \\
-0.5743 \\
\end{array}$ & $\begin{array}{r}0.2683 \\
0.0903 \\
43.0501 \\
0.0937 \\
18.3201\end{array}$ \\
\hline $\begin{array}{l}\text { Panel C Model statistics } \\
-2 \text { Lag Likelinood } \\
\text { Goodness of Fit } \\
\text { Cox \& Snell - R } \\
\text { Nagelkerke - } R^{2}\end{array}$ & $\begin{array}{r}1987.096 \\
1859.759 \\
0.185 \\
0.264 \\
\end{array}$ & & $\begin{array}{r}2297.470 \\
1924.681 \\
0.182 \\
0.245 \\
\end{array}$ & \\
\hline $\begin{array}{l}\text { Panel D: Model comparisons } \\
\text { Chi-Square } \\
\text { df } \\
\text { Number of cases }\end{array}$ & $\begin{array}{r}120.094 \\
5 \\
2039\end{array}$ & & $\begin{array}{r}62.677 \\
5 \\
2039\end{array}$ & \\
\hline
\end{tabular}

Table 4.96: 1975-1985 w. 1986-1997 in the U.S.

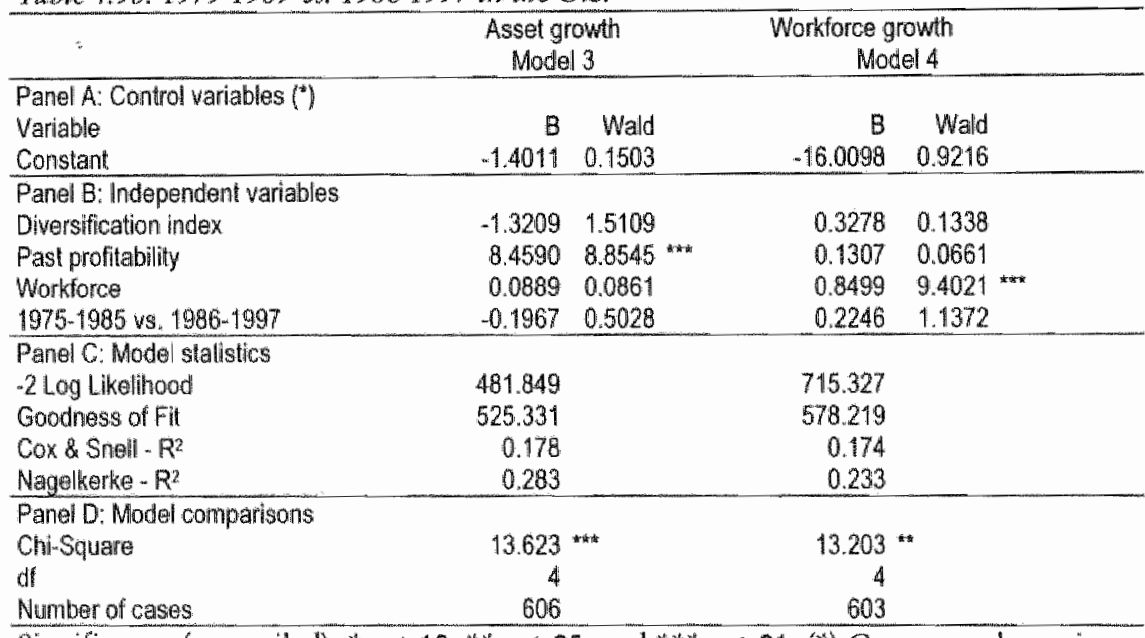

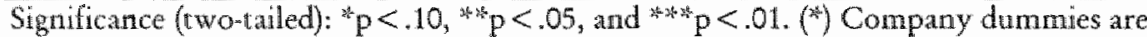
included but not reported. Models are compared to the models with constant and fixed effects only.

The results in Models 3 and 4 indicate that we cannot find evidence for our period break-up conjecture in the United States. For asset adjustment, the sign is as expected but not significant; for workforce adjustment the estimator lacks both the expected sign and significance. Then, for Hypothesis 1c, we again find support for both the hypothesis within Europe, and for the proposed period break-up. Overall, wre 
might conclude that the influence of the macro-cycle phase as proposed by Abrahamson (1997) influenced the international paper and pulp industry as predicted, whereas Van Witteloostuijn's (1999) suggested stage sequence holds for Europe.

Table 4.96:1975-1990\%\%.1991-1997 in Europe

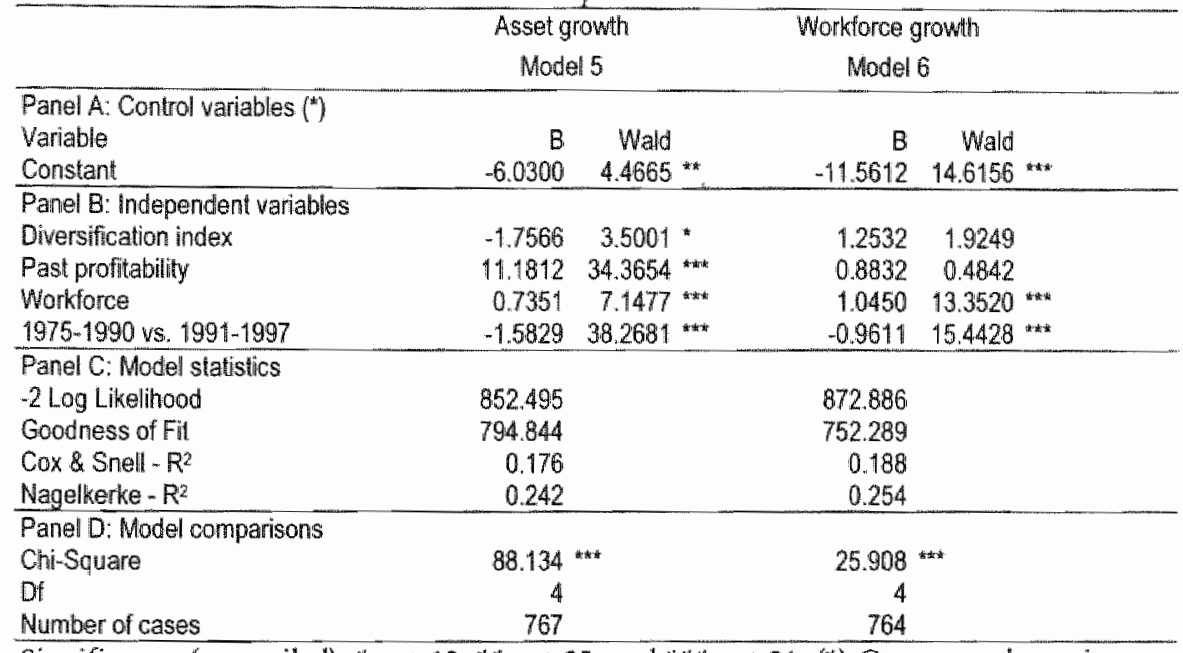

Significance (two-tailed): $* p<.10, * p<.05$, and $* * * p<.01$. (*) Company dummies are included but not reported. Models are compared to the models with constant and fixed effects only.

Diversification, past profitability and size (workforce) are present in these models as covariants. The estimators for past profitability indicate that a strong positive relation (Models 1, 3 and 5) exists between the level of past profitability and asset growth. The results reveal the same sign but without yielding significance for the growth of the workforce (Models 2, 4 and 6). The level of diversification decreases the probability of asset growth (Models 1 and 5). This indicates that the more related a firm is (diversification goes to 1), the lower its probability to expand. Conversely, firms expanding in unrelated activities that, in turn, decrease the diversification index might dilute this effect. A diversification effect on workforce could not be found. The size of a firm seems to have a positive effect on the probability of an increase in assets (Models 1 and 5) or workforce (Models 2, 4 and 6), indicating that bigger firms tend to have a greater chance of getting larger [cf. findings of resource partitioning theory Mezias and Mezias (2000), Boone et al. (2000), Swaminathan (1995), and Caroll (1994); see Carroll and Harrison (1994) for a theoretical simulation approach that 
supports this idea]. A difference in adjustment pattern between USbased firm and firms from other countries could not be traced.

We created dummy variables for each stage and each demarcation point in order to test Hypothesis 2, as noted above. We then compared stages 2,3 and 4 to stage 1 , covering both subhypotheses in this context. We estimated models with stages based on $85 \%$ to $90 \%$ (capacity usage never was under $83.2 \%$ and never was above $92.2 \%$ ), because we were not sure about the precise value of the capacity demarcation ratio. Table 4.10 indicates the likelihood ratio for models run with the different points of reference.

Table 4.10: Influence of stages aver the industry cycle on divestment and measurement $(N=1643)$

\begin{tabular}{|c|c|}
\hline $\begin{array}{l}\text { demarcation use of } \\
\text { capacily }\end{array}$ & $\begin{array}{l}-2 \mathrm{log} \text { likelinood ratio of } \\
\text { the rested model (sig) }\end{array}$ \\
\hline $\begin{array}{l}85 \% \\
86 \% \\
87 \% \\
88 \% \\
89 \% \\
90 \% \\
\end{array}$ & 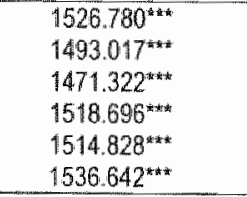 \\
\hline
\end{tabular}

We chose only to display the results for the $87 \%$ demarcation point because testing with this reference point gave the smallest likelihood ratio (and thus had the best fit compared to the other options). Figure 4.2 pictures the development of capacity utilization and shows the cycle stages.

Figwre 4.3. Gycle stages of capacity utitization whts $87 \%$ as denarcation point (dotted line)

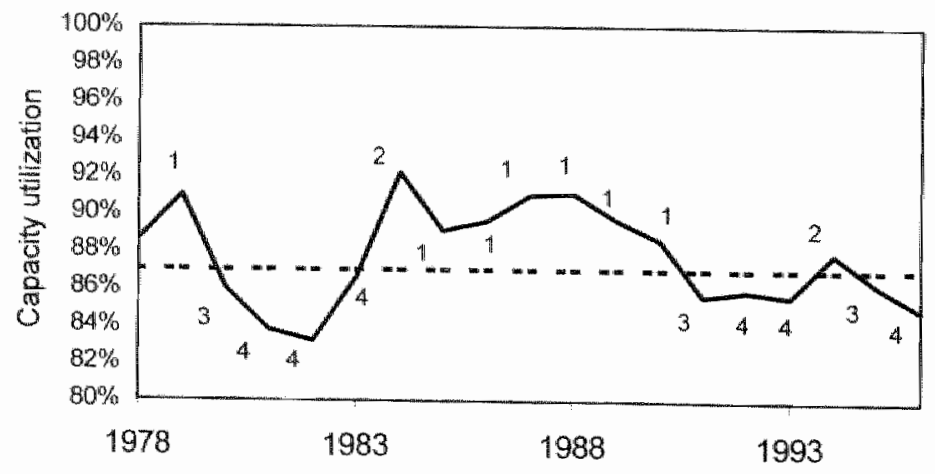


Table 4.11: Testing for the infuence of meso cycles

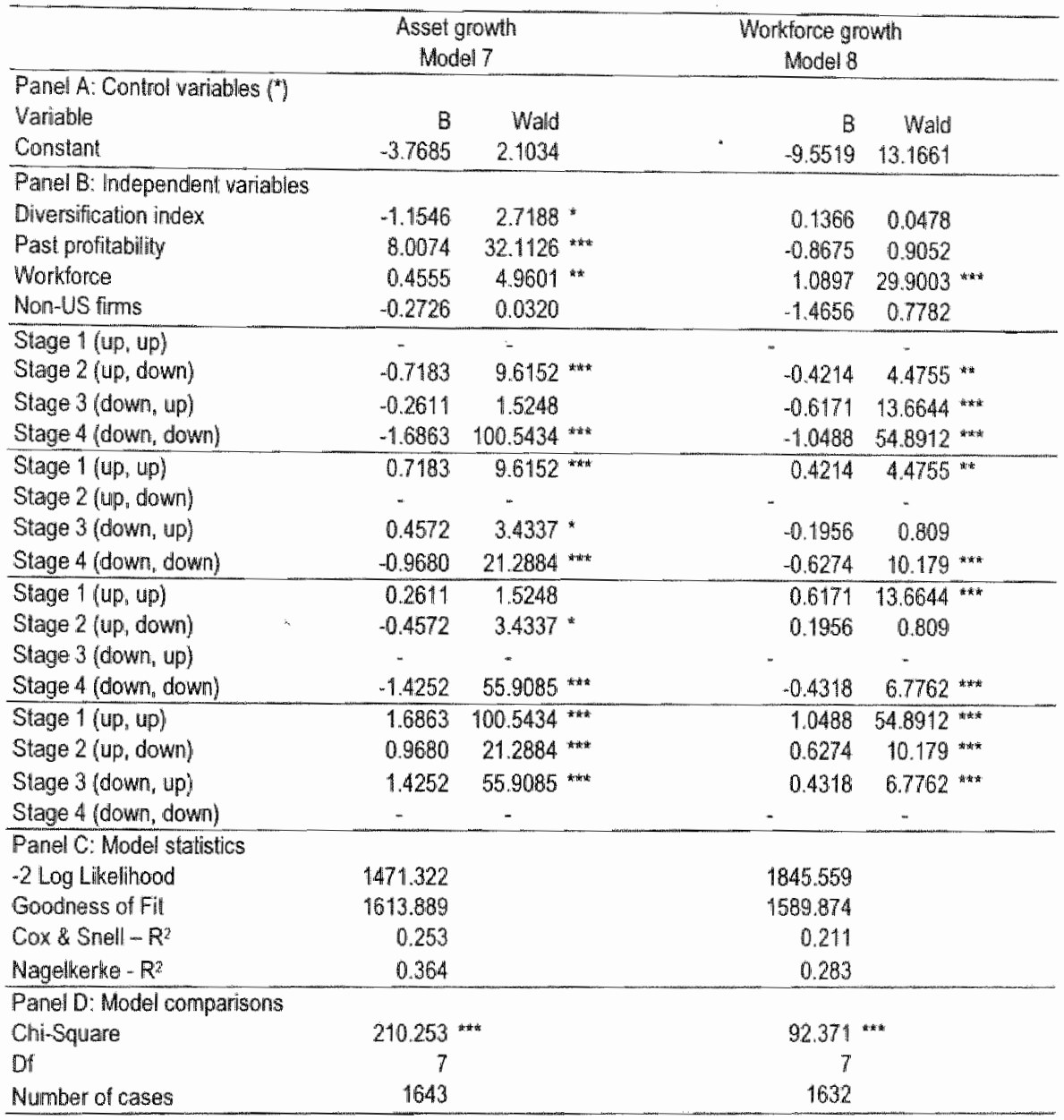

Significance (two-tailed): $* p<.10, * p<.05$, and $* * 2 * 01 .\left({ }^{*}\right)$ Company dummies are included but not reported. Models are compared to the models with constant and fixed effects only.

Clearly, the industry-level or meso cycle, as expressed by deviation of a capacity utilization percentage, influences the investment behavior of individual firms in the paper and pulp industry. The test results presented in Models 7 and 8 offer evidence for the sequence of adjusting in the following way. The probability of downsizing in Stage 1 (this year up, last year up) is lower than in Stage 2 (up, down) which in turn is lower than in Stage 3 (down, up) which is again lower than the 
probability of downsizing in Stage 4 (down, down). Stated otherwise, the probability of downsizing in Stage 4 is the highest as compared to the downsizing probabilities associated with the other stages. The sequence is significant in order and direction for workforce adjustment, except for the difference between Stages 2 and 3 (in the expected direction but not significant). The position of Stage 4 is clearly established for asset adjustment: if an industry is in Stage 4, firms show the highest probability to downsize. However, mixed evidence has been obtained as to the order of Stages 1,2 and 3, especially since the difference between Stage 1 and 3 is as expected but not significant. Besides, being in Stage 2 leads to a significantly higher probability to downsize than being in Stage 3, which is not as expected. Rather, the apparent order is Stage 1, 3, 2 and 4 for assets, in which downsizing probability increases from left to right.

These sequences indicate that firms 'acquire' both assets and employees when they are in Stage 1 but downsize in Stage 4. However, delay and cost effects in dealing with assets might explain the nonhypothesized differences found in the sequence (cf. Abel et al. 1997). A delay of three to five years exists in the paper and pulp industry between the ordering and materialization (i.e. when new capacity starts to generate output) of an investment in assets. Besides, great amounts of cash are needed. Capacity ordered in Stage 2 might materialize in Stage 3. By then, a firm is naturally reluctant to 'mothball' it instantaneously. The finding that Stage 2 is followed by Stage 4 can be explained by reluctance from past experience to add assets to the existing base (chronologically, Stage 2 follows Stage 4 or 3 ). Adding employees is less costly, and employees are more easily 'acquired' and 'dismissed' as compared to assets. We believe that this finding may be typical for capital-intensive industries. 
Table 4.12: Testing for the influence of micro cycles

Symmetric downward asset adjustment
Symmetnic downward workforce adjustment

Model 9

Model 40

Panel A: Control wariables (")

\begin{tabular}{|c|c|c|c|c|}
\hline Wariable & $\theta$ & Walcd & 8 & Wald \\
\hline Constant & 4.6197 & 1.7742 & 14.2584 & $17.8541 * *$ \\
\hline \multicolumn{5}{|c|}{ Panel $B$ : Independent variables } \\
\hline Diversification index & 1.7621 & 2.5712 & -0.0860 & .0098 \\
\hline Past profitability & -5.6681 & 7.4856 & 1.9767 & 2.3596 \\
\hline Morkirarce & -0.5184 & 3.2863 & -1.4460 & 26.1279 wh \\
\hline Won-US fims & -0.8985 & 0.2665 & 0.7349 & 0.2199 \\
\hline
\end{tabular}

Panel C: Model statistics

-2 Log Likelihood

744.909

997.541

Goodiness of Fit

787.155

940.634

Cox \& Snell - $R^{2}$

0.368

0.318

Nagelkerke - $\mathbb{R}^{2}$

0.532

0.429

Panel D: Model comparisons

Chi-Square

15.961 *

$36.405^{* * *}$

D)

Number of cases

1036

1029

Significance (two-tailed): ${ }^{p}<1.10, * p<.05$, and $* * * p<.01 .(*)$ Company and time dummies are included but not reported. Models are compared to the models with constant and fixed effects only.

The results suggest support for Hypothesis $3 \mathrm{a}$, both in direction and in significance, and for Hypothesis $3 \mathrm{c}$ for assets. Hypothesis $3 \mathrm{~b}$ is not supported, though. To the contrary, the negative sign is unexpected, while the estimator approaches significance with workforce adjustment as dependent variable. The size-influence finding supports the idea of structural inertia. Bigger firms may face more difficulties whilst seeking change. Alternatively, larger firms might benefit from slack advantages that make it less necessary for them to change in the first place. We only found find limited support (expected sign, but not significant) for Hypothesis $3 \mathrm{~d}$ regarding the adjustment in assets, and no support for the workforce adjustment hypothesis.

The overall results for Hypothesis 3 are robust if we compare them with the findings of the same variables in the models run to test Hypotheses 1 and 2. However, the influence of diversification on adjustment in the other tests had an unexpected and significant sign. This leads us to conclude that we cannot accept the formulated 
hypothesis on diversification. Rather, the results suggest that a positive relationship exists between the level of diversification and the probability of downsizing. This finding, then, is in line with the idea that diversification is associated with risk spreading, so reducing the vulnerability of a firm to external influences. However, a graphical representation of mean adjustment to diversification levels shows a Ushaped relationship if we regard asset adjustment. Highly diversified firms $(>70 \%)$ tend to downsize less, whereas the same pattern emerges for firms that are diversified less $(<50 \%)$. It is no accident, then, that we find no significant relationship here and that the sign is not as expected. However, if we look at the number of observations that make up the diversification classes, the following pattern emerges. The left-hand side of the ' $U$ ' is made up of 52 observations, whereas the right-hand side consists of at least a thirty-fold of this number. We thus think it is safest to conclude that the relationship between diversification and adjustment cannot be determined with our current sample.

\subsection{Discussion}

We studied the effects of the macro cycle, the meso cycle and the micro cycle on business position alterations (investing and downsizing). In this chapter, we tried to find agreement between often cited reasons for downsizing and actual downsizing in our sample. Several authors have hinted at the negative side effects of downsizing. We explored data on the paper and pulp industry, looking for factors that influence this phenomenon. The results suggest that firms in the paper and pulp industry adjust symmetrically to cyclical movements. Past profitability, however, strongly moderates this effect for asset adjustment, while size moderates this effect for workforce change. High past profitability, and hence the availability of internal resources, reduces the probability of an asset rationalization strategy. Interestingly, this effect was not found for workforce adjustment. This indicates that firms tend to downsize their workforce in light of cyclical decline, even if enough internal financial resources are available. However, size again moderates this effect for workforce downsizing. Table 4.13 summarizes the hypothesized relationships and the results found in this chapter. 
Table 4.13: Summary of the results

\begin{tabular}{|c|c|c|c|c|}
\hline & \multirow[t]{2}{*}{ Prediction } & \multicolumn{2}{|c|}{ Results } \\
\hline \multicolumn{2}{|c|}{ Hypothesis } & & Assats & Workf: \\
\hline & Macro cycle influence & & & \\
\hline $1 \mathrm{a}$ & Probability of negative adjustment in 1992-1997 vs. 1975-1991 & + & + & + \\
\hline tb & $\begin{array}{l}\text { Probability of negative adjustment in } 1986-1997 \text { vs. } 1975-1985 \text { in the } \\
\text { US }\end{array}$ & + & ns & ns \\
\hline 10 & $\begin{array}{l}\text { Probability of negative adjustment in } 1991-1997 \text { vs. } 1975-1990 \text { in } \\
\text { Europe }\end{array}$ & + & + & + \\
\hline
\end{tabular}

\section{Meso cycle influence}

2

Probability of negative adjustment in increasing order (cycle stages) $1,2,3$ and 4

$1,3,2 \quad 1,2,3$

and 4 and 4

Micro cycle infurence

3a Probability of negative adjustment and size

3b Probability of negative adjustment and degree of diversification

3c Probability of negative adjustment and past profitability

3d Probability of negative adjustment and US-based headquarters.

$+\quad-\operatorname{lns} \quad-\operatorname{lns}$

- ns

$+\quad n s \quad n s$

Overview of the hypotheses, the predicted relationships and the results after testing, with ns = mot significant.

First of all, the results provide evidence for macro cycle influence in spite of the merger wave that characterizes the $1990 \mathrm{~s}$. The concentration ratio still is relatively low, although a pattern of increasing concentration is visible within the industry. The combined sales of the ten largest firms in our data set reflect 34 percent of total sales in 1997. The real concentration ratio is about 20 percent, given that our data covers at least 60 percent of total world sales. Our tests treat growth by merger or acquisition and growth by investment in green-field operations as equal. Obviously, the concentration process may well have affected our results.

That we did not find significant evidence for the conjectured break-up period for the US could be a consequence of the merger wave that started in the US in the second half of the 1980s. The combined sales of the four largest US companies amounted to 35 percent of total US sales in the data in 1985 and 49 percent of total US sales in 1997, (for Europe this is 39\% in 1991 and $41 \%$ in 1997), which is different from the development of overall world sales concentration. Probably, we have not been able to identify the relative effect of downsizing on firm of US origin due to this feature of the data set. We should compare pre- and post-merger assets and workforce of the combined 
entity to be able to test the timeframe relationship. The results are thus a conservative test of our prediction as actual downsizing may be masked by merger and acquisition growth. Of course, an alternative explanation might be that the downsizing wave started earlier in the United States. However, we could not ground this idea in the existent literature, so we have refrained from formulating hypotheses about this.

It would be very interesting to devise tests that take into account the magnitude of cycles and the magnitude of adjustments. However, as with most industries, the international pulp and paper industry encounters a concentration tendency that spans at least the period within our time window. The data set lacks the information necessary to correct for this fact. Thus, instead of measuring continuously, we chose the dichotomous (symmetrical or asymmetrical adjustment) approach, so disregarding the size of the reaction. The concentration movement is in itself an argument that might support the idea that companies strive for other goals than profit maximization alone. The dramatic merger, for example, by KNP in 1993 that ended with its split-up in 1998, is a case in point.

Secondly, the evidence as to meso cycle effects may suggest that a delay structure between investment initialization and investment materialization could be an explanation for the stage order found. However, taking the lag structure into account poses problems in testing and interpreting the results. For one, increasing the lag period incurs a loss in degrees of freedom. Additionally, it becomes more difficult to formulate a sensible theory. It is hard (not to say undoable) to disentangle causal relationships over a time span of, say, four years. Still, the results found support our original theory, especially in the case of workforce adjustment, in two ways: (1) industry cycle stages can be expressed as the amount of capacity usage compared to a benchmark; and (2) firms are susceptible in their adjustment behavior according to the stage the industry is in.

Thirdly, by far the strongest effects are revealed in the tests of the impact of micro cycles and firm-level characteristics on investment behavior. In Models 1-6 we took into account both macro and micro level data, and in Models 7 and 8 both meso and micro-level data were taken aboard. The effect of profits (and thus free cash flow) was highly significant in all cases, which probably offsets the influences of the macro and meso cycles on asset investment and divestment behavior. Related diversification increases the probability of downsizing assets if 
the effects are moderated by macro or meso cycle influences. Significance of this estimator was lost in the case of firm-level data only. The size of a firm increased the probability of expansion in almost all cases, where the effect seemed to be the strongest on workforce expansion. This means that a kind of momentum is in operation that increases the probability for bigger firms to get bigger.

Our examination has several drawbacks. For example, we would have liked to test the relationship between firm age and asymmetric reactions because this is a well-examined parameter in the organization ecology field. Unfortunately, all firms in our data set were established before the beginning of our time window, without. information about their actual establishment date being readily available. Probably, the firms in our data set are all rather old. Apparent new entries into the data set are, by and large, the result of concentration by mergers and acquisitions. This results in combinations of older firms and the simultaneous entry of yet existing firms.

In this chapter we have examined the question "Can we find specific firm adjustment patterns that are linked with different stages of (environmental) cycles?". The results suggest that firms tend to adjust symmetrically, and that they try to achieve a strategic fit by exploiting an ability to change. However, the results do not show that this aimedfor-fit (expressed in higher performance) is achieved by the change strategies pursued. For example, firms that downsize readily might be subject to a liability of change (Delacroix and Swaminathan 1991), while firms that postpone downsizing might reap the benefits of a more trustworthy organization (Mishra and Spreitzer 1998). Or, as Haveman (1992) suggested, change may enhance performance only if a firm is faced with the dilemma to change or to die. Van Witteloostuijn (1998) finds that, contrary to established economic thought, firms do not divest inefficient plants, thus behaving asymmetrically. The current examination does not explain for this fact either. Therefore, the next chapter focuses on the effects of adjustment (especially downsizing) on performance to gain insight into the consequences of (a)symmetric adjustment behavior. 


\section{Chapter 5}

\section{THE B(H)OLD AND THE BEAUTIFUL}

Sticky downsizing routines with an inert versus

versatile nature

The effect of downsizing on the performance of a company has been questioned extensively over the past two decades. Several perspectives guide management in the question whether or not to downsize. This study attempts to bridge the gap between traditional literature on downsizing and the literature that emphasizes the inertness of certain change routines. It introduces a three-dimensional framework for downsizing that distinguishes between downsizing reluctantly and downsizing readily in the face of organizational decline. Results indicate that firms that downsize assets and workforce reluctantly, outperform those that downsize readily in terms of both profitability and market share. These findings suggest that a reluctant atritude towards downsizing enhances long-term performance. Likely reasons for these findings are proposed as well. This examination adds to the existing literature by trying to uncover the effects of cumulative downsizing, defining change routines and tracing what routine yields the highest performance. In doing so, it contributes to an understanding of the link between downsizing and performance. Downsizing has attained a high degree of acceptance as a legitimate strategy. It takes boldness to deviate from the trend in the face of declining profits. Alternatively, firms strive for more superficial beauty (strategic fit) if they do follow this downsizing trend. 


\subsection{Introduction}

Probably the most examined research question within organization studies focuses on the explanation of the performance of firms. Within the confines of this question, the current study concentrates on the effect of downsizing on performance. Two measures of performance have been taken aboard: profitability and market share. This examination adds to the existing downsizing literature by testing the relationship between downsizing routines and organizational performance. Specifically, the model developed in this study answers the question as to what routine yields the highest performance. Ir proposes the idea that downsizing routines are sticky and defines two routines that differ in nature.

The concept of downsizing is multi-dimensional. We develop a three-dimensional conception of downsizing. First, a downsizing program is implicitly or explicitly grounded in a theory of action (Argyris and Schön 1978). That is, managers react to stimuli based on a set of assumptions (their theory) that their actions will result in the wished for effect. This is the nature aspect of downsizing. Next, downsizing can follow many patterns over time. This is the process aspect of downsizing. Finally, the downsizing operation can affect different resources of the firm. This is the content aspect of downsizing. Figure 5.1 summarizes the theoretical framework of this study.

Figure 5.1: Natwre, process and content of downsizing and the influence on performance
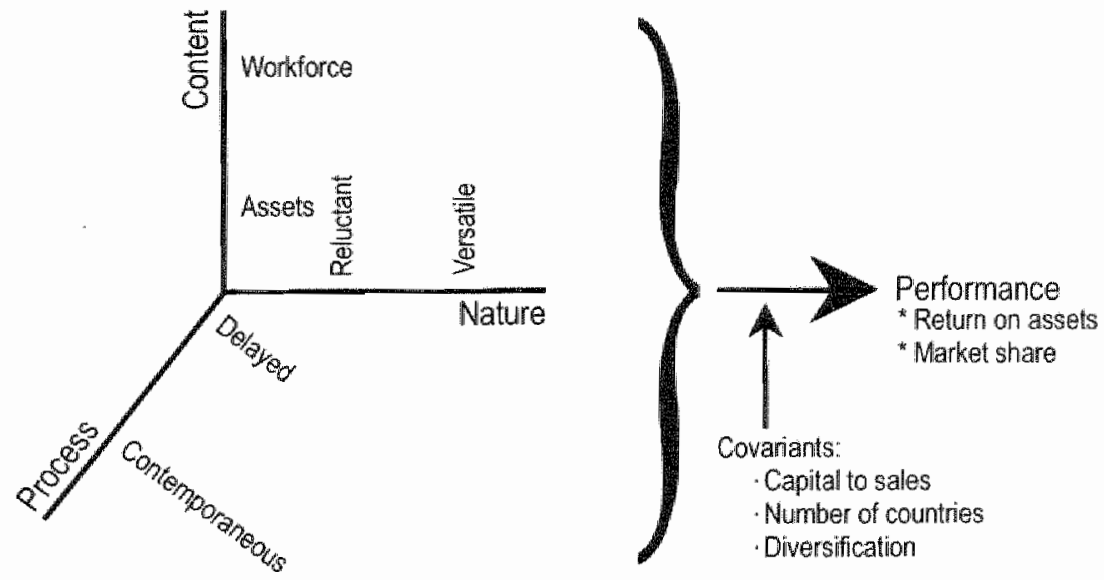
We examine whether or not a downsizing routine is sticky and what routine yields the highest performance. Theory is developed about the stickiness of routines to define the nature of the routine from extremely inert to completely versatile. We suggest that the way in which a firm reacts to a decline of environmental resources is stable over time hence our reference to stickiness of routines. The nature of downsizing routines can be explained from a structural inertia or sociological argument (reluctantly downsizing routine) or from a strategic choice or economic efficiency argument (versatile downsizing routine). The process aspect refers to the timing of downsizing strategies. The content dimension pertains to how the resource positions of the firm are affected by the downsizing operation. In this study, we look at three process and two content aspects. The timing of a downsizing program (pattern) can be contemporaneous, delayed or cumulative. Contemporaneous downsizing refers to an action in year $t$ that follows a decline in year $t$, whereas delayed downsizing follows a decline in year $t-1$. Cumulative downsizing regards all downsizing operations from $t-x$ until $t^{1}$. Theoretically, this typology also has to do with the contemporaneous, delayed or cumulative effect of downsizing. The content character of downsizing is expressed by looking at assets and workforce. The indicators of change most extensively covered in the literature appear to be (a) assets or the capital position and (b) personnel or the workforce position (Hammermesh and Pfann 1996). This study follows this tradition by defining the routines based on changes in the assets base and in the workforce base.

This chapter adds to the existing literature on firm performance by taking aboard downsizing routine as a characteristic of the firm. The current examination tests competing hypotheses that originate from different but still complementing strands of literature, thus carrying arguments to support either of these theories within the context of the industry studied. On top of this, the study contributes to the existing literature in that it does not only account for the effect of (core) changes, but additionally looks at routine actions of firms that face temporal decline. Ultimately, we are interested in understanding the influence of downsizing on performance. Here, the examination below assesses both profitability (return on assets) and market share development over time as indicators of performance.

"We take a yearly perspective here for the sake of convenience. 


\subsection{Theory and hypotheses}

This section provides an overview of the downsizing literature and introduces the idea of sticky downsizing routines. This idea is embedded in two strands of literature: the concept of strategic choice (the possibility of obtaining a fit between external environmental conditions and the internal position of the firm) and the notion of structural inertia (a change increases the vulnerability of the firm). Because we do not know beforehand what theory best describes reality in the paper and pulp industry, we formulate two conflicting propositions based on these bodies of literature. This examination follows a tradition that incorporates ideas from both economic and organization studies. Like Boone and Van Witteloostuijn (1995) and Van Witteloostuijn (1998) we seek to exploit both branches of the social sciences to enrich our understanding of organizational phenomena that cannot be explained solely by maximization arguments, by selection mechanisms or by the influence of individual traits.

\subsubsection{Two seemingly opposing theoretical framewarks. Darwin versus Lamarck}

T'wo seemingly opposing theoretical frameworks exist with regard to organizational performance and performance-enhancing strategies. The Lamarckian or strategic choice school, which origins in industrial organization (cf. Porter 1985, Scherer and Ross 1990), holds a contingency-adaptation view that states that firms are able to influence their performance by establishing a sound link between the position of the firm and the features of the environment. Porter (1991), for example, attributes firm success to initial conditions and managerial choices. Miller and Cardinal (1994) suggest in a meta study of 26 empirical examinations that strategic planning is indeed often associated with higher performance. The Darwinian school (particularly evolutionary economics and population ecology) claims that the availability of choice alternatives is limited as behavioral routines are sticky (Nelson and Winter 1992) and change endangers the surviving capacity of a firm as a result of decreasing accountability towards various stakeholders and resistance to change within an organization (Hannan and Freeman 1993, Baum 1995, Carroll 1988). Downsizing is a strategy aimed at improving the position of the firm, and implicitly originates in a contingency or strategic choice idea. Over the past two 
decades an impressive body of downsizing literature has seen the light. The following paragraphs give a short (in no way exhaustive) summary of what has been written.

\subsubsection{Downsizing studies}

Cameron et al. (1991) distinguish between downsizing and decline. Decline is a situation in which a firm starts to dissolve. This is a phase of the corporate life cycle. Downsizing is an attempt of the organization to recover performance and competitiveness. While downsizing might be an instrument to avoid decline, it also has gained importance as a management instrument in temporary crises, as is the case in cyclical industries (cf. De Wit 1994). McKinley et al. (2000) deal with the question as to why downsizing became so popular among managers. Interestingly, they conclude that mainly social processes of mimetic behavior reinforced this "myth". Several economists and sociologists predict that the downsizing trend will continue for many years to come (Gordon 1996, Micklethwait and Wooldridge 1997, Mishra 1998), even in the current times of greater growth and prosperity. Cameron et all. (1987a, 1987b, 1991) observe that downsizing has become the number one medicine against corporate decline in the US. Note, however, that the late 1980 s and early $1990 \mathrm{~s}$ were characterized by a macroeconomic depression as opposed to the current roaring times (cf. Ideas developed around the so-called New Economy). At this moment, a growing body of evidence both from the US (Gordon 1996, Reynolds-Fisher and White 2000) and Europe (Van Witteloostuijn 1999) reveals that downsizing does not influence performance in the planned direction. However, Cascio et al. (1997) find that a combination of both capital and workforce restructuring has produced higher returns on assets; workforce adjustments alone have not had any effect. This findling seems to support the results of Cameron et al. (1991) that downsizing should be part of an overall strategy.

Many reasons have been suggested to account for the seemingly under-performance of downsizing firms. These explanations mainly focus on the hidden (social) costs of the downsizing operation. Examples studied in the literature include the destruction of social networks (Shah 2000), decreased capabilities of organizational learning (Reynolds-Fisher and White 2000), and increased job insecurity, declining trust and deteriorating loyalty (Moser-llles 1995, Mishra and Spreitzer 1998). McKinley et al. (1992) point at asymmetry between 
downsizing strategies and organization structures (less personnel does not necessarily mean less centralization), which might dilute the expected gains.

Special attention has been given to the way in which the downsizing operation is executed. Notably Cameron et al. (1991) extract six policies that contain 'best' practices to implement effective downsizing strategies. Their final conclusion has been that effective corporations (in the automobile industry) continuously seek to improve their positions while embedding short-term actions in longterm goals (cf. Brown and Eisenhardt 1997). Other research has focused on the effects on surviving employees of the way in which the rationalization was performed (Allen et al. 1995, Mishra and Spreitzer 1998, Shah 2000). Mishra and Spreitzer (1998) find that the reactions are mediated by the perception of the (in)justice and (dis)trust that is associated with the downsizing operation. They have reported that if the operation was appraised as trustworthy and just, survivors reacted more constructively. Negative attitudes toward the firm tend to increase after the reorganization (Allen et al. 1995) but seem to be mediated by career perspectives and the employee"s new position in the social structure of the firm (Shah 2000).

\subsubsection{Change and inertia studies}

Above, the literature about (the consequences of) downsizing has been reviewed. Downsizing is an important example of organizational change. Therefore, this subsection introduces insights from the literature on (the lack of) organizational change that may prove relevant in the context of downsizing strategies. Downsizing involves changing the position of the firm. Below, we will give an overview of the relation between change and performance. Miller and Cardinal (1994), interpreting the results from a meta study of 26 previous examinations, have suggested that strategic planning yields higher returns. This is in striking contrast with an increasing body of literature that claims that strategic planning restricts firm flexibility (Mintzberg 1994) or that it is useless because planned results hardly materialize (Stacey 1995, 2000). This debate is important in our setting because it determines in part how firms should deal with downsizing as an element of an explicit strategic process: to downsize or not to downsize as an important incident of flexibility versus inertia. The downsizing strategy presumably is executed from the implicit or 
explicit belief that firms can establish a fit between the external environmental and internal resources.

The debate between adaptation (contingency theory and strategic choice) and selection (evolutionary economics and population ecology) theories has resulted in an expanding body of literature that tests the different predictions that follow from these opposing stances. Some important work from the last decade is mentioned here. Haveman (1993) examines the relationship between size and change (i.e., the speed and readiness to enter new markets), and proposes an inverted U-shaped relationship. This implies that, as firms grow larger, they change more easily, but this effect diminishes again as firms grow very large. She also suggests (Haveman 1992) that the impact of change on performance depends critically on the perceived need to change (change or fail). Greve (1998) has examined the causes of core change (of radio stations), and has reported that changes now predict further changes in the future. He has also found that a change disrupts the performance level. Both Haveman and Greve have revealed that change is more likely to succeed if it is well established in routines [see for similar results Brown and Eisenhardt (1997) and Haleblian and Finkelstein (1999)]. Greve (1999) has introduced a nice phenomenon into the change literature: regression toward the mean. Change is more likely to be beneficial for low-performing firms than for firms that do well; the probability for both is to regress to the mean.

Hannan and Freeman (1993) argue that organizations possess two characteristics that justify their existence: (1) reliability (highly walued in an uncertain world, being especially intense during the early stages of organizational building so as to satisfy stakeholder interests), and (2) accountability (producing internal consistent accounts of how resources are used). It follows from these two factors that organizations face difficulties in changing and that they are in effect inert. That is not to say that firms cannot change. Rather, the ability to change competes with the requests for reliability and accountability (Hannan and Freeman 1993). Changing has three consequences: first of all, it is not certain that the change contributes to the improvement of an organization's performance; secondly, it increases the hazard rate of organizational failure; and thirdly, change increases the likelihood of additional changes of the same type (Amburgey et al. 1993, Carrol 1993).

This present study applies the idea of organizational inertia to the nature of the reaction of a firm to the event of declining 
profitability. When organizations adhere to current operating routines and resist change, we can say that they exhibit inertia. A different form of inertia (momentum) results when organizations develop modification and change routines through processes established over time (Amburgey et al. 1993: 53). Nelson and Winter (1982) define routines as the basis of the ability to act. Three factors make routines 'sticky' (Nellson and Winter 1982, Klaas and Ullman 1995): (1) routines take long periods to learn and, they tend to be hard to unlearn; (2) the way firms procure and perceive information determines their sensitivity to that information; and (3) many routines are tacit. Several reasons have been suggested why routines are so persistent, particularly as people associate costs with changing accepted schemata (Argyris and Schön 1978, Hannan and Freeman 1984). People hardly change compared to the environmental turbulence they are facing (Leavitt 1996). Furthermore, a change in a certain direction predicts more change in that same direction (Greve 1998).

Interestingly, McKinley et al. (2000) basically argue along the same lines to explain the popularity of 'downsizing', as reliability and accountability are at the core of their socio-cognitive interpretation of downsizing. Downsizing has gained an accepted status as a management tool. Thus managers face relatively little risk in applying such measures. We argue that a firm facing decline displays similar reactions over time. That is, firms develop a routinized reaction to decline. Some firms tend to move down symmetrically with the decline. So they downsize readily. Other firms persistently tend not to adjust, and thus behave asymmetrically in the face of decline. Hence, they downsize reluctantly. Interestingly, both response patterns follow from the inertness of change routines (see above). Downsizing readily can be explained from the strategic choice idea. Within this line of thought it is possible to actively achieve a fit between environmental resources and internal positions. Downsizing reluctantly fits more with the "liability of change" line of thought (cf. Carroll 1993, Van Witteloostuijn 1998). This means that change is possible, but hardly for the better.

Recapitulating, we distinguish three downsizing routines that are defined in nature, process and content. The nature of the routine is expressed in terms of downsizing reluctantly, downsizing inconsistently or downsizing readily (versatile). The inconsistent group is included for convenience purposes, serving as a performance benchmark to which the performance of the other two change routines 
are compared. The routines are associated with the cumulative effects of contemporaneous and delayed downsizing strategies. Finally, assets and workforce reduction make up the content part of our downsizing routines typology.

Normally, the link between performance and inertia within population ecology studies is examined by looking at survival rates as a proxy for performance (Delacroix and Swaminathan, Baum 1995, Caroll 1993). This study focuses on two different performance measures: profitability and market share development.

\subsubsection{Propositions and bypotheses}

Due to the exploratory nature of this examination, we formulate two opposing propositions. The hypotheses follow from this couple. First of all, proposition 1 reflects a strategic choice or economic efficiency view:

P1. Downsizing readily in response to falling profits yields the bighest performance

Secondly, proposition 2 reflects a relative inertia or organization ecology argument:

P2. Downsizing reluctantly in response to falling profits yields the bighest performance

Four hypotheses follow from these propositions that deal with downsizing strategies as to assets and employees, respectively.

Hla. Downsizing assets readily in response to falling profits yields the bighest performance

H1b. Downsizing workforce readily in response to falling profits yields the bighest performance

H2a. Dorensizing assets reluctantly in response to falling profits yields the bighest performance

H2b. Downsizing workforce reluctantly in response to falling profits yields the bighest performance 
Clearly, each of these hypotheses can be split up further in two process aspects: contemporaneous and delayed downsizing. We refrain from formulating explicit hypotheses because we have no $a$ priori expectations here. However, we will take them aboard when running the analyses. The inertia idea is present at two different levels: first of all, we examine the effect of specific reactions, versatile versus inert, to decline on performance; and secondly, we look at the inertness of the change routines, which holds for both routines, to downsize readily or reluctantly.

\subsection{Data and Methods}

\subsubsection{Research setting}

We chose the international pulp and paper industry for the following reasons. Firstly, the sample is fairly homogeneous. We refer to strategic group research suggesting that the effects of competitive strategies depend on the specifics of the industry context (Boone et al. 1996, McGee and Thomas 1986). The choice of a sample from one industry enhances internal validity, but at the same time decreases the external validity of the results found. However, we prefer increasing internal vallidity to increasing external validity because this provides richer results; simillar studies performed in other contexts should contribute to external validity (cf. Cooper and Emory 1995). Secondly, the pulp and paper industry is notoriously cyclical in nature, which gives us a proper setting to study hypotheses as to at what level of cycle features influences the adjustment of firm positions. Besides, the industry is relatively stable regarding the main players. Entry is very costly and production is knowledge specific. This means that only existing firms adjust their capital positions and that relatively few factors from outside the industry influence the decisions made. Thirdly, it was relatively easy to obtain data on a large sample of pulp and paper firms. In total, our data set contains information on 100-150 paper and pulp producers per year from 1974-1997. This group of manufacturers together account for $60-75 \%$ of total industry output. Although the sample is biased toward size, the sample itself guarantees sufficient size variation. Moreover, we have chosen this data set because of its firmlevel richness and longitudinal reach. Limitations of the use of secondary data in doing organizational research apply to our examination, too, of course. However, we feel that this set of data 
passes the tests of prudence, given the topic of interest: downsize routine and performance.

Basically, the data were collected from one source (PPI's yearly top 150), and thus should be regarded as a secondary data set. In total, the rough data comprises approximately 3000 firm/year observations on total sales, paper-related sales, earnings, total assets, amount of pulp, paper and converted products production, workforce and the number of countries in which a company has production facilities (numbers are in US $\$$ or units). The final subsample used for the analyses in this chapter holds approximately 2000 firm/year observations. We lose the observations of 1974 and 1975 because assets have been recorded only from 1975 on and because we take aboard one-year lagged values of certain variables. This also means that discontinuous firm/year observations have been lost as well.

We believe that the mode of adjustment is a result of decisions to downsize or rationalize costs (cf. plant closures, sell-outs, overall personnel reductions and diversification profile). Thus, we deem the acting more important than its ultimateform. However, we distinguish between personnel and assets downsizing.

\subsubsection{Variables and Measurement}

The dependent variable is the performance of firms. This examination measures this variable as the natural log of return on assets (of course, adjusted for negative numbers). It follows from the data that this transformation makes the distribution of the dependent more normal (the results found are robust, though). "The independent variables that are associated with the idea of sticky routines, are defined as follows.

Contemporaneous asset adjustment group membership
Group membership assigned $e x$ post on the basis of the number of cases in which a firm downsized assets in the year that profitability fell (indicator variable with three groups). 
Contemporaneous workforce adjustment group membersbip

Delayed asset adjustment group membership

Delayed workforce adjustment group membership
Group membership assigned ex post on the basis of the number of cases in which a firm downsized workforce in the year that profitability tell (indicator variable with three groups). Group membership assigned ex post based on the number of cases in which a firm downsized assets in the year after a decline in profitability (indicator variable with three groups).

Group membership assigned ex past on the basis of the number of cases in which a firm downsized workforce in the year after a decline in profitability (indicator variable with three groups).

The data set has been manipulated to arrive at the routines classification for our purpose. We performed an ex-post analysis on the data to calculate the percentage of cases in which a firm downsized its positions (assets and workforce), contemporaneous and delayed. Thus we examined reactions in years in which profitability $\left(\pi_{t}\right)$ fell and in years in which past year"s profitability $\left(\pi_{t-1}\right)$ decreased; we defined this percentage as the contemporaneous and delayed "propensity to downsize', respectively. We then forced a split-up of the firms into three groups of approximately the same size, based on their ranking in terms of their propensity to downsize. Subsequently, we assigned a routine to each group (high, moderate and low propensity to downsize, either contemporaneous or delayed). Below, the influence of group membership on profitability will be tested. In this way, we look at the effects of cumulative downsizing as a meta-level change routine.

The covariants are variables that were found to be important profitability determinants in prior research (see below). Furthermore, we added the year of observation as a fixed-effect variable. The covariants are defined and measured as follows. 
Diversification

Capital to sales

Number of countries

Firn size

Year
Degree of diversification, measured as the percentage of sales related to paper-producing activities to total sales.

The amount of capital needed to produce total sales, proxied by toral assets to total sales.

The number of countries where a firm has production facilities, which serves as a proxy for geographical spread.

Firm size, measured as the natural logarithm of the number of employees.

Variable that indicates the year of the observation, with a dummy being constructed for each year.

Studies examining profitability within the context of economic and organization studies have mainly focused on inter-industry settings. The idea of profit maximization is centripetal in many of these studies, linked with the equilibrium thought that it is impossible to elevate prices above marginal costs in the long run. Scherer and Ross (1990) give an overview of industrial economic studies performed over the last decades. The most comprehensive examination they report, was done by Weiss (cited in Scherer and Ross 1990: 426), who performed a crosssectional analysis on 399 census industries. He found positive and significant relationships between profitability and (1) $\mathrm{C}_{4}$ measure of concentration, (2) capital to sales, (3) advertising to sales, (4) past output growth, and (5) the interaction between output to end consumers and $\mathrm{C}_{4}$. In addition, he revealed a significantly negative relationship between profitability and lower geographical dispersion (measured in production locations in the US).

Specifically, the concentration-performance link received considerable attention due to the potential role of the state in anti-trust matters. The relationship found by Weiss seems to be suspect to a cyclical pattern, showing a stronger relationship in prosperous years (Domowitz et al. 1986, as cited in Scherer and Ross 1990: 441). Robbins and Wiersema (1995) use a model on firm performance (ROA) with industry characteristics (e.g. concentration and capital to sales ratios, 
both revealing a negative impact) and firm characteristics (e.g. market share and firm size, both producing positive signs). Additionally, they report the extent of diversification. For our examination, we will incorporate the covariants mentioned, substituting the concentration index for firm size. Other factors such as luck or firm-specific capabilities certainly play a role, but these are all taken aboard in the disturbance term (Sharma and Kesner 1996). Measurement problems, missing data and the lack of an appropriate theory inhibit us from taking these factors into account.

Another widely examined question deals with the performancediversification link. For one thing, the link between the extent of diversification and financial performance has been empirically highly unequivocal (Teece et al. 1994, Varadajan and Ramanujam 1987, Ramanujan and Varadarajan 1989, Stimpert and Duhaime 1997, Palich et al. 2000). Today, conventional wisdom holds that related diversification yields better results than unrelated diversification (Rumelt 1974, Varadarajan and Ramanujam 1987, Hamilton and Shergill 1993), that the link between diversification and performance manifests itself indirectly (Stimpert and Duhaime 1997), that the differences found should be attributed to differences between actual and potential relatedness (Teece et al. 1994), and that the functional form has been misinterpreted (Palich et al. 2000). Varadarajan and Ramanujam (1987) have replicated the elaborate framework study of Rumelt (1974), and found support for the results reported earlier. Rumelt's classification scheme demands data on the business-level activities. However, most studies have focused on cross-industry differences, due to lack of data, combining standard industrial classification (SIC) codes with financial performance data. Davis et al. (1992) have found evidence in the pulp and paper industry that relatedness at the production or at the market level yields better performance than non-relatedness. Palich et al. (2000) scrutinized 82 studies published on the performance-diversification link over the past three decades, and performed a meta-study on the results of 55 diversification-performance studies. They found an inverted U-shaped relationship between the degree of diversification and financial performance. That is, related (or a medium degree of) diversification yields higher performance if compared to single businesses (no degree of diversification) and unrelated highly diversified conglomerates.

The sales-diversification measure that we have chosen, is the proportion of paper-related sales compared to total sales. The data only 
allows us to measure unrelated and related sales. Several diversification measures have been developed in the literature, often proxying the relatedness of the different diversified activities within a firm. Two well-known examples of such measuring sticks are Rumelt's (1974) classification scheme and Berry and Jacquemin's (1979) entropy definition of diversification. To calculate both proxies, however, information is needed on the relatedness of the activities. Computing entropy measures of diversification or the classification method of Rumelt (1974) requires detailed business-level information that is generally not available; and if available, it is of untested reliability (Varadarajan and Ramanujam 1987). Chatterjee and Blocher (1992) find that continuous measures as proposed here are good predictors for Rumelt's classification.

A workforce measure has been chosen as a proxy for firm size. In additional, we applied a natural log transformation in order to pay respect to the fairly large amount of kurtosis in the size distribution. Besides, we expect firm size to have an increasing influence on asymmetric adjustment in years of decline. We are aware of the fact that most performance studies have a cross-industry character. However, the intra-industry independent variables serve as good proxies, all industry influences being equal within one industry. Table 5.1 gives an overview of the variables explaining profitability and the direction of their expected effects.

Tables 1: Hypothesized effects of covariants on profitability

\begin{tabular}{lc}
\hline Explanalory varlable & Effect \\
\hline Diwersification & + \\
Size (market share) & + \\
Proximity to resources & + \\
Capital to sales & - \\
\hline
\end{tabular}

Table 5.2 provides an overview of the variables used, including their coding and measurement.

As indicated above, we have constructed variables that indicate adjustment group membership to test the hypotheses on the influence of downsizing routine group membership (in terms of asset and workforce adjustment). We have annual information on individual responses to the rise or fall in firm-level profitability. From this information, it is possible to see (1) whether a firm is time-consistent in its behavior and (2) if such consistency pays off. We have defined three 
different groups, constructing the groups following the steps as indicated below:

1. downsizing reluctantly,

2. downsizing inconsistently (reference group), and

3. downsizing readily.

Mathematically, our tests try to uncover

(1) Routine $1,2,3 \rightarrow \pi$.

Tatble 5.2: Description of the wariables ysed in this study

\begin{tabular}{|c|c|c|}
\hline Code & Name & Values \\
\hline LMROAI & Pertormance & Scalar, natural log of return on assets $\left(R_{R} O A\right)+1$ \\
\hline ASSGR & $\begin{array}{l}\text { Conlemporaneous asset } \\
\text { adjustment group }\end{array}$ & $\begin{array}{l}1=\text { reluctant propensity to downsize assets } \\
2=\text { moderate propensity to downsize assets } \\
3=\text { high propensity to downsize assets }\end{array}$ \\
\hline WFGR & $\begin{array}{l}\text { Contemporaneous workforce adjusiment } \\
\text { group }\end{array}$ & $\begin{array}{l}1=\text { reluctant propensity to dowmsize warklorce } \\
2=\text { moderate propensity to downsize workforce } \\
3=\text { high propensity to downsize workforce }\end{array}$ \\
\hline LASSGR & $\begin{array}{l}\text { Delayed asset adjustment } \\
\text { group }\end{array}$ & $\begin{array}{l}1=\text { reluctant propensity to downsize assets } \\
2=\text { moderate propensity to downsize assets } \\
3=\text { high propensity to downsize assets }\end{array}$ \\
\hline LWFGR & $\begin{array}{l}\text { Delayed workforce } \\
\text { adjustment group }\end{array}$ & $\begin{array}{l}1=\text { reluctant propensity to downsize workforce } \\
2=\text { moderate propensity to downsize workforce } \\
3=\text { high propensity to downsize workforce }\end{array}$ \\
\hline PERCPAP & Divarsificiation & $\begin{array}{l}\text { Scalar; percentage of paper-related sales to } \\
\text { total sales }\end{array}$ \\
\hline CAPSAL & Capital to sales ratio & Scallar" ratio of assets to sales \\
\hline LWWF & Fin size & $\begin{array}{l}\text { Scalar" nalural log al workforce (number of } \\
\text { employees) }\end{array}$ \\
\hline GEO & Nimber of countries & $\begin{array}{l}\text { Scalar, number of countries in which a firm has } \\
\text { production facilities }\end{array}$ \\
\hline YEAR & Year & Indicator for year of observalion (1974,1997) \\
\hline
\end{tabular}

We discerned two possible reactions and, hence, two different ways to split up the firms; firstly, a reaction in the year of the decline (contemporaneous) and, secondly, a reaction in the year after the year of decline (delayed). In the first case, the routine groups are defined as the number of years in which a firm reacted symmetrically (i.e., by downsizing) to a decline in profits $\pi_{2}$ to the total number of years with 
declining profits. In the second case, the groups are defined by the number of years a firm reacted symmetrically to a decline in one-year lagged profits $\pi_{\mathrm{t}-1}$ relative to the total number of years with declining profits.

We forced a split in three groups so that all groups are of approximately the same size. As has been argued above, we have examined reactions of firms in terms of both assets (assets in US \$) and workforce (number of employees) adjustments. To arrive at a sensible definition of the routine groups, we counted the number of occasions in which a firm faced declining profits and the number of occasions in which it downsized assets or workforce, contemporaneous or delayed. We then divided the latter sum by the first, thus determining the percentage of downsizing responses to years of decline. To assign companies to the routine groups, as said, we forced a division so that each routine group had approximately equal size. We labeled each routine as to the nature (inert versus versatile), content (assets or workforce) and process (delayed or contemporaneous) dimension. Group 1 is defined as reluctant adjusters, group 2 is defined as inconsistent, and group 3 is defined as easy adjusters (versatile). We thus impose the nature dimension on our primary classification. Appendix D goes into the details of the procedure followed. It is important to add here that firms are assigned a routine in each of the content and process downsizing divisions. So, a firm that reluctantly downsizes assets might readily downsize workforce in the same process (reluctant or versatile) dimension. Table 5.3 delineates the boundaries of the downsizing ratios that determine the nature dimension of downsizing of a firm.

Table 5.3: Routine boundaries and beir descriptives

\begin{tabular}{|c|c|c|c|c|c|c|}
\hline & & $\mathrm{N}$ & Lower bound & Upper bound & Mean & Stdl. Dev. \\
\hline \multirow{3}{*}{$\begin{array}{l}\text { Contemporaneous assel } \\
\text { adjusiment group }\end{array}$} & reluctant & 76 & 0.00 & 0.11 & 0.02 & 0.04 \\
\hline & inconsistant & 76 & 0.43 & 0.38 & 0.26 & 0.06 \\
\hline & wersathe & 70 & 0.40 & 1.00 & 0.62 & 0.21 \\
\hline \multirow{3}{*}{$\begin{array}{l}\text { Contemporaneous workforce } \\
\text { adjustment group }\end{array}$} & reluclant & 70 & 0.00 & 0.46 & 0.19 & 0.18 \\
\hline & inconsistant & 77 & 0.50 & 0.73 & 0.58 & 0.07 \\
\hline & wersatile & $\pi 7$ & 0.75 & 1.00 & 0.92 & 0.11 \\
\hline \multirow[t]{3}{*}{ Dellayed assel adjustment group } & reluctant & 62 & 0.00 & 0.14 & 0.02 & 0.04 \\
\hline & inconsistant & 57 & 0.17 & 0.45 & 0.30 & 0.09 \\
\hline & versatile & 76 & 0.50 & 1.00 & 0.67 & 0.20 \\
\hline \multirow{3}{*}{$\begin{array}{l}\text { Delayed workforce adjusiment } \\
\text { group }\end{array}$} & reluctant & 78 & 0.00 & 0.50 & 0.30 & 0.19 \\
\hline & inconsistant & 53 & 0.55 & 0.75 & 0.66 & 0.07 \\
\hline & versatile & 62 & 0.78 & 1.00 & 0.93 & 0.09 \\
\hline
\end{tabular}


It is conceivable that there is a positive correlation between the number of downward adjustments and the total number of years of decline. Thus, if the number of decline years increases, then the percentage of downward adjustment reactions also increases. To check for this undesirable characteristic of the data, we calculated correlations between the number of decline years and the downsizing reactions, which are depicted in Table 5.4. The correlation coefficients show a weak negative relationship with the number of 'down' years, and only the correlation between the ratio of downward asset adjustments and number of decline years is significant. Luckily, Table 5.4 reveals that there is hardly any correlation between the number of down years and the ratio of adjustment to these down years.

Table 5.4: Pearson correlations

\begin{tabular}{llrrr}
\hline Correlations & & & \\
\hline$\#$ & Variable & 1 & 2 & 3 \\
1 & N decline years & 1.00 & & \\
2 & Workforce downsizing & -0.14 & 1.00 & \\
3 & Asset downsizing & -0.18 & 0.15 & 1.00 \\
\hline
\end{tabular}

Significance (two-tailed): * $p<.05$.

\subsubsection{The method}

We might apply an Ordinary Least Squares (OLS) regression technique on return on assets, because we expect the model to be linear in its parameters. Tables 5.5 and 5.6 give the usual descriptives for our examination. Before interpreting the results of our analysis ${ }^{2}$, we will scrutinize the sample for the common plagues in an OLS setting: (1) multicollinearity, (2) heteroscedasticity, and (3) autocorrelation. We will deal with them subsequently.

Multicollinearity refers to the situation in which two or more independent variables are related. Multicollinearity does not effect point estimation. It does increase the size of the estimation interval, though, and thus will increase the probability of rejecting a hypothesis while it might be correct (type-I error). It suffices not to take correlations

\footnotetext{
2 The results of the OLS estimation are reported in Appendix C.
} 
Table S.5: Descriptive Statistios

\begin{tabular}{|c|c|c|c|c|}
\hline Variable & Minimum & Maximum & Mean & Std. Deviaton \\
\hline Performance & -0.6080 & 0.7525 & 0.0551 & 0.0669 \\
\hline Contemporaneous assel adjustment group̣ & 0 & 2 & $\mathrm{~nm}$ & $\mathrm{~nm}$ \\
\hline Contemporaneous workforce adjustment group & 0 & 2 & $\mathrm{~nm}$ & $\mathrm{~nm}$ \\
\hline Delayed asset adjustment group & 0 & 2 & $\mathrm{~nm}$ & $\mathrm{~nm}$ \\
\hline Delayed workforce adjustment group & 0 & 2 & $\mathrm{~nm}$ & $n \mathrm{~m}$ \\
\hline Diversification & 0.0547 & 1.4016 & 0.8056 & 0.2182 \\
\hline Capilal to sales ratio & - & 14.1422 & 1.2374 & 0.8544 \\
\hline Fim size & 1.1888 & 11.3737 & 8.6662 & 1.0794 \\
\hline Mumber of countries & $\uparrow$ & 58 & 3.2214 & 4.3432 \\
\hline Year & 1974 & 1997 & $\mathrm{~nm}$ & $\mathrm{~nm}$ \\
\hline
\end{tabular}

*nm: not meaningful

as an indicator in a multi-variant model (Gujarati 1988). Instead, more advanced methods should be used. We looked at the condition index, which is the result of taking the square root of the condition number (Gujarati 1988). This statistic indicates severe multicollinearity between the independent variables in our sample. Auxiliary regressions on the scalar independents revealed that our firm-size indicator was the main culprit. Because it is a variable taken up as a covariant, we decided to drop it from the analyses. This indeed resulted in a dramatic drop in the condition index while not changing the direction of the estimates.

Heteroscedasticity pertains to the situation in which the variance of the disturbances is not constant. This leads to inefficient estimators where the direction of the inefficiency cannot be revealed. This situation produces an increase in both type-I and type-II errors. As heteroscedasticity is more likely to be found in cross-sectional data, it might be a property of our panel type of data set as well. To detect the presence of heteroscedasticity, we plotted both the squared standardized and unstandardized residuals (as a proxy for the disturbances) to the predicted values of performance and the scalar independent variables. Luckily, the plots did not reveal any pattern, and we thus assume that out data do not suffer from this plague. 


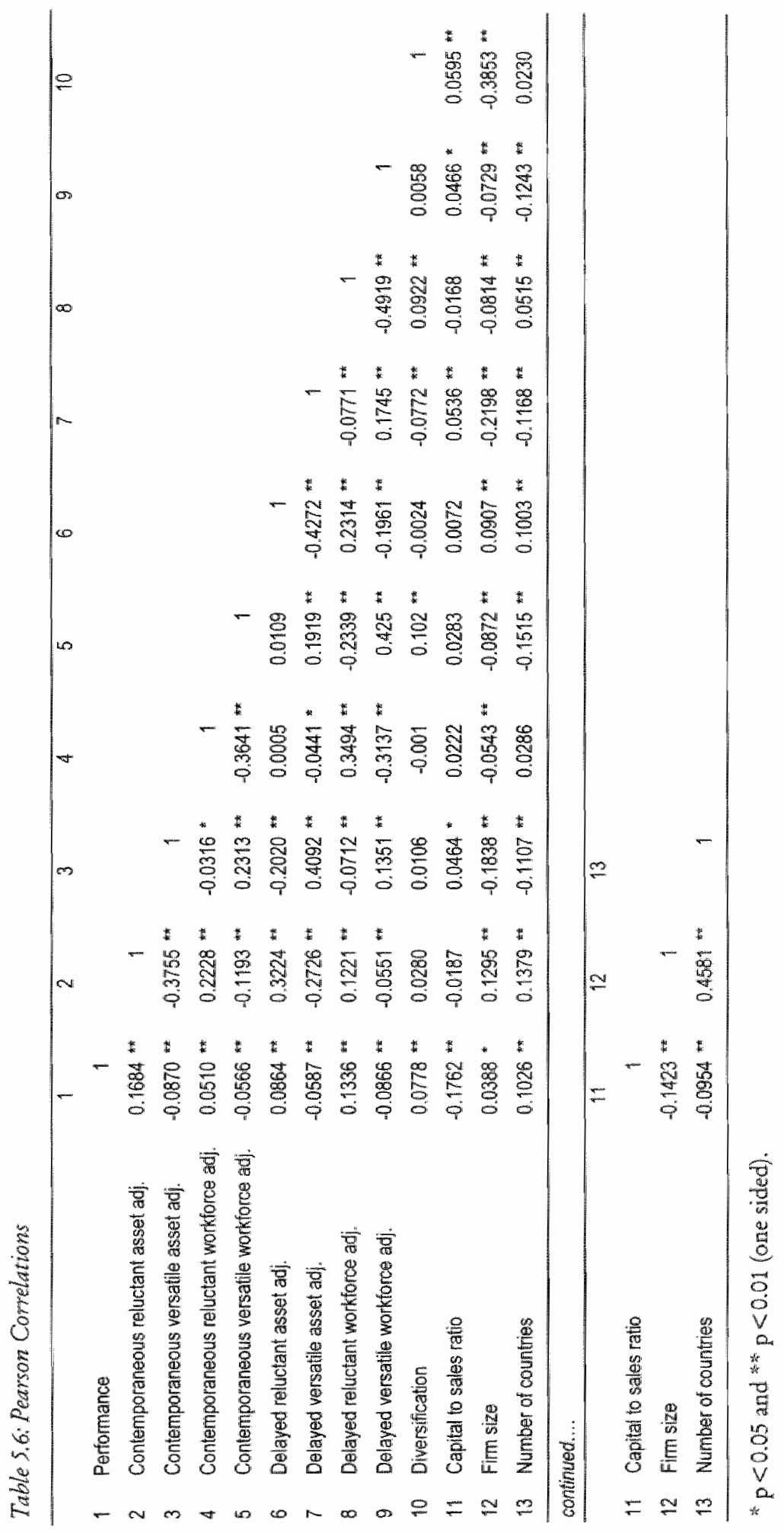


Autocorrelation emerges when subsequent disturbances are related to each other in a time series context. This leads to inefficient estimators, even asymptotically (Gujarati 1988). We plotted the residuals to their lagged values and indeed uncovered a linear relationship. The plots lead us to assume that we are dealing with a first-order autoregressive scheme (AR1). The Durbin Watson ' $d$ '-test indicates that our data set is associated with a coefficient of autocorrelation of approximately .5, which is too high. To correct for this autocorrelation, we first transformed the variables using the coefficient of autocorrelation. Subsequently, we performed an OLS estimation on the transformed variables. This technique is also known as Generalized Least Squares (GLS), in which 'general' indicates the extra information taken up in the original model. We will use these results to test our hypotheses.

Furthermore, we performed analyses on two sub-sets of the data: one containing only companies that had at least faced four years of declining profits, and one sub-set that included firms that were present over the whole time range of the data. We found that the results were robust for all tests performed. Because throwing away data is not desirable, we have chosen to report our findings based on all available data. 'The results reported here are thus based on all valid cases $(\mathrm{N}=2094)$.

\subsection{Results}

\subsubsection{Key findings}

The GLS results are given in Table 5.7, which contains the pooled results only'. Model 1 contains fixed-year effects and the 'conventional' covariants. Model 2 adds the panel of contemporaneous downsizing groups to the basic model. Model 3 finally, introduces the delayed downsizing groups into the model.

The contemporaneous reluctant asset downsizing group outperforms the benchmark group, whereas the result for readily downsizing is not significant. If we only regard the contemporaneous downsizing routines, workforce group membership does not matter. However, if we also take into account delayed workforce downsizing, we notice that adjusting reluctantly in the year of the profitability

\footnotetext{
Appendix D features all results.
} 
decline leads to decreased performance, whereas belonging to the reluctant delayed workforce downsizing routine group is associated with higher performance. Hence, we might conclude that downsizing the workforce enhances performance only if the downsizing operation takes place in the year of profit decline. Rationalizing afterwards decreases profitability. Interestingly, this result supports the central findings of research in which the idea of justice and fairness plays an important role in the downsizing process (Mishra and Spreitzer 1998). People are able to

\section{Table 5.7: GLS coefficients (unstandardized)}

\begin{tabular}{|c|c|c|c|c|}
\hline \multirow{2}{*}{\multicolumn{2}{|c|}{$\frac{\text { Mordel }(N=2094)}{\text { Panel A: Control variables (*) }}$}} & \multirow[t]{2}{*}{1} & \multirow[t]{2}{*}{2} & \multirow[t]{2}{*}{3} \\
\hline & & & & \\
\hline 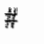 & Variable & B & $B$ & B \\
\hline & (Constant) & $0.0166(0.0047)$ & $0.0142(0.0047) * *$ & $0.0130(0.0048)^{*}$ \\
\hline 10 & Diversification & $0.0166(0.0059)$ & $0.0154(0.0058)$ & $0.0137(0.0059)^{*}$ \\
\hline 11 & Capital to sales ratio & $-0.0185(0.0015)^{* * * * 0}$ & $.0 .0189(0.0015) *$ & $-0.0187(0,0015)^{*}$ \\
\hline 13 & Number of countries & $0.0006(0.0003)^{* *}$ & $0.0004(0.0003)$ & $0.0004(0.0003)$ \\
\hline \multicolumn{5}{|c|}{ Panel E: Independent variables } \\
\hline 2 & Contemporaneous reluctant asset adj. & & $0.0132(0.0019)^{\text {wi* }}$ & $0.0121(0.0020)$ \\
\hline 3 & Contemporaneous versatile asset adj. & & $0.0001(0.0019)$ & $0.0009(0.0020)$ \\
\hline 4 & $\begin{array}{l}\text { Contemporaneous reluctant workforce } \\
\text { adj. }\end{array}$ & & $-0.0024(0.0020)$ & $-0.0039(0.0021)$ \\
\hline 5 & $\begin{array}{l}\text { Contemporaneous versatile workforce } \\
\text { adj. }\end{array}$ & & $-0.0006(0.0020)$ & $0.0001(0.0021)$ \\
\hline 6 & Delayed reluctant asset adj. & & & $0.0024(0.0021)$ \\
\hline 7 & Delayed wersatile asset adj. & & & $-0.0011(0.0020)$ \\
\hline 8 & Delayed reluctant workforce adj. & & & $0.0053(0.0019)^{\text {* }}$ \\
\hline 9 & Delayed wersatile workforce adl. & & & $0.0000(0.0022)$ \\
\hline
\end{tabular}

Pranet C: Model statistics

Adjusted R-square

0.2133

0.2319 : thit

$0.2357 * * *$

Durbin Watson "d"

1.9883

Significance (two-talled): $p<0.10,{ }^{*} p<0.05$ and ${ }^{*}$ the $p<0.01$. The significance level of the $\mathrm{R}$-square statistic indicates significant change. $\left.{ }^{t}\right)$ Model includes year fixed-effects.

understand that costs have to be cut when times are tough, but have difficulty (hence decreasing job security and organizational loyalty) if the rationalizing process continues there after. So, here we find mixed evidence for both Propositions 1 and 2 (hypothesis $1 b$ and $2 b$ ). However, the overall results (see also Appendix D) indicate a favorable position for Proposition 2.

The previous interpretation is based on a significant difference between downsizing reluctantly or readily on the one hand, and the benchmark group on the other. The following picture emerges if we compare reluctantly and readily downsizing groups directly, running 
auxiliary regressions. The reluctant group outperforms the versatile group for contemporaneous assets downsizing, whereas the difference between these groups for workforce downsizing is not significant. Moreover, the results for asset downsizing are similar (and significant), looking simultaneously at contemporaneous and delayed downsizing. It seems better to be a contemporaneous versatile job cutter rather than a delayed inert people downsizer. These differences are also significant. Overall, these results suggest that holding on to what you own as long as possible is the better strategy, rather than trying to adapt all the time. In four of our six cases this finding was supported, and only in one case (contemporaneous readily workforce downsizing) this conclusion was not justified. Before drawing a final conclusion, though, the next subsections (1) assess the robustness of the results and (2) scrutinize the development of performance of firms with the different roucines over time.

\subsubsection{Robustness tests}

Our rough method of forced group membership and the results it has produced, can be subject to arguments of arbitrary boundary setting. Therefore, we distinguish two cases to test whether our classification method yields robust results: either the cut-off points are too low (case A) or they are too high (B). Case A leads to enlarging the membership groups 1 and 3 , while case $B$ leads to making groups 1 and 3 smaller. We chose to increase and to decrease the size of groups 1 and 3 with one standard deviation of group 2, because we tested the results against group 2. The resulting cut-off points are summarized in Table 5.8, alongside the cut-off points of the original groups.

Table 5.8. Descriptives: group membership under orginal and adjusted (case $A$ and case B) bowndary settings

\begin{tabular}{|c|c|c|c|c|c|c|c|c|c|c|}
\hline & & & & & & & $\begin{array}{l}\text { Case } \\
\text { A: }\end{array}$ & & $\begin{array}{l}\text { Case } \\
\text { B: }\end{array}$ & \\
\hline & & $N$ & $\begin{array}{l}\text { Lower } \\
\text { bound }\end{array}$ & $\begin{array}{l}\text { Upper } \\
\text { bound }\end{array}$ & Mean & Std Dev. & $\begin{array}{l}\text { Lower } \\
\text { bound }\end{array}$ & $\begin{array}{l}\text { Upper } \\
\text { bound }\end{array}$ & $\begin{array}{l}\text { Lower } \\
\text { bound }\end{array}$ & $\begin{array}{l}\text { Upper } \\
\text { bound }\end{array}$ \\
\hline Contemporaneous asset & " & 76 & 0.00 & 0.11 & 0,02 & 0.04 & 0.00 & 0.18 & 0.00 & 0.05 \\
\hline \multirow[t]{2}{*}{ adjustinent group } & 2 & 76 & 0.13 & 0.38 & 0.26 & 0.06 & 0.19 & $0.3 \|$ & 0.06 & 0.44 \\
\hline & 3 & 70 & 0.40 & 1.00 & 0.62 & 0.21 & 0.34 & 1.00 & 0.46 & 1.00 \\
\hline
\end{tabular}


Table 8 continut

\begin{tabular}{|c|c|c|c|c|c|c|c|c|c|c|}
\hline & & & & & & & $\begin{array}{l}\operatorname{Cas} \theta \\
\mathrm{A}\end{array}$ & & $\begin{array}{l}\text { Case } \\
B\end{array}$ & \\
\hline & & $\mathrm{N}$ & $\begin{array}{l}\text { Lower } \\
\text { bound }\end{array}$ & $\begin{array}{l}\text { Upper } \\
\text { bound }\end{array}$ & Masn & Sid. Dev. & $\begin{array}{l}\text { Lower } \\
\text { bound }\end{array}$ & $\begin{array}{l}\text { Upper } \\
\text { bound }\end{array}$ & $\begin{array}{l}\text { Lower } \\
\text { bound }\end{array}$ & $\begin{array}{l}\text { Upper } \\
\text { bound }\end{array}$ \\
\hline Contemporaneols workforce & 1 & 70 & 0.00 & 0.46 & 0.19 & 0.18 & 0.00 & 0.54 & 0.00 & 0.39 \\
\hline \multirow[t]{2}{*}{ adisustment group } & 2 & 77 & 0.50 & 0.73 & 0.58 & 0.07 & 0.57 & 0.65 & 0.43 & 0.80 \\
\hline & 3 & 77 & 0.75 & 1.00 & 0.92 & 0.11 & 0.68 & 1.00 & 0.82 & 1.00 \\
\hline \multirow{3}{*}{$\begin{array}{l}\text { Delayed asset adjustment } \\
\text { group }\end{array}$} & 1 & 62 & 0.00 & 0.14 & 0.02 & 0.04 & 0.00 & 0.23 & 0.00 & 0.05 \\
\hline & 2 & 57 & 0.17 & 0.45 & 0.30 & 0.69 & 0.26 & 0.36 & 0.08 & 0.54 \\
\hline & 3 & 76 & 0.50 & 1.00 & 0.67 & 0.20 & 0.41 & 1.00 & 0.59 & 1.00 \\
\hline \multirow{3}{*}{$\begin{array}{l}\text { Delayed workforce } \\
\text { adjustment } \\
\text { group }\end{array}$} & 1 & 78 & 0.00 & 0.50 & 0.30 & 0.19 & 0.00 & 0.57 & 0,00 & 0.43 \\
\hline & 2 & 53 & 0.55 & 0.75 & 0.66 & 0.07 & 0.61 & 0.68 & 0,48 & 0.82 \\
\hline & 3 & 62 & 0.78 & 1.00 & 0.93 & 0.09 & $0.7 \pi$ & 1.00 & 0.84 & 1.00 \\
\hline
\end{tabular}

Testing the model with both cases A and B generates the same results as those with the original variables. Table 5.9 summarizes the coefficients for the grouping variables under cases $\mathrm{A}$ and $\mathrm{B}$. The results show that the test results obtained above are robust for reasonable variations in asset adjustment group membership, revealing limited support for the influence of workforce adjustment group membership. If the boundaries are enlarged (case A) or decreased (case B), the significance of the results for the reluctant workforce adjustment group disappears. The sign even reverses if the boundaries are enlarged. This indicates

Table 5.9. Tent reswls

\begin{tabular}{|c|c|c|c|c|}
\hline & Casse $\bar{A}$ & & Case B & \\
\hline Contemporaneous reluctant assel adj. & $0.0072(0.0021)$ & $* x+x$ & $0.0136(0.0023)$ & $=$ \\
\hline Contemporaneous versatile asset adj. & $-0.0045(0.0020)$ & kix & $-0.0011(0.0023)$ & \\
\hline Contemporaneous reluctant workforce adj. & $0.0004(0.0022)$ & & $0.0014(0.0023)$ & \\
\hline Contemporaneous versalte workorce adj. & $0.0014(0.0022)$ & & $-0.0055(0.0024)$ & * * \\
\hline Delayed reluctant asset adj. & $0.0026(0.0023)$ & & $0.0017(0.0022)$ & \\
\hline Delayed versatille assel adj. & $0.0028(0.0022)$ & & $0.0011(0.0023 j$ & \\
\hline Delayed reluctant workforce adj. & $0.0040(0.0021)$ & $=$ & $0.0043(0.0020)$ & $* *$ \\
\hline Delayed wersatile worktorce adj. & $-0.0011(0.0022)$ & & $-0.0022(0.0022)$ & \\
\hline Adjusted R-square & 0.2295 & & 0.2352 & \\
\hline
\end{tabular}

Significance (two-tailed): ${ }^{*} p<0.10, * * p<0.05$ and ${ }^{* * * *} p<0.01$. Only independentvariable coefficients are reported. 
that the results for this group are sensitive to the boundaries we have set. Interestingly, if we decrease the size of the readily workforce adjustment group, the effect on performance becomes significantly negative (as originally expected in Proposition 2). The results for delayed downsizing are robust, compared to the earlier findings.

\subsubsection{Performance of the routines over time}

As argued above, we chose to report our findings for all cases in the data set (i.e., no data-binning). The statistical methods used result in a time-invariant group-membership formula that represents all cases present over the period of our time window. Yet, another measuring stick for performance is the development over time of the consequences of employing a routine. By way of illustration, we have constructed graphical representations of the development in mean rank ( 1 is highest) of paper-related sales for the firms that are present in the data set for 23 years $(\mathrm{N}=35)$. The ranking of paper-related sales indicates relative market position, whereas the mean ranking per group indicates the strength of a group.

Figures 5.2 to 5.5 tentatively show the effect of downsizing routines, strongly supporting Proposition 2. Starting at approximately equal mean ranks, the development through time shows a divergence in favor of the reluctantly downsizing group. Specifically, the results for the contemporaneous asset and workforce downsizing routine group are striking. Figure 5.3 even suggests a reason for the weak GLS results for workforce downsizing. The reluctant group only gained pole position after 1986. 
Figure 5.2: Development of mean paper sales rank $(1=$ bigbest $)$ per year for the contemporaneous asset downsizing groups

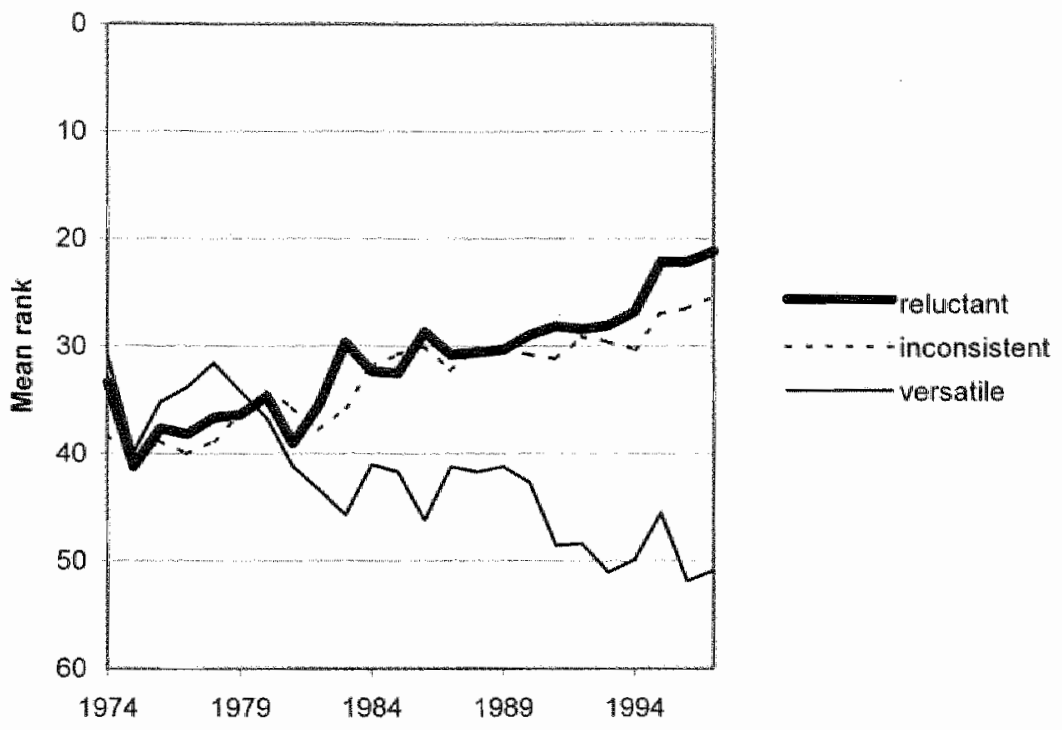

Figure 5.3: Development of mean paper sales rank ( $1=$ bighest $)$ per year for the contemporaneous workforce downsizing groups
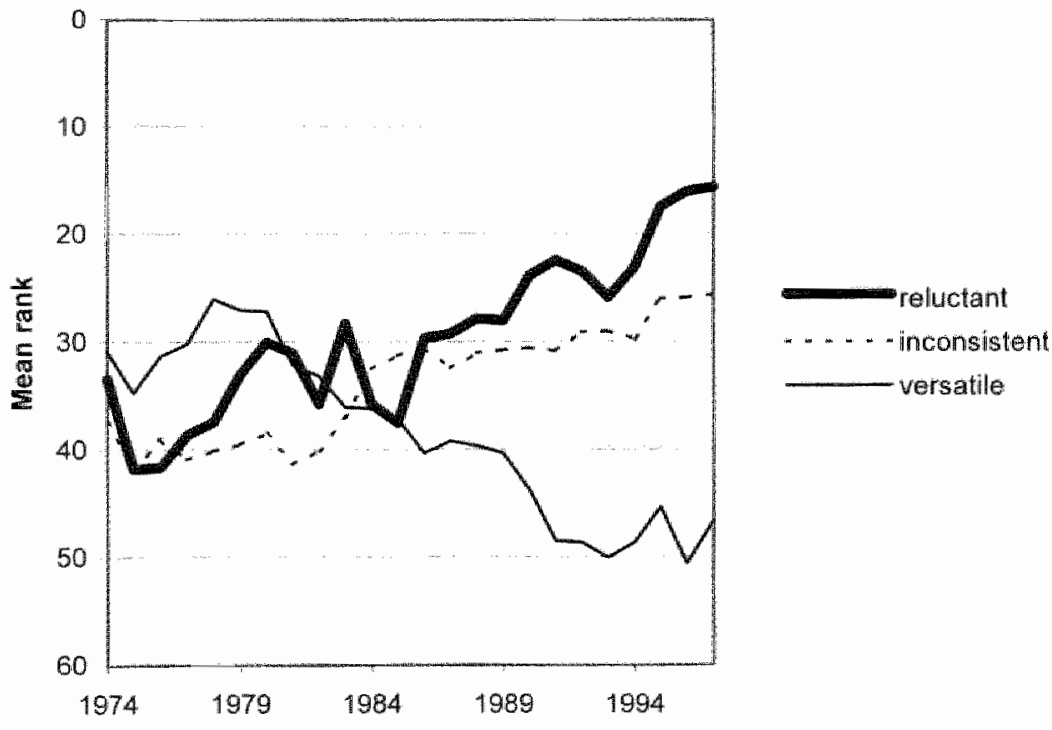
Figure 5.4: Development of mean paper sales rank $(1=$ bighest) per year for the delayed assel downsizing groups

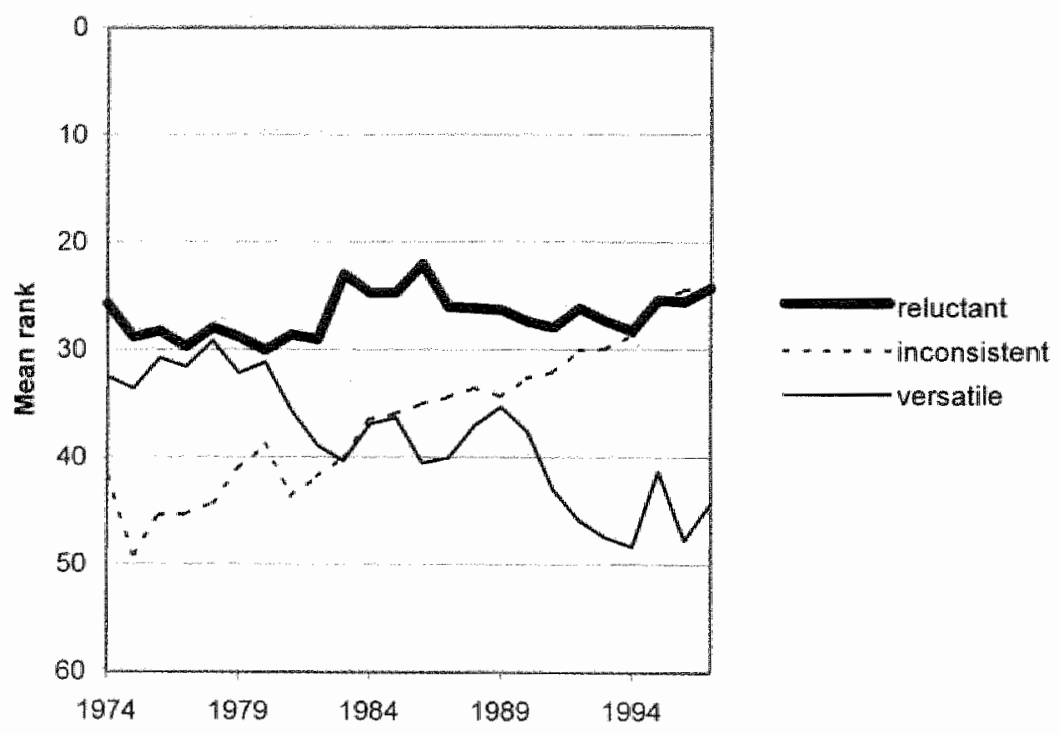

Figure 5.5: Dewelopment of mean paper sales rank $(1=$ bighest $)$ per year for the delayed workforce downsizing groups

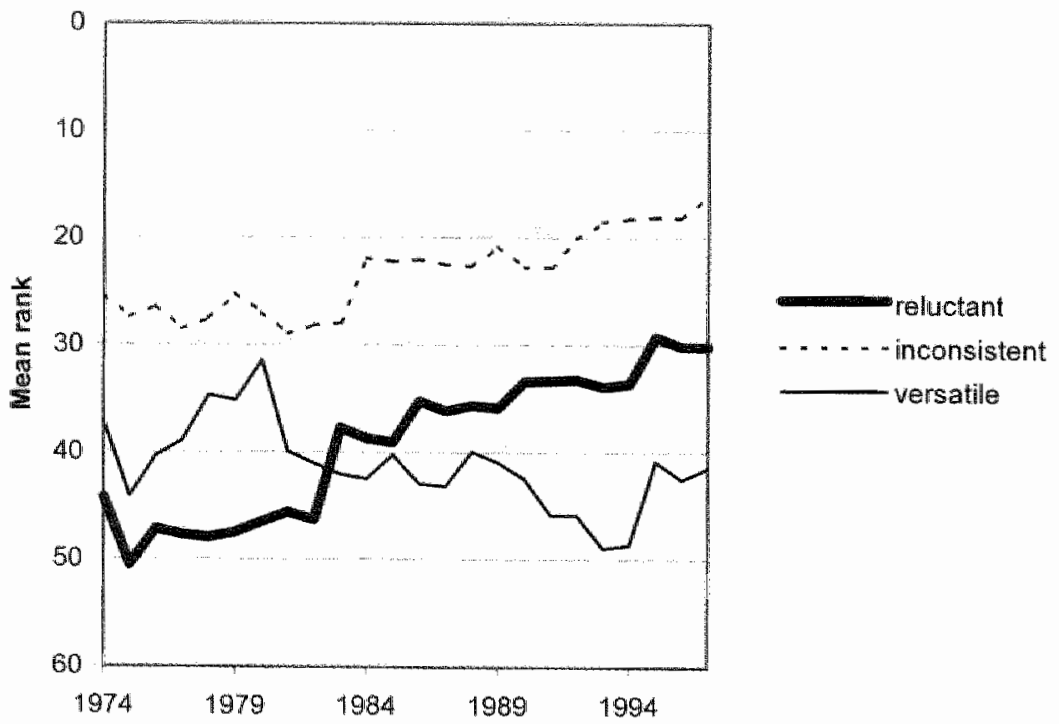


The results are similar in the delayed routine development: the reluctant group outperforms the versatile group. However, Figures 5.3 and 5.4 show that for both asset and workforce downsizing, the development of the benchmark group stands out remarkably. Figure 5.3 reveals a strong development for the reference group, while Figure 5.4 pictures the strongest position for the reference group throughout the time frame. Although the results from these graphs are mixed for delayed downsizing, they clearly show the negative effects of a high versatile downsizing propensity. Thus, the econometric and the graphical evidence suggest that holding on to what you have as long as possible, yields better performance than adjusting readily as soon as the conditions change.

\subsection{Discussion}

The most interesting finding is that the results suggest that being reluctant to downsize assets when facing decline yields a higher performance than downsizing readily in response to a declining financial performance. The examination of the link between strategy and performance has a long tradition. This study adds empirical evidence to the "do-not-react-too-quickly-to-downfalls-by-rationalizing" argument. In the case of workforce adjustments, the data seem to reveal that adjustment in the year of the decline does pay (albeit less convincingly than in the case of assets), but not employees downsizing thereafter. However, the values of the estimators regarding personnel (workforce) are very small compared to those for the assets groups.

That we find clear evidence for higher average performance for the asset adjustment strategy, but not for the personnel downsizing strategy might have several reasons. First of all, assets in the paper and pulp industry are specific to that industry, that is, more specific than personnel. The degree of specificity of an asset is the fraction of its value that would be lost if it were excluded from its major use. Except for R\&D, the operation of a paper and pulp plant does not require very special skills compared to those needled for craftsmanship or knowledge-intensive industries. Secondly, productivity per person has increased over the years, both through learning effects but also through increasing the scale, implying that the number of employees did not increase at the same pace as assets did. Thirdly, if we take yearly asset value as our measure of the asset adjustment strategy, declining assets 
might also capture depreciations whout replacements. This is, in fact, also a kind of rationalizing strategy by leaving the firm more emptyhanded compared to its more reluctant competitors when the industry starts booming again. However, we find strong support for Proposition 2: that it pays to be reluctant when deciding on a downsizing strategy, if we rake the graphical evidence and full results into account. This is not to say that downsizing should not occur at all (we use relative measures to distinguish adjustment groups). In light of the results, we rather propose that firms be careful in their downsizing processes.

We believe that people are important assets of the firm; they are important because much of the invisible firm-specific assets of the firm are embedded in people. This links to the literature on the resource based view of strategy (cf. Peteraf 1993, Pennings et al. 1998), the literature on learning capabilities in organizations (Argyris 1978, Reynolds-Fisher and White 2000) and the literature focusing on the consequences of downsizing for both survivors and 'victims' (Cameron et al. 1987a and 1987b, Moser-Illes 1995, Mishra and Spreitzer 1998, Allen et al. 1995, Gordon 1996, Van Witteloostuijn 1999). People carry and exchange information necessary for achieving a strategic fit. People are important resources, not just as participants in the labor force, but also as accumulators and producers of invisible assets (Chang 1996).

We argued in this examination why routines seem to be such a persistent feature of people and organizations. Firms that downsize readily should notice that their performance over time lags behind the performance of their reluctant competitors. One reason why firms do not adapt their downsizing routines might be that they do not establish a causal link between downsizing strategies and disappointing results. Because downsizing is regarded as a viable tool to rationalize costs (preterred in times of environmental decline), other reasons will be sought to explain deteriorating performance. Managers tend to attribute disappointments to causes outside their sphere of control (fundamental attribution error; of. Buchanan and Huczynski 1997) like the general economic situation, increasing factor prices or a dysfunctional workforce. Firms that do not downsize readily in the face of decline, might have developed a better judgment of the situation, bear core employee values in their hearts or follow a strategy of sustainable growth, in which they build reserves for bad times. The results might also explain why $\operatorname{Van} W i t t e l o o s t u i j n ~(1998)$ finds that firms do not divest plants (not even when inefficient) where the utilitymaximizing theory would have predicted so. 


\section{Chapter 6 CONCLUSION}

The purpose of this study is to examine the reciprocal influence of economic cycles on firm behavior and performance in the international pulp and paper industry, particularly in the period 1974-1997. The examinations made use of several perspectives and the results contribute in interesting ways to the existing literature. This final chapter summarizes the findings of the empirical chapters $(3,4$ and 5$)$ and presents suggestions for future research. The results of these chapters are summarized without referring to underlying theories or advancing alternative explanations, as the chapters themselves have done so extensively. The chapter is organized as follows. Section 6.1 briefly restates the background of this study and deals with the methodologies used. Next, Section 6.2 summarizes the findings along the framework presented in Chapter 1. Subsequently, Section 6.3 discusses the results. Finally, Section 6.4 summarizes the contribution of this examination to the existing literature and presents suggestions for further research.

\subsection{Problem statement and methodology review}

This thesis deals with economic cycles, the adjustment behavior of firms and the resulting organizational performance in a dynamic context. This means that world-wide industry movements over a 
period of roughly 25 years have been examined. The international pulp and paper industry is chosen as the research setting of this thesis.

The research questions arose from an amazement about the huge and sustainable dynamics in the paper and pulp industry. For one thing, the pulp and paper industry is one of the oldest industries of our society. Additionally, it cannot be disputed that the industry is a typical example of a mature low growth industry. Why is an industry that is so old not in a kind of equilibrium but rather features persistent cyclicality? And, given the dynamics of the industry, how can a firm best conduct in such a state of permanent flux? These two statements of wonder gave rise to the following research questions.

1. What causes industrial economic cycles in mature capital-intensive industries?

2. How do economic cycles at different aggregation levels influence firm behavior?

3. How does the nature of firm reactions to cyclicality influence their performance?

This study should be located in the area of single-industry studies applying multiple theoretical perspectives. As explained in Chapter 2, the study reported here is a historical data study, applying different empirical methods to test the developed hypotheses. Data have been collected about individual paper and pulp firms on a wide range of parameters covering the period 1974-1997. As a data-driven study, this thesis primarily uses a quantitative estimation perspective, attempting to uncover meaningful (i.e., statistical significant) relationships.

The empirical studies of this thesis mainly rely on yearly reported data on individual firms and industry conditions (either annual or bi-annual). We obtained our data from an independent agency (Paper and Pulp International) that publishes industry journals and reports. Our most important data set is a compilation of their yearly publication about the top-150 producers. We were able to trace back usable copies until 1974. To obtain colloquial evidence in the thesis' pilot stage, four unstructured interviews were conducted with important industry insiders: two strategic planners, a consultant and a $\mathrm{CEO}$, respectively.

As explained in Chapter 2, this thesis employs several and different methods. Throughout Chapter 3, we make use of a simulation technique to examine the reciprocal influence of economic cycles on behavior of firms. The model has been validated, using North 
American paper and pulp data. Then, in Chapter 4, the logistic regression technique is applied to unravel the influence of cycle stages on growth or downsizing decisions. The study reported here makes extensive use of both data sources in the sample as described in Chapter 2 and of macromeconomic data for the two and a half decades (19741997) spanning this research. Chapter 5 finally, employs a generalized least square approach to test the relationship between inert downsizing routines and performance, in terms of market share and financial performance.

\subsection{Summary of the findings and contribution to the literature}

The summary of the empirical results is structured along the lines of the framework presented in Figure 1.1, which is replicated in Figure 6.1. The key questions and results found are being discussed consecutively.

Figwre 6.1: Framework of this thesis

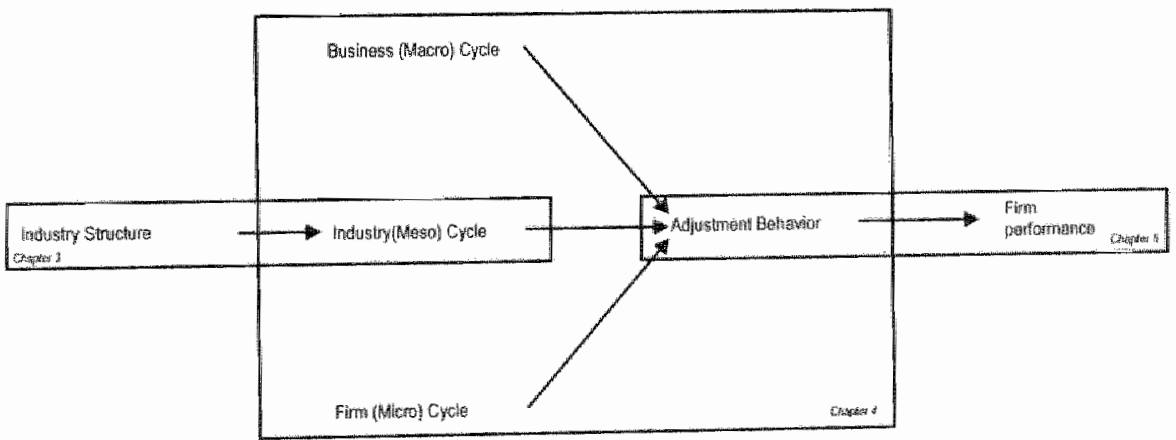

The first research question deals with the causes of industrial cycles. The conventional way of looking at economic cycles in capitalintensive industries is to attribute these economic cycles mainly to external causes, such as prices of raw material and demand fluctuations. Chapter 3 proposes to complement this perspective with an industryendogenous explanation. Based on a model developed by Meadows for the agricultural industry, an adjusted and extended simulation model for the (capital-intensive) paper and pulp industry is developed. The results of the (validated) model suggest support for the endogenous causation proposition. The model is validated with data from the US paper industry, first, for the price determination sector of the model, 
and second, for the model's capacity determination sector. Overall, the results of these validation processes are promising. Finally, the influence of the introduction of new process technologies was simulated by means of the validated model. These simulation runs show that certain technologies tend to reinforce cyclicality in capitalintensive industries, in terms of both the amplitude and the period of economic cycles, whereas others do not. So, this chapter results in a model that describes and simulates how capital-intensive industries generate their own volatility. Thus, this study provides a challenging view on industrial cyclicality, possibly implying other than traditional cures to business cycles. For instance, it might be beneficial from an industry perspective to hold larger inventories to cushion demand fluctuations.

Chapter 4 covers the second research question. This study examines the question "Can we find adjustment patterns that are linked with different stages of cycles?" The effect of either the macro, the meso or the micro cycle on business position alteration (investment, downsizing) is investigated. This study tries to find agreement between often-cited reasons for downsizing. Several authors have hinted at the negative side effects of downsizing. The results suggest that firms in the pulp and paper industry adjust symmetrically to cyclical movements. Past profitability, however, strongly moderates this effect for asset adjustment, while size moderates this effect for workforce adaptation. High past profitability, and hence the availability of internal resources, reduces the probability of asset rationalization. Interestingly, this effect has not been found for workforce. This indicates that firms tend to downsize their workforce in the light of a cyclical decline, even if enough internal financial resources are available. However, size moderates this effect for workforce downsizing. A graphical representation illustrates the test results. Although the results suggest that firms adjust symmetrically, and thus try to achieve a strategic fit, the results are sillent about the question whether or not this aimed-forfit (expressed in higher performance) is achieved by the changes implemented. For example, firms that downsize readily might be subject to liability of change, while firms that postpone downsizing might reap the benefits of a more trustworthy organization. Alternatively, change may enhance performance only if a firm is faced with the dilemma to change or to die.

Chapter 5 develops theory to answer this 'fit-performance question". This examination argues why routine responses to 
environmental threats seem to be such a persistent feature of people and organizations. The most interesting finding is that the results suggest that being reluctant to downsize assets when facing decline, yields higher performance than downsizing readily to declining performance. The results found in Chapter 5 add empirical evidence to the "do-not-react-too-quickly-to-downfalls-by-rationalizing" idea. In the case of workforce adjustments, the data seem to reveal that adjustment in the year of the decline does pay but downsizing following previous year decline does not. Interestingly, the values of the estimators regarding personnel (workforce) are very small in comparison to those relating to assets. Moreover, a graphical picture of the development of firms employing either a reluctant or a readily downsizing routine clearly shows that firms in the 'reluctant' groups outperform those in the 'versatile' groups.

Table 6.1 summarizes both the propositions per chapter and the test results. This thesis contributes to the current state of the art in the organization performance literature in several ways. First of all, the study examines a set of factors affecting firm performance in the international pulp and paper industry over a twenty-four year period, 1974-1997. Studies of industries covering such a time span allow for the examination of dynamic interaction. Secondly, this thesis studies firm behavior related to cyclical movements, and contributes to the discussion about whether firms respond symmetrically or asymmetrically. Thirdly, a theory is forwarded on behavioral routines at a firm level, assessing the longer-term influence on performance. Fourthly, this thesis contributes to the structure-conduct-performance paradigm in arguing that the endogenous cyclicality is important in explaining industry-wide phenomena. Finally, each of the three empirical studies produces a specific contribution to the literature in which it is embedded. 
Table 6.1 Overview of the main propositions, variables and conclusions

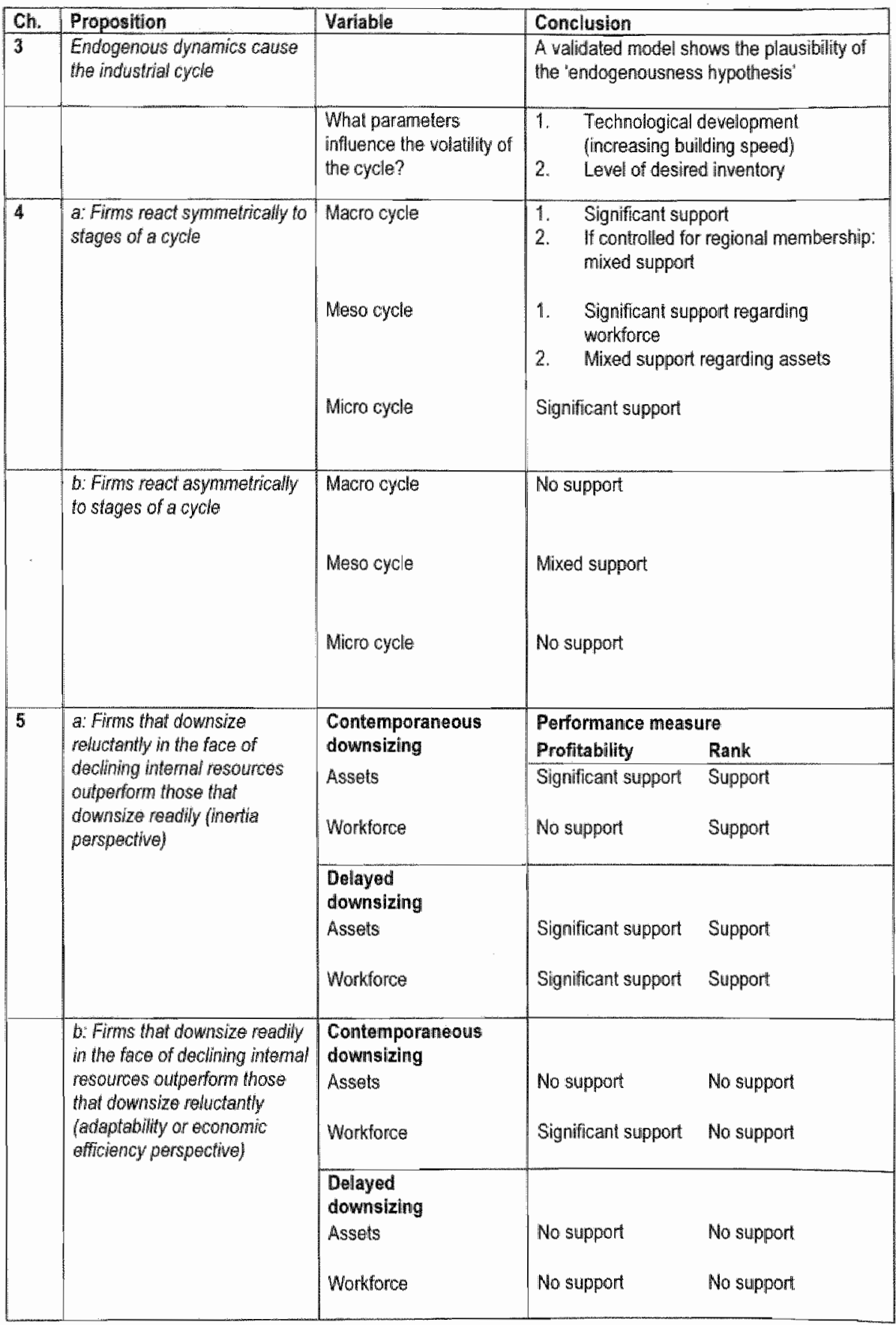


This study pertains to the international pulp and paper industry only. While some of the observed relationships could be industry specific and may apply only to the context of this study, they may be generalized to other industries. For instance, the findings of endogenous cycle causation have been observed in the chemical industry as well. Perhaps, the results observed in Chapters 4 and 5 hold true for other mature capital-intensive industries, too. However, specific research in these industries is needed to confirm this conjecture.

\subsection{Limitations of the studies}

This thesis has a logical order, both in content and in process. Chapters 3 and 4 predominantly dealt with testing the existing theory in the setting of this examination. Chapter 5 makes a start with extending the theory on downsizing, first of all by focusing on routines and, secondly, by taking into consideration long-term organizational performance. The propositions and hypotheses of Chapters 4 and 5 are all constructed with reference to two well established core paradigms viz. the strategic choice and structural inertia perspectives. Chapter 3 adds to these the idea that feedback loops and delay structures strongly influence the dynamics of industrial systems. Thos illustrates that managerial choice and environmental inertia might well interact subtly. Within each chapter, we tried to give a sufficient overview of the existing literature and the state of the art of the fields in the context of the study in question. In studying the literature on economic cycles, we hardly found any examinations that deal with industrial cycles, their causes and their consequences. De Witt's (1994) observation apparently still holds: there is a lack of academic work in the field of industry boom and bust cycles. This study hopes to contribute to filling that lacuna.

All results should be assessed in the context of the limitations of the models and methods used, of course ${ }^{1}$. For example, in Chapter 3, a perfect supply-side monopoly has been assumed. Of course, in realityr

1 A more fundamental limitation of the models used, arises from the nature of any model as a limited and simplified representation of the real world. Thus, some authors argue that walidation or verification of models, in the sense of establishing truth, is inpossible (ct. Sterman 2000). Regardless of whether one agrees with this rather pessimistic position, models seem to be most useful when they are used to challenge existing formulations, rather than to validate or verify them. 
micro behavior of many interacting firms determines industry behavior. We tried to accomplish a proxy by aggregating micro strategies in both the algorithms for the producer and consumer side. As in all studies, these simplifications are convenient, serving as starting points for more fine-grained examinations.

Chapter 4 , then, uses a set of definitions and proxies to indicate cyclical movement. For sure, several other indicators do exist. For example, it would be very interesting to devise tests that take into account the magnitude of economic cycles and the magnitude of adjustment. Additionally, as with most mature industries, the international pulp and paper industry encounters a concentration tendency that spans at least the time period we have data on. The data set lacks the information, though, to adjust for this fact. Thus, instead of measuring continuously, we chose to design a dichotomous proxy (symmetric or asymmetric adjustment), thus disregarding the size of the reaction. The concentration movement, by the way, is in itself an argument that may support the idea that companies strive for other goals than profit maximization alone.

That the results from Chapter 5 suggest evidence for higher average performance in the asset adjustment strategy, and not in the personnel strategy, might have several reasons. Firstly, asset specificity may make it more difficult to downsize dedicated machinery. Secondly, the productivity per person has increased over the years, both through learning effects but also as a result of increasing scale, implying that the number of employees did not increase at the same pace as assets did. Thirdly, as we look at the yearly asset value to measure our asset adjustment strategy, declining assets might also reflect depreciations of assets without replacements. However, if we consider the graphical evidence, we find strong support for our proposition that it pays to be reluctant when deciding to downsize. This is not to say that downsizing should never occur (we wse relative measures to distinguish adjustment groups). We only propose, in light of the results, that firms must be careful in their downsizing processes in response to performance decline.

Finally, working with a ranking list has several drawbacks. For example, we would have liked to test the relationship between age and asymmetric reactions because this is a well-examined parameter in the population ecology field. Unfortunately, the firms we have data on are older than the first data-entry period. Moreover (but this is an assumption) the firms in the set are all rather old. Apparent new entries 
into the data set are the result of one dominant phenomenon: concentration by mergers and acquisitions. This results in combinations of older firms and the simultaneous entry of yet existing firms.

To conclude, we made the decision to take advantage of the breadth of information as opposed to depth of information. This choice enabled us to examine characteristics of the industry dynamically over a long period of time.

\subsection{General conclusions and recommendations for further research}

\subsubsection{General conclusions}

What have we learnt from this study? This section seeks to answer this question by bringing forth the general conclusions from this study and by showing how it could apply to other situations. It seeks to make two contributions. The first is in the area of the theory and the second lies within the methodology used. Furthermore, we have composed a future research agenda based on the findings in this study.

If we take the results of the separate examinations together, an interesting picture emerges. First of all, it is plausible that firms in the pulp and paper industry, by their investment behavior, cause the industrial cycle. This was validated using American pulp and paper data. One of the assumptions not tested in the model was that firms behave symmetrically to cycle stages. The results of Chapter 4 confirm the symmetrical behavior hypothesis. Then, the study in Chapter 5 reveals that downsizing reluctantly (thus conservatively) contributes to the performance of firms, both in terms of profitability and market share. This finding again fits nicely into the simulation results in Chapter 3 that show that not downsizing increases the stability of the industrial cycle. It seems that a strategy that works well for the individual firm (downsizing reluctantly) is beneficial for the industry as a whole. This conclusion leads to an adjustment of Figure 1.1, the original framework of this study, in that the strategies uncovered in Chapter 5 feed back to the origins of the industry cycle as dealt with in Chapter 3 . 
Figure 6.2 Adjusted Framework of this thesis

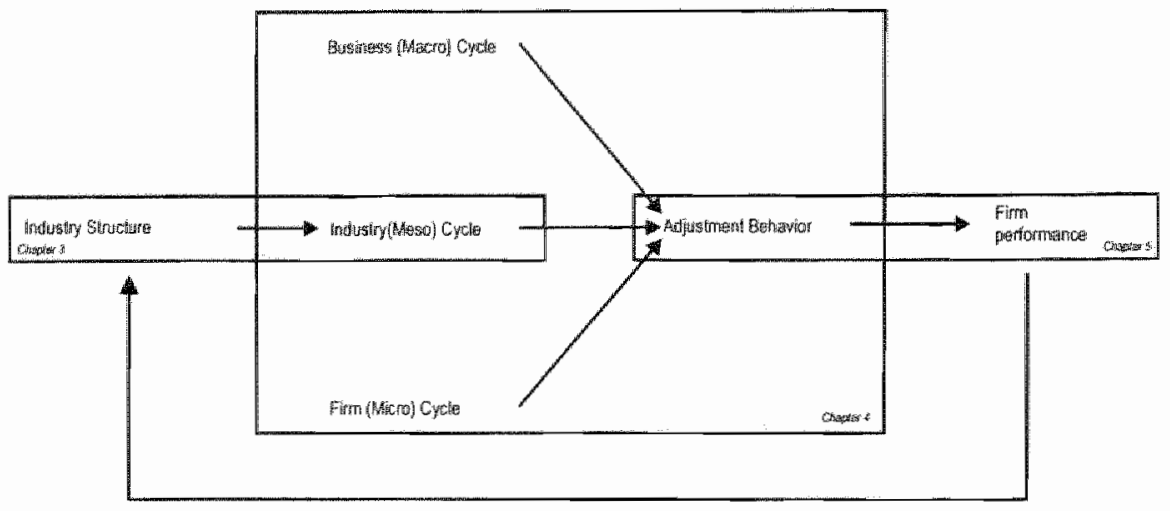

However, an important caveat must be taken into account. This general conclusion should be treated with caution for at least two reasons. First and foremost, the uncovered 'reluctant' strategy could be only beneficial in light of the other strategies employed. This means that if all firms were to switch behavior towards this routine, the competitive advantage might disappear. Second and related is that we have employed a historical data analysis at a high aggregation level. This means that, although the results are robust, we are very careful to not to claim universal truth for our findings (in the industry).

As Chapter 2 argues and Chapter 3 shows, simulation studies of certain economic phenomena strongly enhance our understanding. The possibility to test dynamic hypotheses combined with the kind of empirical instruments used in the other chapters promises a clearer understanding of the structure of the systems under study and enhances the ability to unravel causal relationships. 'The 'static' results found in Chapter 5, for instance, can be interpreted in another way by graphically-looking at the development over time

\subsubsection{Future research}

Cyclicality of other capital-intensive industries can be examined in future studies. In this respect, industries such as chemicals, primary metals and civil aviation have a similar structure (such as significant scale economies and substantial delays between investments and their materialization), also suffering from cyclicality, regardless of the high concentration ratios in some of these industries. Two questions could guide further research in such capital-intensive industries: (a) to what extent should the concentration of supply rise in order to have a 
dampening effect on price volatility, and (b) what other strategies can be applied by producers when influential coordination cannot be attained? These questions can be explored in the same manner, by means of simulation modeling and statistical inference, as was done in this study.

Then, a logical step following Chapter 3 is to dewelop a dynamic simulation model with multiple firms employing the downsizing routine strategies as developed here. The proposition would be that firms employing a reluctant strategy outpace the other firms, given that these employ the other routines. This means adjusting the model in Chapter 3 in a significant way, allowing for multiple producers with their idiosyncratic characteristics and adding a financial structure.

Regarding the change performance studies that were reported in Chapters 4 and 5 , we could assess the effect of different core changes on short-term and long-term performance. In order to do this, we must of course develop proxies for core changes. A logical candidate would be the degree of diversification changing significantly, say 5 percent, in either or both directions. Another parameter of interest is CEO succession and replacement.

To get a deeper insight into the downsizing routines, an examination of firm characteristics of both groups can be made. It can be studied, for instance, to what extent a coherent theory of action guides the investment and downsizing decisions. Logically, this requires a broader data set including more detailed information extracted from, for example, interviews. Furthermore, as the graphs in Chapter 5 show, we might incorporate a demarcation indicator into the regressions to address the start of the era of popularity of downsizing.

Of course, the above list of suggestions for future research is anything but complete. Hopefully, though, this list and this thesis' empirical chapters convincingly communicate the key message that the quantitative panel type of industry research has a bright future. Relentless profit maximizing is a key trend observed in the literature. As has been argued, this trend necessarily leads to an estrangement between people and their work situation. This study shows that being human pays in the longer run and thus, hopefully, provides some food for thought about how to deal with situations of decline. 


\section{Appendix A \\ STOCK-FLOW DIAGRAMS AND EQUATIONS FOR MODELS USED IN CHAPTER 3}

This appendix gives an overview of the development of the simulation model that was used in Chapter 3. First, the basic model and the typical system dynamics iconography will be explained. Additionally, Section 1 provides a graphical sketch and the equations belonging to the model. Then, Section 2 provides the same information about the adjusted model (i.e., both a graphical representation and the equations added).

\section{A.1 Stock and flow representation of the original model (source: Meadows 1970)}

Figure A.1 shows the original model as proposed by Meadows (1970). Within the System Dynamics school, a symbolic language has been developed to represent systems. Without going into much detail, the model represents material stocks, material and informational flows. To explain stocks and flows, it is instructive to use a bathtub as a metaphor. The tub is the container able to hold a certain amount of water, the amount of inflow and outflow of water determines the level of water in the tub. To set the valves, the person taking a bath needs information on the current level and needed level. This example can be seamlessly transposed to the level of capacity. To make an investment decision, a producer needs information on the desired level of capacity, 
the current level of capacity, and the capacity that is already under construction. The sketch of the model clearly distinguishes between flows of goods (double lined arrows) information (single lined arrows) and containers (rectangles).

One feature of system dynamics modeling needs extra attention. The model makes use of curvi-linear functions that have the form of (inverted) S-curves in determining price, per capita consumption and desired capacity. This means that the functions are of a monotonically increasing or decreasing nature. The logic for the form of these curves are highly similar and therefore only the 'per capita consumption requirements' will be high-lighted as an example. Economic theory suggests that consumption is a decreasing function of price: the higher the price, the lower the amount consumed. We are used to graphs that display only the linear parts of this relationship and we take this linearity for granted for computational reasons. Nothing is wrong with this assumption of linearity as long as the conclusions drawn are within the plausible range. Besides, it is commonly accepted that elasticities are not constant. For example: the relationship between price and consumption is as follows. Certain amounts of produce will always be taken no matter how high the price is. Conversely, a maximum amount of produce will be taken no matter how low the price is. We refer to these non-linear (but monotonically increasing or decreasing) relationships as Look-ups and these are defined in the list of equations as pairs in a grid. The hexagons represent their symbol in the graphical description of the model.

We have chosen to abbreviate certain variables in the model for the sake of readability. Those variables, which interpretation might be subject to misinterpretation, are explained below.
- Adj del exp con rate
= adjustment delay for expected consumption rate
- Des prod cap look up
- Efffect of rel inv on paper price look up
- Eq per cap con look up = equilibrium per capita consumption look up




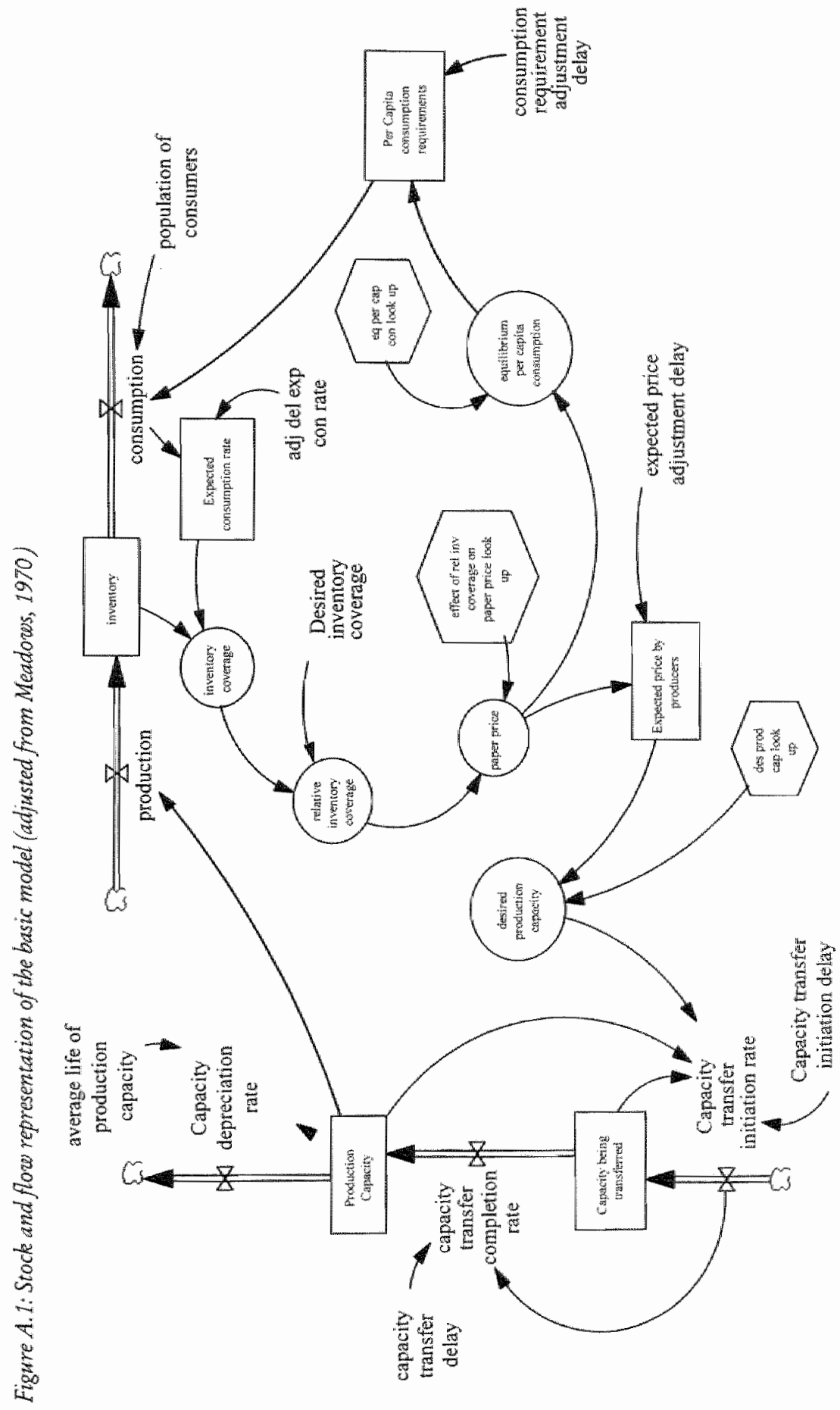




\section{Equations list}

1. capacity transfer completion rate = DELAY FLXED (Capacity transfer initiation rate, capacity transfer delay,0)

2. consumption $=$ population of consumers * Per Capita consumption requirements

3. production $=$ Production Capacity

4. population of consumers $=200$

5. equilibrium per capita consumption = eq per cap con look up(paper price)

6. desired production capacity $=$ des prod cap look up(Expected price by producers)

7. adj del exp con rate $=3$

8. average life of production capacity $=10^{30}$

9. Capacity being transferred = INTEG (Capacity transfer initiation rate-capacity transfer completion rate, 0$)$

10. Capacity depreciation rate $=$ Production Capacity/average life of production capacity

11. capacity transfer delay $=3$

12. Capacity transfer initiation delay $=3$

13. Capacity transfer initiation rate $=$ (desired production capacityProduction Capacity-Capacity being transferred)/Capacity transfer initiation delay

14. consumption requirement adjustment delay $=3$ 
15. des prod cap look up

$([(0,0)-$

$(100,2000)],(0,0),(20,40),(40,200),(60,1000),(80,1200),(100,1280))$

16. Desired inventory coverage $=10$

17. effect of rel inv coverage on paper price look up $([(0,0)-$

$(2,100)],(0,100),(0.25,95.5),(0.5,87),(0.75,72.5),(1,50),(1.25,27),(1.5,15)$ $,(1.75,7.5),(2,0))$

18. eq per cap con look up

$([(0,0)-(100,8)],(0,7),(20,6.5),(40,5),(60,1),(80,0.3),(100,0))$

19. Expected consumption rate $=$ INTEG ((consumption-Expected consumption rate)/adj del exp con rate,600)

20. expected price adjustment delay $=3$

21. Expected price by producers = INTEG ((paper price-Expected price by producers)/expected price adjustment delay, 50)

22. inventory = INTEG (+production-consumption, 6000)

23. inventory coverage $=$ inventory/Expected consumption rate

24. paper price $=$ effect of rel inv coverage on paper price look up(relative inventory coverage)

25. Per Capita consumption requirements = INTEG ((equilibrium per capita consumption-Per Capita consumption requirements)/consumption requirement adjustment delay $\backslash, 3$ )

26. Production Capacity $=$ INTEG (+ capacity transfer completion rate-Capacity depreciation rate, 600$)$

27. relative inventory coverage $=$ inventory coverage/Desired inventory coverage 


\section{A.2 Extended model for the paper and pulp industry}

Figure A.2 shows the extended stock and flow diagram for the paper industry as used in Chapter 3. The added parts are depicted bold and in italics. Variables in brackets $\langle>$ indicate replication of original variables for the sake of representational purposes only.

Abbreviated variable:

- des prod cap add on look up = desired production capacity addition, based on a deviation of the projected price to the equilibrium price. 


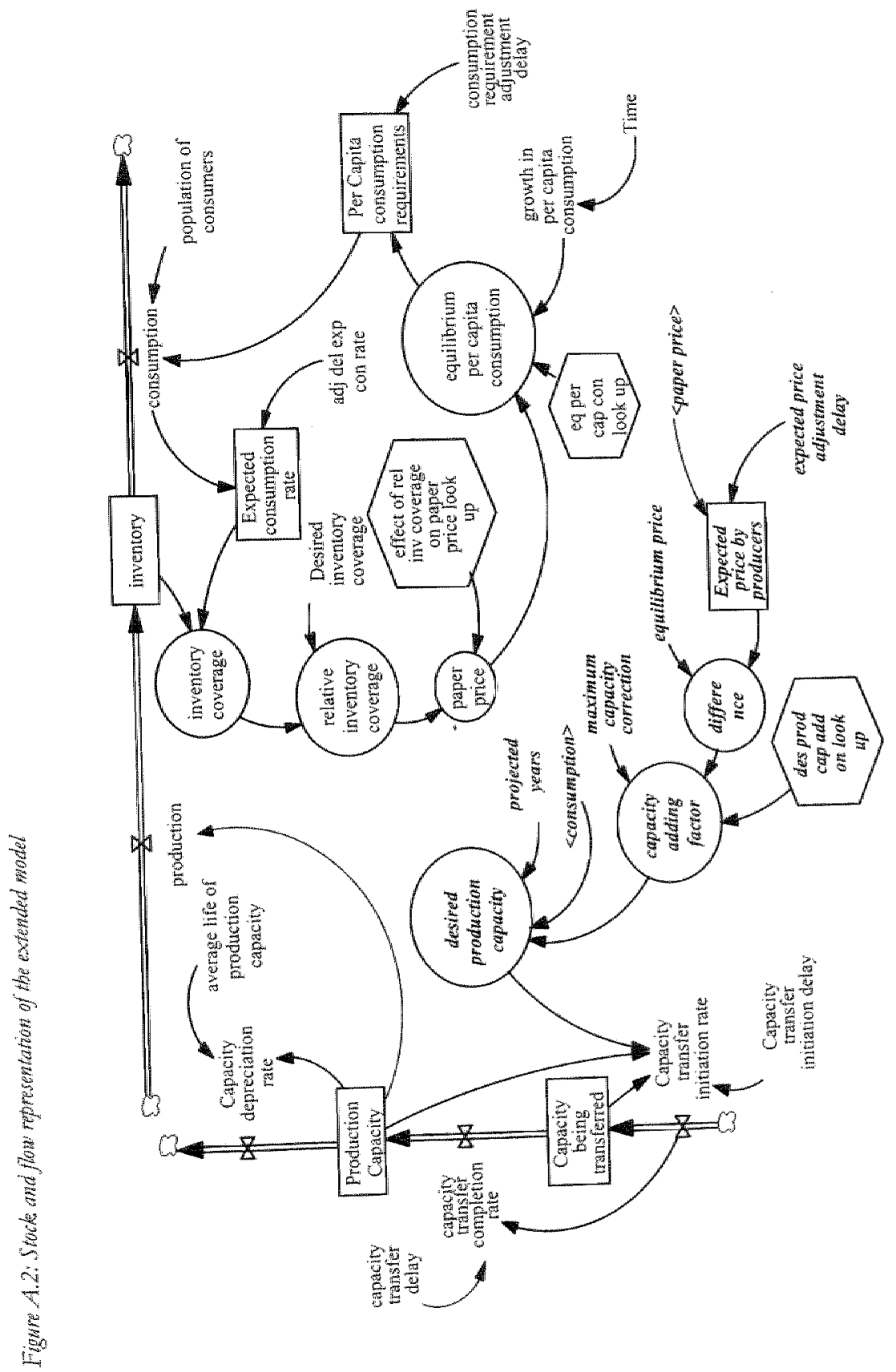


Equations of extended model (only additional or changed equations)

I. desired production capacity $=($ consumption"(1.02) projected years) $)^{*}(1+$ capacity adding factor)

II. capacity adding factor $=$ (des prod cap add on look up(difference)/640)* maximum capacity correction (by changing the look-up so that it reflects capacity addition rather than desired capacity, an equilibrating system is designed. The division through 640 takes care that values range from - 1 to 1 .

III. equilibrium price $=50$

IV. difference $=$ Expected price by producers-equilibrium price

V. maximum capacity correction $=5$

VI. projected years $=4$

VII. Expected price by producers = INTEG ((paper price-Expected price by producers)/expected price adjustment delay, equilibrium price)

VIII. Capacity transfer initiation rate $=$ (desired production capacityProduction Capacity-Capacity being transferred)/Capacity transfer initiation delay

IX. des prod cap add on look up $([(-50,-650)-(50,650)],(-50,-640),(-30,-600),(-10,-$ $440),(0,0),(10,440),(30,600),(50,640))$ 


\section{Appendix B \\ DATA FOR US PAPER AND PULP INDUSTRY}

Table B.1 reports the data that were used to validate the simulation model in Chapter 3. This data set was chosen because Zhang and Buongiorno (1993) used it to test a competing model for investment decisions.

Table B. 1: Data used for model validation

\begin{tabular}{rrrrrr}
\hline Year & Capacity & Price* & Year & Capacity & Price $^{*}$ \\
\hline 1957 & 15185 & - & 1973 & 27621 & 6,441441 \\
1958 & 16030 & 7,404844 & 1974 & 28532 & 7,099391 \\
1959 & 16825 & 7,42268 & 1975 & 28922 & 7,583643 \\
1960 & 17410 & 7,398649 & 1976 & 29210 & 7,557118 \\
1961 & 18134 & 7,324415 & 1977 & 29831 & 7,557756 \\
1962 & 13531 & 7,284768 & 1978 & 30460 & 7,453988 \\
1963 & 19149 & 7,156863 & 1979 & 31179 & 7,451791 \\
1964 & 19662 & 7,16129 & 1980 & 32659 & 7,342233 \\
1965 & 20499 & 7,079365 & 1981 & 33706 & 7,249725 \\
1966 & 22423 & 7,098765 & 1982 & 34665 & 6,994819 \\
1967 & 23167 & 7,065868 & 1983 & 35675 & 6,676707 \\
1968 & 24147 & 6,896552 & 1984 & 37106 & 6,871992 \\
1969 & 25257 & 6,757493 & 1985 & 37581 & 6,644901 \\
1970 & 25806 & 6,752577 & 1986 & 38014 & 6,587591 \\
1971 & 26270 & 6,641975 & 1987 & 39080 & 6,628521 \\
1972 & 27156 & 6,555024 & 1988 & 40211 & 7,032967 \\
\hline
\end{tabular}

*Adjusted for inflation; source: Zhang and Buongiorno (1993). 


\section{Appendix C \\ DETAILED REPORT OF OLS \\ TRANSFORMATION STEPS FOR GLS RESULTS PRESENTED IN CHAPTER 5}

This appendix describes the steps followed to adjust the estimation procedure used in Chapter 5 for the common plagues in an OLS setting. First, however, Table C.1 provides information as to the original OLS results obtained without any adjustment. From these results it is clear that the original OLS results are in line with the GLS results reported in Chapter 5.

Table C.I: Rough OLS coefficients (unstandardized)

\begin{tabular}{|c|c|c|c|}
\hline \multicolumn{4}{|c|}{$N=2401, R^{2}$ adjusted: 0,3139$)$} \\
\hline \multicolumn{4}{|c|}{ Panel A: Control wariables * } \\
\hline$\#$ & Variable & $\mathrm{B}$ & \\
\hline & (Constant) & -0.0234 & $(0.0139) *$ \\
\hline 10 & Diversflication & 0.0218 & $(0.0049) *$ \\
\hline 11 & Capital to sales rakio & -0.0157 & $(0.0012)^{2014}$ \\
\hline 12 & Firm size & 0.0052 & $(0.0012)^{\text {* * * in }}$ \\
\hline 43 & Nuriber of countrias & 0.0001 & 0.0002 \\
\hline \multicolumn{4}{|c|}{ Panel $\mathrm{B}$ : Indlependent variables } \\
\hline 2 & Contemporaneous reluctant asset adi. & 0.0242 & $(0.0024)^{* *}$ \\
\hline 3 & Contempcraneous versatile assel adj. & 0.0011 & $(0,0024)$ \\
\hline 4 & Contemporaneous reluctant workforce adj. & $-0,0061$ & $(0.0024) *$ \\
\hline 5 & Contemporaneous versatile workforce adj. & -0.0013 & $(0.0025)$ \\
\hline 6 & Delayed reluctant asset adj. & 0.0040 & $(0.0025)$ \\
\hline 7 & Delayed versatille asset adj. & .0 .0003 & $(0.0024)$ \\
\hline 8 & Delayed reluctant workforce adj. & 0.0114 & $(0.0023) * *$ \\
\hline 9 & Delayed versatile workforce adj. & 0,0009 & $(0.0026)$ \\
\hline
\end{tabular}

Dependent retum on assets. 
We will subsequently report below how we dealt with (1) multicollinearity, (2) heteroscedasticity and (3) autocorrelation. We scrutinized the sample using the detection methods, suggestions and possible cures as stated by Gujarati (1988).

\section{Multicollinearity}

First of all, an OLS on the dependent variable was run (see Table C.1). The condition index (CI) was chosen as an indicator for the presence of multicollinearity. SPSS reported a $\mathrm{CI}$ of 38 , which indicates severe multicollinearity. It was clear that the covariants caused the highest degree of multicollinearity in the panel. Partial regressions were run on each of the covariants with the others serving as independent variables. Firm size was associated highest with the other three covariants, compared to the other variables. The results of this partial regression are depicted in Table C.2.

Table C. 2 : Coefficients of the most important partial regression

\begin{tabular}{lrl}
\hline Variable * & $B$ & \\
(Constant) & 9.8613 & $(0.0687)^{* \text { *nt }}$ \\
Capital to sales ratio & 0.0482 & $(0.0205)^{* * 4}$ \\
Number of countries & 0.1124 & $(0.0038)^{* * * *}$ \\
Diversification & -1.8561 & $(0.0774)^{* * *}$ \\
\hline
\end{tabular}

* Dependent Variable: Firm size.

We have chosen to drop firm size from the panel, as was indicated in Chapter 5. However, we should first convince ourselves of the effect of this remedial measure. According to Gujarati (1988),

$$
\frac{R_{x_{1} \cdot x_{2} x_{3} x_{4}}^{2} /(k-2)}{\left(1-R^{2}\right) /(N-k+1)}
$$

follows the F-distribution, where $k$ is the number of independent variables, including covariants and the constant, and $N$ denotes the total number of cases. Significance of this statistic indicates multicollinearity. Tests, even without firm size, yielded significant statistics. From the formula it appears that the higher $\mathrm{N}$, the lower the value of $R^{2}$ needs to be in order to produce a significant statistic (with $N=3000$ a $R^{2}$ of 0,0013 suffices!). A random sample of 100 cases from 
the data was drawn and the statistics have been calculated for this subset. Table C.3 summarizes seven OLS regressions in which $\mathrm{X}$ assumes the role of a dependent. Panel $B$ shows no significant Fstatistics any longer. Hence, the conclusion is that multicollinearity is now corrected for. Table C.4 reports the results obtained from a full regression without firm size.

Tabie C.3: Partial regression results on a random sample of 100 cases

\begin{tabular}{|c|c|c|c|c|}
\hline \multirow[b]{2}{*}{$x$} & \multicolumn{4}{|c|}{$\begin{array}{l}\mathrm{R}^{2} \text { from OLS of } \\
X \text { on the others }\end{array}$} \\
\hline & & $n$ & $k$ & F-stat \\
\hline \multicolumn{5}{|l|}{ Panel A: all covanants } \\
\hline Firm size & 0,451 & 100 & 4 & $39,84 *$ \\
\hline Diversilication & 0,331 & 100 & 4 & $24,00 * * *$ \\
\hline Capital to sales ratio & 0,001 & 100 & 4 & 0,05 \\
\hline Number of countries & 0,306 & 100 & 4 & $21,38 *$ \\
\hline \multicolumn{5}{|c|}{ Panel $B$ : firm size dropped } \\
\hline Diwersiffication & 0,010 & 100 & 3 & 0,99 \\
\hline Gapital to sales ratio & 0,009 & 100 & 3 & 0,89 \\
\hline Number of countries & 0,007 & 100 & 3 & 0.69 \\
\hline
\end{tabular}

Table C. 4: Test results corrected for multicollinearity:

OLS Coefficients (unstandardized)*

\begin{tabular}{|c|c|c|c|c|}
\hline \multicolumn{2}{|c|}{ Model } & $\uparrow$ & 2 & 3 \\
\hline \multicolumn{5}{|c|}{ Panel A: Control variables } \\
\hline \multirow[t]{2}{*}{ 批 } & Variable & B & $B$ & $B$ \\
\hline & (Constant) & $0.0350(0.0058)$ & $0.0298(0.0061)^{\text {thtix }}$ & $0.0289(0.0062)^{* 2 *}$ \\
\hline 10 & Diversification & $0.0147(0.0041)^{\text {tutw }}$ & $0.0115(0.004 .4)^{-* *}$ & $0.0100(0.0045)^{* *}$ \\
\hline 11 & Capital to sales ralio & $-0.0149(0.0012)$ & $-0.0145(0.0011)^{\text {twiti }}$ & $-0.0144(0.0011)^{n * *}$ \\
\hline 13 & Number of countries & $0.0010(0.0002)$ **ith & $0.0006(0.0002)^{* \ldots *}$ & $0.0006(0.0002)$ \\
\hline \multicolumn{5}{|c|}{ Panel B: Independent variables } \\
\hline 2 & Contemparancous reluctant asset adj. & & $0.0258(0.0022)$ & $0.0249(0.0023)^{\text {wint }}$ \\
\hline 3 & Contemporaneous versatile asset adj. & & $-0.0023(0.0021)$ & $-0.0009(0.0022)$ \\
\hline 4 & $\begin{array}{l}\text { Contemporaneous reluctant workforce } \\
\text { adj. }\end{array}$ & & $-0.0054(0.0022)$ & $-0.0080(0.0023)^{*}$ \\
\hline 5 & $\begin{array}{l}\text { Contemporaneous versatile workforce } \\
\text { adj. }\end{array}$ & & $-0.0019(0.0022)$ & $0.0000(0.0024)$ \\
\hline 6 & Delayed reluctant asset adj. & & & $0.0013(0.0024)$ \\
\hline 7 & Delayed versatile asset adj. & & & $-0.0025(0.0022)$ \\
\hline 8 & Delayed reluctant worktorce adj. & & & $0.0089(0.0022)$ \\
\hline 9 & Dalayed versatile workforce adj. & & & $.0 .0009(0.0024)$ \\
\hline
\end{tabular}

Panel C: Model statistics

Adiusted R-squuare

0.2533

0.3106

$0.3171^{* * * * *}$

Durbin Walson 'd'

"Dependeni. performance, owtiens removed. 


\section{Heteroscedasticity}

An efficient manner to detect heteroscedasticity is to plot the squared residuals $\left(e_{i}^{2}\right)$ on the predicted values of the dependent $\left(\mathrm{Y}^{\wedge}\right)$ and on the covariants. Figures C.1 to C.4 provide the plots on the predicted dependent variable (C.1), diversification (C.2), the number of countries (C.3) and the capital to sales ratio (C.4).

Figure C.1: Plot of $e_{i}^{2}$ on the predicted $Y$

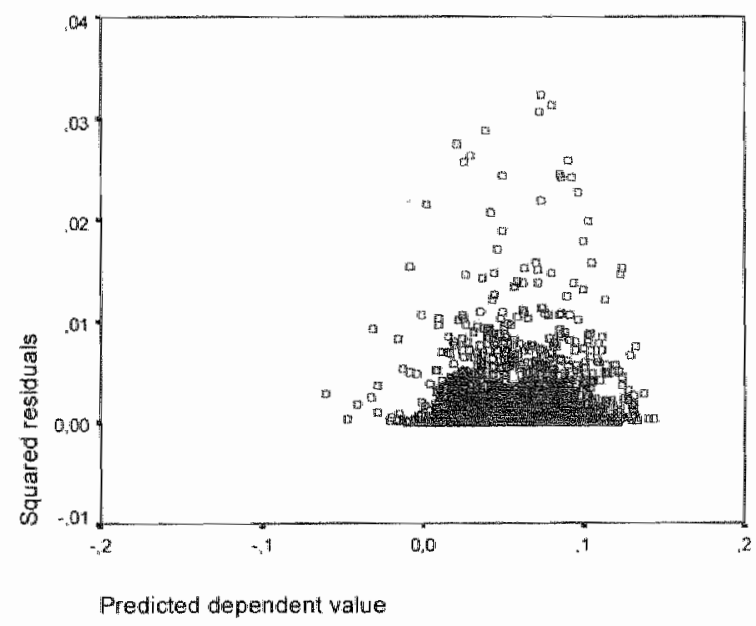

Figure C.2: Plot of $e_{i}^{2}$ on diversification

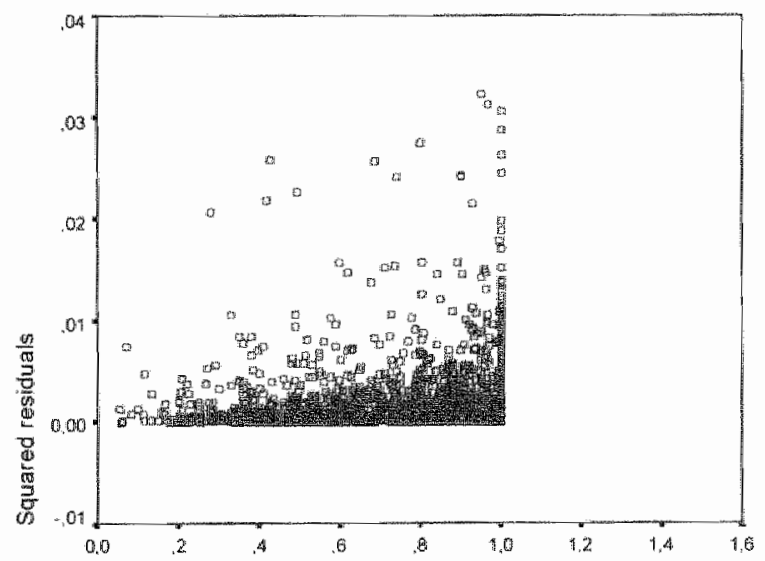

Diversification 
Figure $C_{\text {. }}$ : Plot of $e_{i}^{2}$ on the number of convuries

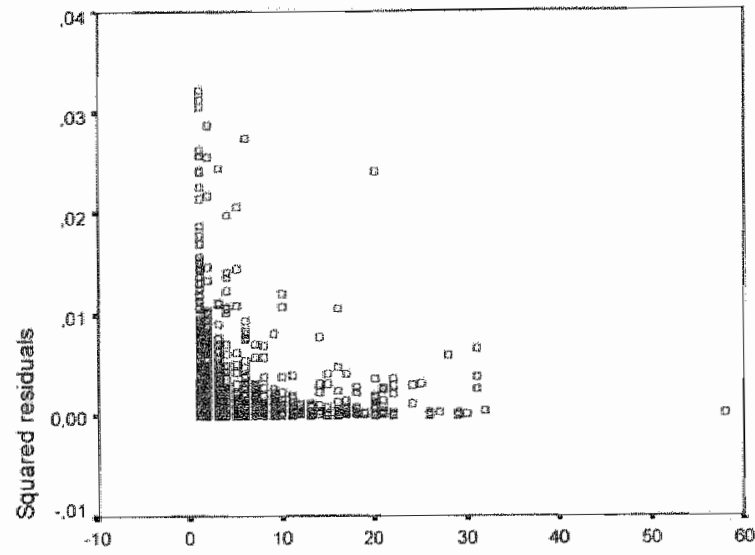

Number of countries

Figme $C_{n} 4:$ Plot of $e_{i}^{2}$ on whe capital to sales ratio

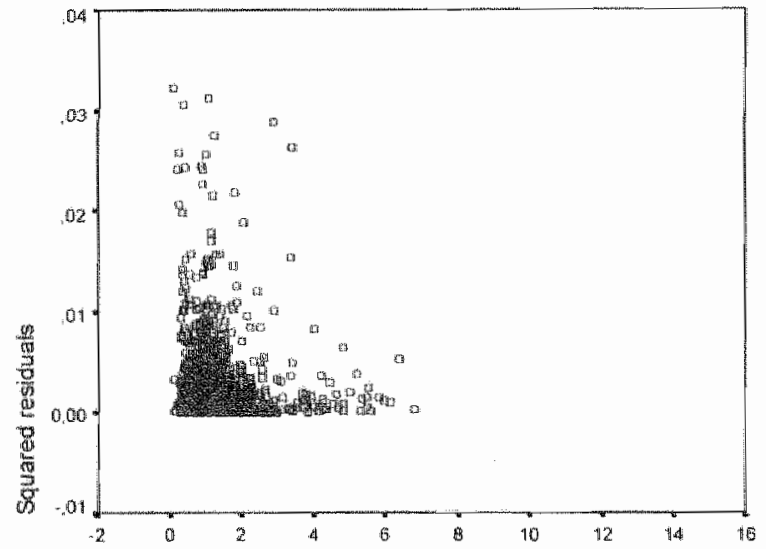

Capital to sales ratio

The squared error on the number of countries seems to increase if the number of countries decreases. This effect, however, dissappears if the number of countries is 1 . Besides, the other variables did not show 
discernible patterns. It has been decided not to correct for heteroscedasticity based on these graphical representations.

\section{Autocorrelation}

Plots of both the unstandardized and standardized residuals ( $\left.e_{i}\right)$ on their one-period lagged values have been constructed, as was indicated in Chapter 5. Figure C.5 and Figure C.6 provide the results for the unstandardized and standardized residuals, respectively.

Figure C.S. Plot of the unstandardized residuals on their one-period lagged values

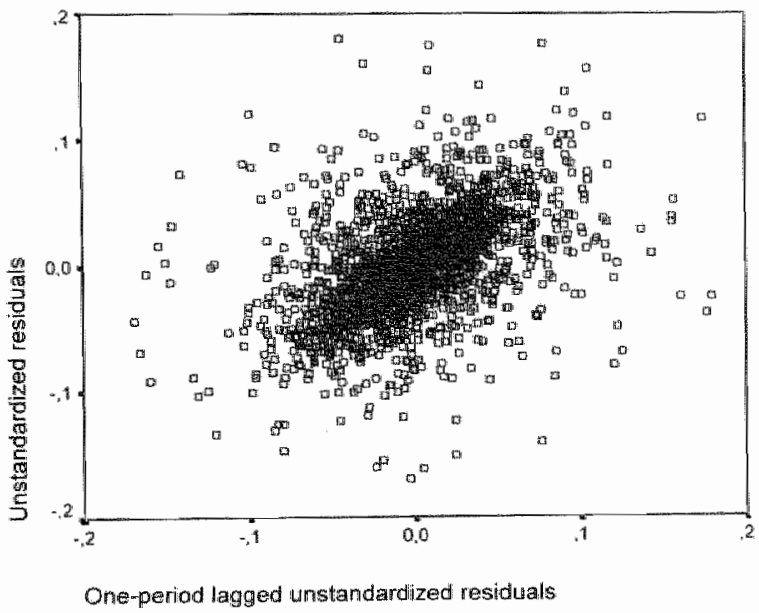


Figure C.6. Plot of the standardized residwals an their one-period laged walues

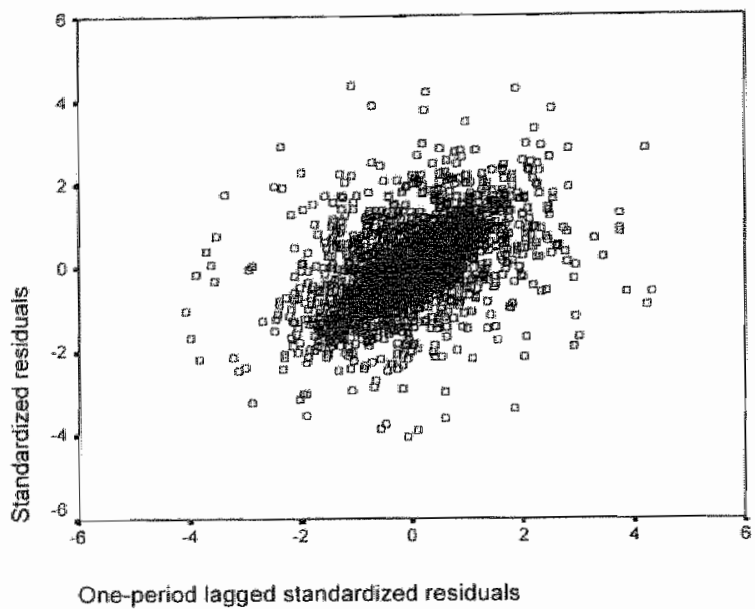

The plots clearly show that autocorrelation is present in the data set. This is confirmed by a Durbin Watson (DW) $d$ of 1.086. The DW sample statistic is derived form comparing lagged residuals to the residuals in the following way:

(2)

$$
d=\frac{\sum_{i=2}^{i=N}\left(e_{r}-e_{t-1}\right)^{2}}{\sum_{t=1}^{=N} e_{t}^{2}}
$$

The acceptation of the hypothesis that auto-correlation is present, depends on sample size and the number of explanatory variables. A table provided by Gujarati (1988: 686) reports the following upper and lower bounds for $\mathrm{N}=200$ and $\mathrm{X}=20: \mathrm{dL}=1.462$ and $\mathrm{dU}=1.896$. Values below $\mathrm{dL}$ indicate positive autocorrelation, and values between $\mathrm{dL}$ and $\mathrm{dU}$ are considered an indecisive indication of autocorrelation. The $d$ from our test thus positively indicates autoregression.

Because $\sum e_{t}^{2} \approx \sum e_{t-1}^{2}$ (for large $\mathrm{N}$ ) and because Gujarati (1988: 376) defines the sample first order coefficient of autocorrelation 
(3) $\hat{\rho}=\frac{\sum e_{i} e_{t-1}}{\sum e_{t}^{2}}$,

the d-statistic can be described as

$$
d \approx 2(1-\hat{\rho}) \text {. }
$$

In our examination we use $\hat{\rho}=0.46$. Note that the OLS coefficients have the optimal properties only asymptotically when estimators are used instead of their true values. However, we think that our sample is sufficiently large to proceed with this estimate. We transformed our original model applying the first autoregressive scheme (Gujarati 1988: 380):

$$
\left(Y_{t}-\rho Y_{t-1}\right)=\beta_{1}(1-\rho)+\beta_{2} X_{2}-\rho \beta_{2} X_{t-1}+\left(u_{t}-\rho u_{t-1}\right),
$$

and performed an OLS on the transformed variables. The resulting $d$. statistic suggested that the autocorrelation was corrected for. The final (GLS) results are depicted in Tables 5.6 and D.3. 


\section{Appendix D \\ CLARIFICATION OF THE SPLIT-UP PROCEDURE FOLLOWED}

As described in the text, the data set consists of firm/year data points. We defined two different 'process' aspects of downsizing 1. Contemporaneous, and 2. Delayed. Both should be considered in context of a downsizing operation in year ' $t$ ' in the following way:

Table D. 1: The process dimension of downsizing

\begin{tabular}{|c|c|}
\hline Doclining finsancial performance in: & Downsizing int \\
\hline$t$ & $\begin{array}{l}\text { contemporaneous } \\
\text { delayed }\end{array}$ \\
\hline
\end{tabular}

Then, the content dimension of downsizing is defined as the area that is influenced by the downsizing decision; in the case of our research these are assets and workforce. Interestingly, the data showed that these two not necessarily coincide. That is, in a given year a company downsizes its assets base but not its workforce or, more often seen, vice versa. Now, every company has been assigned a content membership in each of four resulting main groups:

Group 1: Contemporary asset downsüing

Group 2: Contemporary workforce downsizing

Group 3: Delayed asset downsizing

Group 4: Delayed workforce downsizing

So, each company holds a position in Group 1, Group 2, Group3 and Group 4. 
The nature of downsizing delineates the reaction of a company on declining profits. A company is thought to be a reluctant downsizer if the ratio of downsizes to the number of experienced decline years falls below a certain value. The versatile and inconsistent groups are defined similarly.

The ratios are determined ex post, i.e. we pooled all data per firm over the observation period. These boundary ratio's are reported in Tables 5.3 and 5.8. Thus, a boundary of .20 indicates that firms with a ratio of below 20 are believed to be reluctant in their downsizing propensity (by definition approximately one third of the firms in the data set). The membership (based on process, content and nature) is assigned ex post and is a fixed characteristic of the firm in subsequent analyses.

The consequence of all this is that a firm can have the following characteristics:

Table D.2: Possible downsizing positions of a firm in the sample

\begin{tabular}{lcccc}
\hline & $\begin{array}{c}\text { Contemporaneous } \\
\text { asset downsizing }\end{array}$ & $\begin{array}{c}\text { Contemporaneous asset } \\
\text { downsizing }\end{array}$ & $\begin{array}{c}\text { Delayed asset } \\
\text { downsizing }\end{array}$ & $\begin{array}{c}\text { Delayed wonforce } \\
\text { downsizing }\end{array}$ \\
\hline $\begin{array}{l}\mathrm{ABC} \\
\text { company }\end{array}$ & reluctant & versatile & inconsistent & inconsistent \\
\hline
\end{tabular}

Table D.3 (see pages 140-141) shows the GLS results for 9 runs. As indicated in Chapter 5, Proposition 2 (downsize reluctantly in the face of declining profitability) finds strong support here.

Table D. 4 indicates the number of firms in the sample and their employment of downsizing routines. As can be seen, the majority of firms holds a position on the diagonal, indicating routine preference.

Table D.4: Firms and beir rowtine combinations

\begin{tabular}{lccc}
\hline Number of firms & As. reluctant & As. inconsistent & As. versatile \\
\hline Wt. reluctant & 34 & 17 & 18 \\
Wf. inconsistent & 18 & 40 & 19 \\
W. versatile & 24 & 19 & 33 \\
\hline
\end{tabular}

Table D.5 indicates mean profitability for the different routine combinations. Again, the results suggest superior performance for the reluctant downsizers.

Talale D.5: Mean proftability for the firms bolding different routime combinations

\begin{tabular}{lccc}
\hline Mean ROA (\%) & As. reluctant & As. inconsistent & As. versatile \\
\hline W. reluctant & 8.85 & 3.98 & 7.29 \\
W. inconsistent & 7.65 & 5.00 & 4.41 \\
Wi. wersatile & 7.45 & 4.94 & 3.33 \\
\hline
\end{tabular}




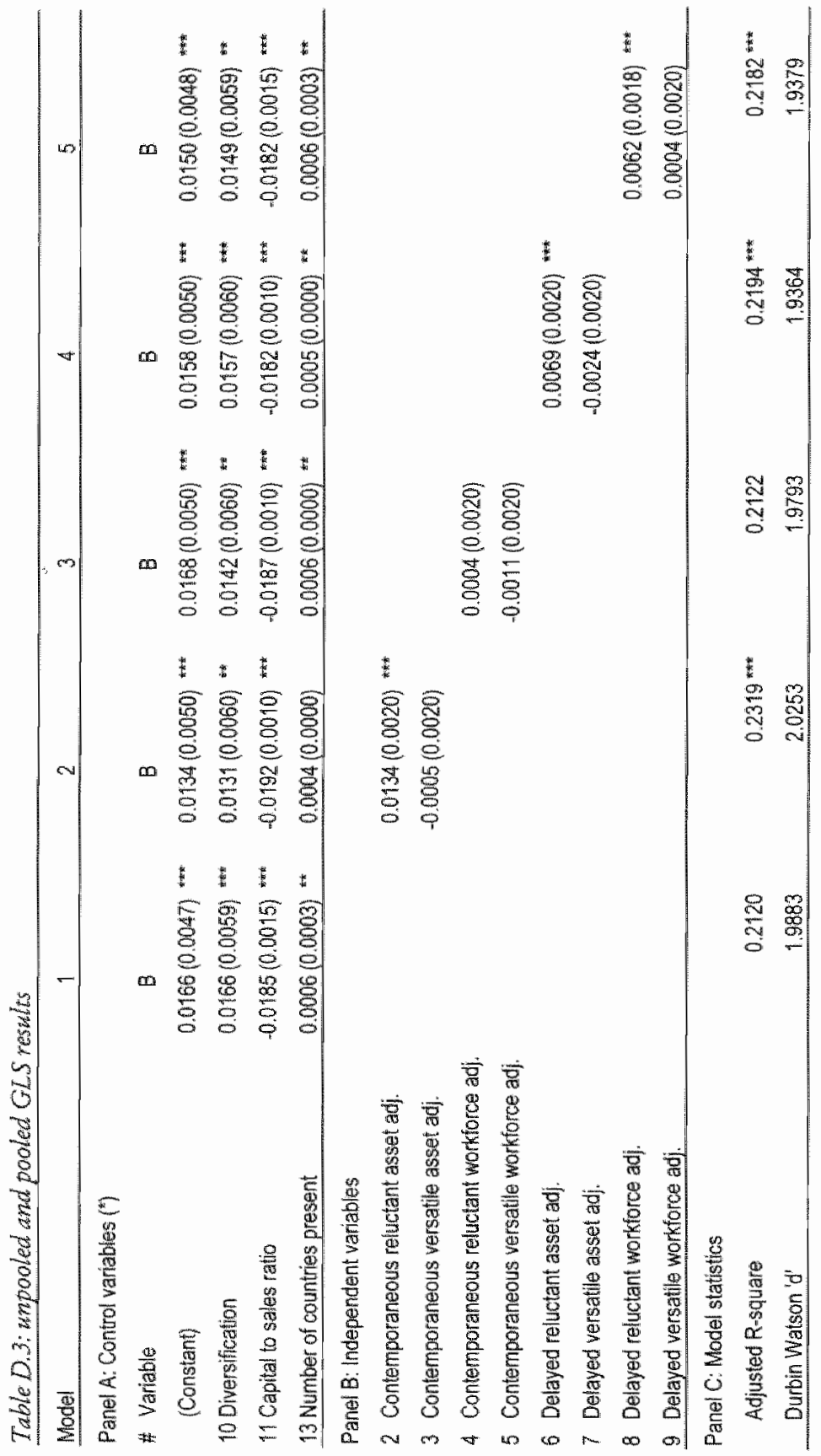




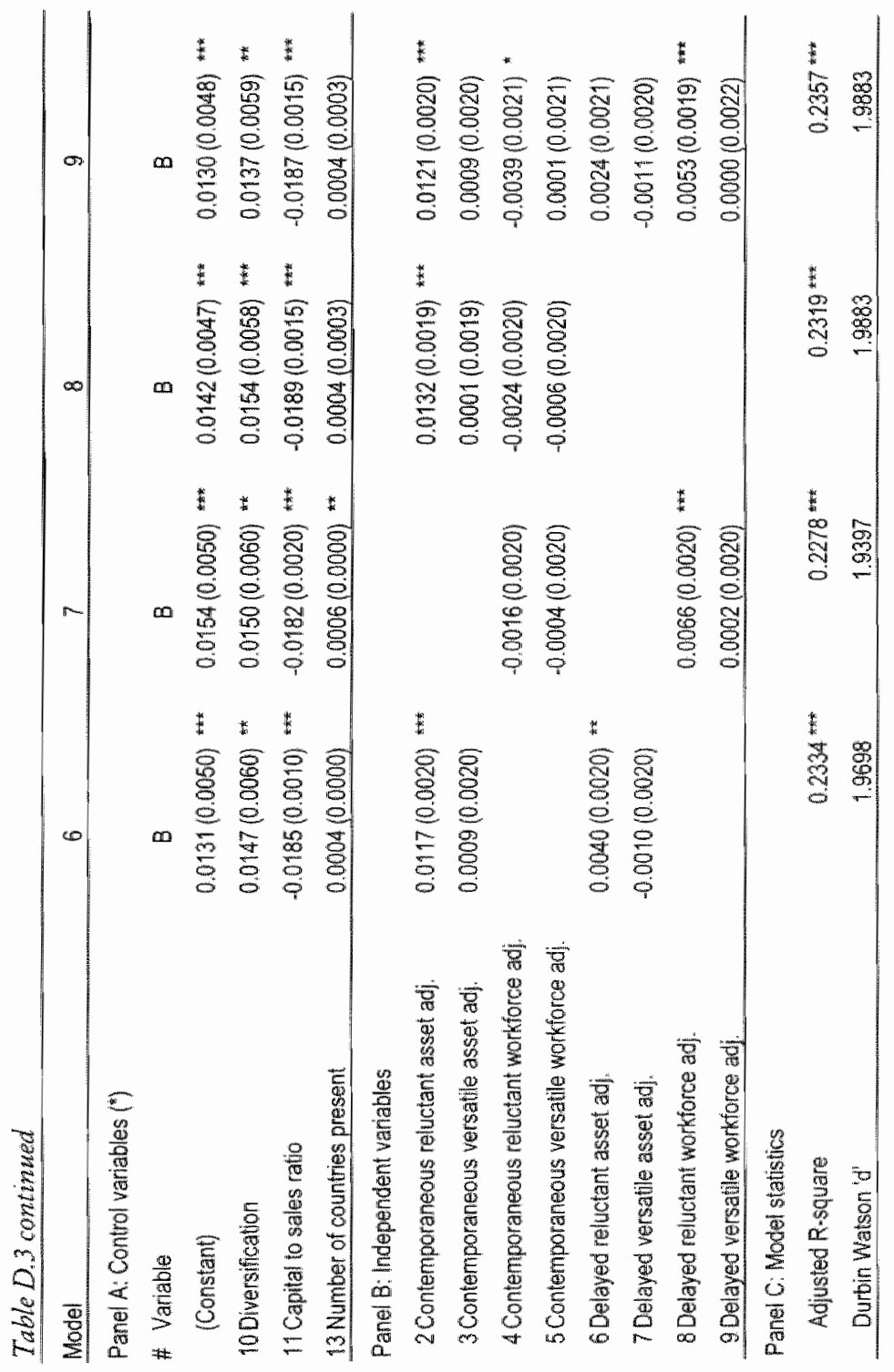




\section{REFERENCES}

Abel, A.B., A.K. Dixit, J.C. Eberly and R.S. Pindyck (1996), 'Options, the Value of Capital and Investment', Quarterly Jowmal of Economics, August pp. 753-777.

Abrahamson, E. (1997), "The Emergence and Prevalence of Employee Management Rhetorics: The Effects of Long Waves, Labor Unions, and Turnover', Academy of Management Jowmal, vol. 40(3) pp. 491-533.

Aken, J.E. van (1998), "Management Theory Development on the Basis of the Design Paradigm', Unpublished paper, Eindhoven University of Technology.

Alibaig, S. and B. Lilly (1999), 'Updating your Forecasting System: Wisconsin Tissue"s Experience', Joumal of Business Forecasting Methods and Systems, vol. 18(3) pp. 13-18.

Allen, T.D., D.M. Freeman, R.C. Reizenstein and J.O. Rentz (1995), 'Just Another Transition? Examining Survivors" Attitudes over Time', Acadeny of Management Journal, vol. 38 pp. $78-82$.

Amburgey, T.I., D. Kelly and W.P. Barnett (1993), 'Resetting the Clock: the Dynamics of Organizational Change and Failure', Administrative Science Quarterly, vol. 38 pp. 51-73.

Anonymous (1982), 'Versatile Computer Modeling System Helps Paper Company Determine Optimum for its Resources', Administrative Management, vol. 43(1) pp. 49-50.

Argyris, C. and D. Schön (1978), Organizational Learning: a Theory of Action Perspective, Philippines: Addison-Wesley Publishing company.

Argyris, C., R. Putnam and D. Mclein-Smith (1985), Action Science, San Francisco: Jossey Bass Publishers.

Barlas, Y. (1989), "Multiple Tests for Validation of System Dynamics Type of Simulation Models'. European Journal of Operational research, vol. 42 pp. 59-87.

Baum, J.A.C. and H.A. Haveman (1997), 'Love thy Neighbor? Differentiation in the Manhattan Hotel Industry, 1898-1990', Administrative Science Quarterly, vol 42(2) pp. 304-338.

Baum, J.A.C. and H.J. Korn (1996), 'Competitive Dynamics of Interfirm Rivalry", Academy of Management Joumal, vol. 39 pp.255291. 
Baum, J.A.C. (1995), 'Organizational Ecology', in: Clegg, S.R, C. Harding and W. Nord (eds.), Handbook of Organization Studies, London: Sage.

Beijdorff, R.O., D.R. Davies and J.Q. Rade (1982), 'Recycling of Waste Paper from Domestic Refuse', in: Ansoff H.J., A. Bosman and P.M. Storm [eds.], Understanding and Managing Strategic Change, Amsterdam: North-Holland Publishing Company, pp. 149-192.

Bell, J. and P. Senge (1980), 'System Dynamics and the Scientific Method,', in: Randers J. [ed.], Elements of the System Dynamics Method, Waltham: Pegasus Communications.

Berends, P.A.J. and A.G.L. Romme (1999), 'Simulation as a Research 'Tool in Management Studies', European Management Journal, vol. 17 pp. 576-583.

Berends, P.A.J. and A.G.L. Romme (1997), 'De Transformatie van KNP BT', Economisch Statistische Berichten, vol. 82(4128) pp. 865-867.

Berry, C.H. and A.P. Jacquemin (1979), 'Entropy Measure of Diversification and Corporate Growth', Joumal of Industrial Economics, vol. 27 pp. 359-369.

Beyer, J.M. and H.M. 'Trice (1982), "The Utilization Process: a Conceptual Framework and Synthesis of Empirical Findings', Administrative Science Quarterly, vol. 27 pp. 591-622.

Black, F. (1987), Business Cycles and Equilibrium, New York: Basil Blackwell.

Boone, C. and A. van Witteloostuijn (1995), 'Industrial Organization and Organizational Ecology: the Potentials for Crossfertilization', Organization Studies, vol. 16. pp. 265-298.

Boone, C., B. de Brabander and A. van Witteloostuijn (1996), 'CEO Locus of Control and Small Firm Performance: an Integrative Framework and Empirical 'Test', Journal of Management Studies, vol. 33(5) pp. 667-699.

Boone, C., V.K. Bröcheler and G.R. Carroll (2000), 'Application and Tests of Resource-Partioning Theory among Dutch Auditing Firms for 1986 to 1992', Organization Studies, vol. 21(2) pp. $355-381$.

Brown, S.L. and K.M. Eisenhardt (1997), 'The Art of Continuous Change: Linking Complexity Theory and Time-paced Evolution in Relentlessly Shifting Organizations', Administrative Science Quarterly, vol.42 pp. 1-34. 
Buchanan, D. and A. A. Huczynski (1997), Organizational Bebaviowr, London et c.: Prentice Hall.

Butler, P., P. Ninios, H. Sabert and J. Morecroft (1998), "Wooing Investors to Prevent Cyclicality', The McKinsey Quarterly, pp. 166-172.

Calori, R. and J.M. Ardisson (1988), "Differentiarion in "Stalemate Industries", Strategic Management Jownal, vol. 9 pp. 255-269.

Cameron, K.S., M.U. Kim and D.A. Whetten (1987a), 'Organizational Effects of Decline and Turbulence, Administrative Science Qwarterly, vol. 32 pp. 222-240.

Cameron, K.S., D.A. Whetten and M.U. Kim (1987b), 'Organizational Dysfunctions of Decline', Academy of Management Jowmal, vol. 30(1) pp. 126-138.

Cameron, K.S., S.J. Freeman and A.K. Mishra (1991), 'Best Practices in White-Collar Downsizing: Managing Contradictions', Academy of Management Executive, vol. 5(3) pp. 57-73.

Carroll, G.R. (1994), 'Organizations.....the Smaller they get', California Management Review, vol. 37(1) pp. 28-41.

Carroll, G.R. and J.R. Harrison (1994), 'On the Historical Efficiency of Competition between Organizational Populations", American Joumal of Sociology, vol. 100(3) pp. $720-749$.

Carroll, G.R. (1993), 'A Sociological View on why Firms Differ', Strategic Management Journal, vol. 14 pp. 237-249.

Carroll, G.R. [ed.] (1988), Ecological Models of Organizations, Cambridge (Mass.): Barlington Publishing Company.

Cascio, W.F., C.E. Young and J.R. Morris (1997), 'Financial Consequences of Employment-Change Decisions in Major U.S. Corporations", Academy of Management Journal, vol. 40(5) pp. 1175-1189.

Chang, S.J. (1996), "An Evolutionary Perspective on Diversification and Corporate Restructuring: Entry, Exit and Economic Performance during 1981-1989', Strategic Management Joumal, Vol. 17 pp. $587-611$.

Chatterjee, S. and J.D. Blocher (1992), "Measurement of Firm Diversification: Is it Robust?', Academy of Management Joumal, vol.35 pp. 874-888.

Checkland, P. and J. Scholes (1990), Soft Systems Methodology in Action, Chicester: Wiley. 
Cohen, M.D., J.G. March and J.P. Olsen (1972), 'A Garbage Can Model of Organization Choice', Administrative Science Quarterly, vol. 17 PP.1-25.

Cooper, D.R. and C.W. Emory (1995), Business Research Methods, Chigago et c.: R.D. Irwin.

Cyert, R.M., and J.G. March (1963), A Behavioral Tbeory of the Firm, Englewood Cliffs (NJ): Prentice Hall.

Davis, P.S., R.B. Robinson, J.A. Pearce and S.H. Park (1992), 'Business

Unit Relatedness and Performance: A look at the Pulp and Paper Industry', Strategic Management Joumal, vol. 13 pp. 349 . 361.

Dawson, R.E. (1962), "Simulation in the Social Sciences", in: Guetzkow, H. [ed.], Simulation in Social Science: Readings, Englewood Cliffs (N.J.): Prentice Hall.

Delacroix, J. and A. Swaminathan (1991), "Cosmetic, Speculative and Adaptive Organizational Change in the Wine Industry', Administrative Science Quarterly, vol. 36 pp. 631-661.

Delacroix, J. and M.E. Solt (1988), 'Niche formation and foundings in the Californian Wine Industry 1941-1984', in: Carroll, G.R. [ed.], Ecological Models of Organizations, Cambridge (Mass.): Barlington Publishing Company.

Dixit, A.K., and R.S. Pindyck (1995), "The Option Approach to Capital Investment', Harvard Business Review, pp.105-115.

Dutton, B. (1992), "Scaling the Heights to Meet Rising Demands", Manufacturing Systems, vol. 10(6) pp. 18-22.

Ford, D.N. and J.D. Sterman (1998), 'Dynamic Modeling of Product Development Processes', System Dynamics Review, wol. 14 pp. $31-68$.

Forrester, J.W. (1961), Indwstrial Dynamics, Cambridge (MA): MIT Press.

Forrester, J.W. (1976), 'Business Structure, Economic Cycles, and Economic Policy", Futtres, June pp. 195-214.

Forrester, J.W. (1987), 'Nonlinearity in High-order Models of Social Systems', European Joumal of Operational Research, vol. $30 \mathrm{pp}$. 104-109.

Forrester, J.W. and P.M. Senge (1980), 'Tests for Building Confidence in System Dynamics Models', in: Legasto A.A.y Forrester J.W. and Lyneis J.M. [eds.] TMMS Studies in the Management Sciences vol. 14 pp. 109-228. 
Fudenberg, D. and J. Tirole (1991), Game Theory, Cambridge (MA): MIT press.

Gallet, C.A. (1997), 'Cyclical Fluctuations and Coordination in the US Steel Industry', Applied Economics, vol. 29 pp. $279-285$.

Gardiner, P.C. and A. Ford (1980), 'Which Policy Run is Best, and Who Says So?', in: Legasto, A.A., J.W. Forrester and J.M. Lyneis [eds.] System Dynamics, TIMS Studies in the Management Sciences, vol. 14 pp. 241-257.

Glass, M. (1997), 'Graphic Papers, where to Next?', Pima's International Papermaker, February pp. 36-40.

Gordon, D.M. (1996), Fat and Mean: the Corporate Squeeze of Working Americans and the Myth of Managerial Downsizing", New York et c.: The Free Press.

Graham, A.K. (1980), 'Parameter Estimation in System Dynamics Modeling', in: Legasto, A.A., J.W. Forrester and J.M. Lyneis [eds.] System Dynamics TIMS Studies in the Management Sciences, vol. 14 pp. 229-245.

Greenberger, M., M. Crenson and B. Crissey (1976), Models in the Policy Process, New York: Russell Sage Foundation.

Greve, H.R. (1998), 'Performance, Aspirations and Risky Change', Administrative Science Quarterly, vol. 43 pp. 58-86.

Greve, H.R. (1999), 'The Effect of Core Change on Performance: Inertia and Regression toward the Mean', Administrative Science Quarterly, vol. 44 pp. 590-614.

Guetzkow, H. [ed.] (1962), Simulation in Social Science: Readings. Englewood Cliffs, N.J.: Prentice Hall.

Gujarati, D.N. (1988), Basic Econometrics, New York: McGraw-Hill. Hair, J.F., R.E. Anderson, R.L. Tatham and W.C. Black (1998), Multivariate Data analysis, Upper Saddle River (NJ): Simon and Schuster.

Haleblian, J. and S. Finkelstein (1999), "The Influence of Organizational Acquisition Experience on Acquisition Performance: a Behavioral Perspective', Administrative Science Quarterly, vol. 44 pp. 29-56.

Hall, R.I. (1976), 'A System Pathology of an Organization: the Rise and Fall of the Old Saturday Evening Post', Administrative Science Quarterly, vol. 21 pp. 185-211.

Hambrick, D.C. (1994), "What if the Academy Actually Mattered?", Academy of Management Review, vol. 19, pp. 11-16. 
Hammermesh, D.S. and G.A. Pfann (1996), Adjustment Costs in Factor Demand', Joumal of Economic Literature, vol. 34 pp. 1264-1292.

Hannan, M.T. and J. Freeman (1984), 'Structural Inertia and Organizational Change', American Sociological Reviews, vol. 49 pp.149-164.

Hannan, M.T. and J. Freeman (1993), Organizational Ecology, Cambridge (US): Harvard University Press.

Haveman, H.A. (1992), 'Between a Rock and a Hard Place: Organizational Change and Performance Under Conditions of Fundamental Environmental Transformation', Administrative Science Quarterly, vol. 37(1) pp. 48-75.

Haveman, H.A. (1993), 'Follow the Leader: Mimetic Isomorphism and Entry into New Markets', Administrative Science Quarterly, vol. 38 pp. 593-627.

Haxholdt, C., C. Kampmann, E. Mosekilde and J.D. Sterman (1995), 'Modelocking and Entrainment of Endogenous Economic Cycles', System Dynamics Review, vol. 11(3) pp. 177-198.

Heijlijes, M.G. (1995), Organizational Fit or Failure, Competitive Environments, Generic and Specific Strategies in Great Britain and The Netberlands, Maastricht: Universitaire pers.

Hofstede, G. (1991), Cultures and Organizations: Software of the Mind, London: McGraw-Hill.

Homer, J.B. (1993), 'A System Dynamics Model of National Cocaine Prevallence", System Dynamics Review, vol. 9 pp. 49-78.

Homer, J.B. (1997), 'Structure Data, and Compelling Conclusions: Notes from the Field', System Dynamics Review, vol. $13 \mathrm{pp}$. 293-309.

Hosmer, D.W. and S. Lemeshow (1989), Applied Logistic Regression, New York et c.: John Wiley and Sons.

Huber, G.P. and W.H. Glick [eds.] (1993), Organizational Change and Redesign: Ideas and Insigbts for Improving Performance, New York: Oxford University Press.

Ingram, P. and J.A.C. Baum (1997), 'Population Level Learning in the Manhattan Hotel Industry, 1898-1990', Administrative Science Quarterly, vol. 42(1) pp. 68-102.

Kandill, M. (1997), 'What Differentiates Industrial Business Cycles? A Cross-country Investigation', Applied Economics, vol. 29 pp. 197-212. 
Klaas, B.S. and J.C. Ullman (1995), 'Sticky Wages Revisited: Organizational Responses to a Declining Market-Clearing Wage', Academy of Management Review, vol. 20(2) pp. 281-310.

Klepper, S. (1997), 'Industry Life Cycles', Industrial and Corporate Change, vol. 6(1) pp. 145-181.

Kydland, F.E. [ed.] (1995), Business Cycle Theory, Aldershot: Edward Elgar Publishing.

Lane, D.C. and R. Oliva (1998), 'The Greater Whole: towards a Synthesis of System Dynamics and Soft Systems Methodology', European Journal of Operational Research, vol. 107 pp. 214-235.

Leavitt, H.J. (1996), 'The Old Days, Hot Groups and Managers' Lib.', Administrative Science Quarterly, Vol. 41 pp. 288-300.

Ledbetter, R. (1993), 'Paper Mill Embraces Open Systems with Open Arms', Marufacturing Systems, vol. 11(9) pp. 42-45.

Lilja, K., K. Räsänen and R. Tainio (1992), 'A Dominant Business Recipe: the forest Sector in Finland', in: Whitley, R., European Business Systems, Firms and Markets in their National Contexts, London et c.: Sage Publications, pp. 137-154.

Lucas, R.E. (1981), Studies in Business-Cycle Theory, Oxford: Blackwell. Lynch, R. (2000), Corporate Strategy, Harlow et c.: Prentice Hall. Malcolm, D.G. (1962), 'System Simulation: a Fundamental Tool for Industrial Engineering', in: Guetzkow, H. [ed.] (1962) Simulation in Social Science: Readings. Englewood Cliffs (N.J.): Prentice Hall.

Mascarenhas, B. and D.A. Aaker (1989), 'Strategy over the Business Cycle', Strategic Management Journal, vol. 10 pp. 707-727.

McGee, J. and H. Thomas (1986), 'Strategic Groups: Theory, Research and Taxonomy', Strategic Management Journal, vol. 7 pp. 141160.

McKinley, W., J. Zhao and K.G. Rust (2000), 'A Sociocognitive Interpretation of Organizational Downsizing', Academy of Management Review, vol. 25(1) pp. 227-243.

McKinley, W., R.I. Sutton and T. D'Aunno (1992), 'Decreasing Organizational Size: to Untangle or Not to Untangle?; Building a Model of Work Force Reduction that is Grounded in Pertinent Theory and Data: Reply to McKinley', Academy of Management Reviere, vol. 17(1) pp. 112-137.

Meadows, D.L. (1970), Dynamics of Commodity Production Cycles, Cambridge (MA): Wright Allen Press. 
Mezias, J.M. and S.J. Mezias (2000), 'Resource Partitioning, the Founding of Specialist Firms, and Innovation: The American Feature Film Industry, 1912-1929', Organization Science, vol. 11(3) PP. 306-322.

Mickletwait, J. and A. Woolridge (1997), The Witch Doctors: Making Sense of Management Gurus, London: Viking Press.

Miles, G., C.C. Snow and M.P. Sharfman (1993), 'Industry Variety and performance', Strategic Management Journal, vol. 14 pp.163-177. Miller, C.C. and L.B. Cardinal (1994), 'Strategic Planning and Firm Performance: a Synthesis of more than Two Decades of Research', Academy of Management Joumal, voll. 37 pp. 16491665.

Miller, D. and P.H. Friesen (1984), 'A longitudinal Study of the Corporate Life Cycle', Management Science, vol. 30(10) pp. 1161-1183.

Mills, D.E. (1990), 'Capacity Expansion and the Size of Plants', RAND Journal of Economics, vol. 21(4) pp. 555-566.

Mintzberg, H. (1994), The Rise and Fall of Strategic Planning, New York et c.: Prentice Hall.

Mishra, A.K. and G.M. Spreitzer (1998), 'Explaining How Survivors Respond to Downsizing: the Roles of Trust, Empowerment, Justice, and Work Redesign', Academy of Management Review, vol. 23(3) pp. 567-588.

Mitchell, W.C. (1950), Business Cycles and Their Causes, Berkeley: University of California Press.

Morecroft, J.D. and J.D. Sterman (1994), Modeling for Learning Organizations, Portland (OR): Productivity Press.

Moselkilde, E. and S. Rasmussen (1986), 'Technical Economic Succession and the Economic Long Wave', European Journal of Operational Research, vol. 25 pp. 27-38.

Moser-Illes, L. (1995), Sizing Down: Chronicle of a Plant Closing, Ithaca (NY): ILR Press/Cornell University Press.

Nehrt, C. (1996), 'Timing and Intensity Effects of Environmental Investments', Strategic Management Journal, vol. 17 pp. 537-547.

Nelson, R.R. and S.G. Winter (1982), An Evolutionary Theory of Economic Change, Cambridge (Mass.) et c.: The Belknap Press of Harvard University Press.

Oreskes, N., K. Shrader-Frechette and K. Belitz (1994), 'Verification, Validation, and Confirmation of Numerical Models in the Earth Sciences', Science vol. 263 pp. 641-646. 
Palich, L.E., L.B. Cardinal and C. Miller (2000), "Curvilinearity in the Diversification-Performance Linkage: an Examination of over Three Decades of Research', Strategic Management Journal, vol. 21 pp. 155-174.

Penn, R., K. Lilja and H. Scattergood (1992), 'Flexibility and Employment Patterns in the Contemporary Paper Industry: a Comparative Analysis of Mills in Britain and Finland', Industrial Relations Joumal, vol. 23(3) pp. 214-223.

Pennings, J.M., K. Lee and A. van Witteloostuijn (1998), 'Human Capital, Social Capital and Firm Dissolution', Academy of Management fournal, vol. 41(4) pp. 425-440.

Penrose, E.T. (1959), The Theory of the Growth of the Firm, London: Basil Blackwell.

Peteraf, M.A. (1993), "The Cornerstones of Competitive Advantage: A Resource Based View', Strategic Management Joumal, vol. 14 pp. 179-191.

Pindyck, R.S. and D.L. Rubinfield (1992), Micro Economics, Upper Saddle River (NJ): Prentice Hall International.

Porter, M.E. (1985), Competitive Advantage: Creating and Sustaining Superior Performance, New York: The Free Press.

Porter, M.E. (1991), 'Towards a Dynamic Theory of Strategy', Strategic Management Journal, vol. 12 pp. 95-112.

Ramanujam, V. and P. Varadarajan (1989), 'Research On Corporate Diversification', Strategic Management Journal, vol. 10 pp. 523. 551.

Reynolds-Fisher, S. and M.A. White (2000), "Downsizing in a Learning Organization: Are there Hidden Costs?', Academy of Management Review, vol. 25(1) Pp. 244-251.

Richardson, G.P. (1991), Feedback Thought in Social Sciences, Philadelphia: University of Pennsylvania Press.

Roberts, N., D.F. Andersen, R.M. Deal, M.S. Garet and W.A. Schaffer (1980), Introduction to Computer Simulation: A System Dynamics Approach, Portland (OR): Productivity Press.

Robins, J. and M.F. Wiersema (1995), 'A Resource-Based Approach to the Multi Business Firm: Emperical Analysis of Portfolio Interrelationships and Corporate Financial Performance', Strategic Management Jowrnal, Vol. 16 pp. 277-299.

Romme, A.G.L. (1994), "Changing Business Systems in the European Paper and Pulp Industry', European Management Journal, vol. 12(4) pp. 469-479. 
Rumelt, R.P. (1974), Strategy, Structure and Economic Performance, Cambridge, MA: Harvard University Press.

Scherer, F.M. and D. Ross (1990), Industrial Market Structure and Economic Performance, Boston: Houghton Mifflin Company.

Schumpeter, J.A. (1939), Business Cycles, New York and London: McGraw-Hill.

Senge, P.M. (1990), The Fifth Discipline: the Art and Practice of the Learning Organization, New York: Doubleday Currency.

Shah, P.P. (2000), 'Network destruction: the Structural Implications of Downsizing', Academy of Management Journal, vol. 43(1) pp. 101-112.

Sharma, A and I.F. Kesner (1996), 'Diversifying Entry: Some Ex Ante Explanations for Post Entry Survival and Growth', Academy of Management Joumal, Vol. 39 pp. 635-677.

Sherman, H. and R. Schultz (1998), Open Boundaries, Reading (Mass): Perseus Books.

Stacey, R.D. (1993), Strategic Management and Organizational Dynamics, London: Pitman Publishing.

Stacey, R.D. (1995), 'The Science of Complexity: an Alternative Perspective for Strategic Change Processes', Strategic Management Journal, vol. 16 pp. 477-495.

Stacey, R.D. (2000), Strategic Management and Organizational Dynamics: the Challenge of Complexity, Harlow et c.: Prentice Hall.

Sterman, J.D. (1985), "A Behavioral Model of the Economic Long Wave', Journal of Economic Behavior and Organization, vol. 6 pp. $17-53$.

Sterman, J.D. (1989a), 'Modeling Managerial Behavior: Misperceptions of Feedback in a Dynamic Decision Making Experiment", Management Science, vol. 35 pp. 321-339.

Sterman, J.D. (1989b), 'Misperceptions of Feedback in Dynamic Decision Making', Organizational Bebavior and Human Decision Processes, vol. 43 pp. 301-335.

Sterman, J.D. (2000), Business Dynamics: Systems Tbinking and Modelling for a Complex World, Boston: Irwin/McGraw-Hill.

Stimpert, J.L. and I.M. Duhaime (1997), 'Seeing the Big Picture: The Influence of Industry, Diversification, and Business Strategy on Performance, Academy of Management Journal, vol. 40(3) pp. 560-583. 
Sutton, J. (1991), Sunk Costs and Market Structure: Price Competition, Advertising and the Evolwion of Concentration, Cambridge (US) et c.: The MIT press.

Swaminathan, A. (1995), "The Proliferation of Specialist Organizations in the American Wine Industry, 1941-1990, Administrative Science Quarterly, vol. 40(4) pp. 653-659.

Teece, D.J., R. Rumelt, G. Dosi and S. Winter (1994), 'Understanding Corporate Coherence: Theory and Evidence', Joumal of Economic Behavior and Organization, vol. 23 pp.1-30.

Tirole, J. (1988), The Theory of Industrial Organization, Cambridge (Mass.): MIT-Press.

Truman, E. and P. Draghi (1999), 'The Future Begins on the Floor', Manufacturing Systems, vol. 17(4) pp. 89-94.

Varadarajan, P.R. and V. Ramanujam (1987), 'Diversification and Performance: a Reexamination Using a Two-dimensional Conceptualization of Diversity in Firms', Academy of Management Journal, vol. 30 pp. 380-393.

Wit, R. de (1994), Strategie Bowwen op Golven, proefschrift Erasmus Universiteit.

Witteloostuijn, A. van (1990), 'Learning in Economic Theory: a Taxonomy with an Application to Expectation Formation', Journal of Economic Psychology, vol. 11 pp. 183-207.

Witteloostuijn, A. (1994), Lat Duizend Bloemen Bloeien: Tolerantie in en rond Organisaties, Schoonhoven: Academic Service.

Witteloostuijn, A. van (1998), 'Bridging Behavioral and Economic Theories of Decline: Organizational Inertia, Strategic Competition and Chronic Failure', Management Science, vol. 44(4) pp. 501-519.

Witteloostuijn, A. van (1999), De Anorexiastrategie: Over de Gevolgen van Saneren, Amsterdam: De Arbeiderspers.

Zarnowitz, V. (1985), 'Recent Work on Business Cycles in a Historical Perspective: a Review of 'Theories and Evidence', Journal of Economic Literature, vol. 23 pp. 523-580.

Zavatta, R. (1993), 'The Pulp and Paper Industry' in: Jong, H.W. de [ed.], The Structure of European Industry, Dordrecht: Kluwer Academic Publishers, pp. 91-119.

Zhang, D. and B. Buongiorno (1993), 'Capacity Changes in the United Stated Paper and Paperboard Industries: Q-theory and Empirical Models', Canadian Joumal of Forestry Research, vol. 23 pp. $72-80$. 


\section{Summary in Dutch \\ OVER CYCLICITEIT, AANPASSING EN \\ BEDRIJFSRESULTAAT}

Het onderzoek naar de verklarende factoren van bedrijfsresultaat neemt een prominente plaats in binnen het vakgebied van de organisatiestudies. Bedrijven zijn enerzijds vrij in hun beslissingen en worden anderzijds beperkt in hun invloed door omgevingsfactoren. Inzicht in de effectiviteit van strategische beslissingen, maar ook begrip van het samenspel van omgeving en bedrijf, dragen bij aan een gefundeerd beleid en bestuur.

Dit proefschrift heeft de wederzijdse invloed van ondernemingsprestatie en cycliciteit onderzocht. De verschillende empirische studies in dit boek maken gebruik van de internationale pulp- en papierindustrie alls achtergrond. Het onderzoek, zoals dat in dit proefschrift is gepresenteerd, is gebaseerd op gegevens uit de internationale pulp- en papierindustrie die verzameld zijn over een periode van 24 jaar (1974-1997). De verschillende onderzoeken passen wisselende perspectieven toe en de resultaten dragen bij aan de bestaande literatuur. Deze Nederlandstalige samenvatting geeft de hoofdvragen en de gevonden empirische resultaten uit het onderzoek weer. Wij zullen hier niet uitgebreid refereren aan de gebruikte onderliggende theorieën noch alternatieve verklaringen aandragen aangezien dit in de individuele hoofdstukken is gebeurd. 
Dit proefschrift gaat over economische cycli, het aanpassingsgedrag van ondernemingen onderhevig aan deze cycli en de invloed van anpassingsroutines op de bedrijfsresultaten. We hebben gekozen voor de internationale pulp- en papierindustrie als onderzoeksachtergrond.

De onderzoeksvragen zijn ontstaan vanuit een verwondering over de regelmatige en voortdurend cyclische beweging van winstgevendheid in de pulp- en papierindustrie. Bovendien is de industrie een van de oudste die onze samenleving kent. Daarnaast is de pulp- en papierindustrie een goed voorbeeld van een volwassen industrie die gekenmerkt wordt door weinig groei. Waarom verkeert een industrie die zo oud is en waar ogenschijnlijk de rek uit is niet in een soort equilibrium? En, gegeven de cycliciteit, hoe kan een individueel bedrijf zich nu het beste opstellen in het licht van zijn omgeving, die een permanente golfbeweging laat zien? Deze twee algemene vragen hebben aanleiding gegeven tot de volgende onderzoeksvragen.

1. Wat veroorzakt cycliciteit in volwassen industrieën?

2. Hoe beinvloeden golfbewegingen op verschillende aggregatieniveaus het gedrag van ondernemingen?

3. Hoe beinvloedt de manier wan reageren op cycliciteit bet individuele bedriffsresultaat?

De hier gerapporteerde historische gegevensonderzoeken moeten geplaatst worden in het kader van individuele bedrijfstakstudies, met toepassing van verschillende onderzoekstechnieken. We hebben data verzameld van individuele bedrijven in de pulp- en papierindustrie over verschillende indicatoren die de periode 1974-1997 overspannen. Door het datagedreven karakter van dit proefschrift, ligt de nadruk vooral op kwantitatieve analysetechnieken met als doel betekeniswolle relaties te ontdekken. In de verschillende hoofdstukken worden telkens andere technieken -die in die situatie het meest geschikt leken- toegepast. Zo maakt Hoofdstuk 3 gebruik van systeem dynamische simulatie om de reciprociteitsrelatie tussen investeringen en cycliciteit te onderzoeken. Vervolgens hebben we in Hoofdstuk 4 logistische regressie toegepast 
om groei of daling van productiefactoren van individuele ondernemingen te verklaren. De winstgevendheidshypotheses uit hoofdstuk 5 , tenslotte, zijn getest met behulp van een regressietechniek die bekend staat als 'generalized least squares' (GLS).

In hoofdstuk 2 wordt de pulp- en papierindustrie beschreven alsook de dataset. De gegevens die we gebruikt hebben voor het onderzoek, dekken ongeveer 70 procent van de totale wereldomzet. Ook hebben we in dit hoofdstuk de industrie geanalyseerd an de hand van een industriële-organisatieraamwerk. Vervolgens draagt hoofdstuk 2 argumenten aan voor het gebruik van simulatietechnieken in de sociale wetenschappen.

Hoofdstuk 3 behandelt de eerste onderzoeksvraag en daarmee de oorzaken van industriecycli. "Traditioneel wordt de oorzaals van economisch cycli in een industrie toegeschreven aan invloeden van buiten de industrie, zoals grondstofprijzen, vraagbewegingen en de algemene macro-economische situatie. Hoofdstuk 3 breekt een lans om naast deze externe verklaringen het gedachtegoed aan te vullen met de idee van een interne verklaring. Dat wil zeggen dat de cycliciteit zou kunnen ontstaan vanuit het samenspel van aanbieders binnen de industrie. In Hoofdstuk 3 passen we een model ontwikkeld voor de agrarische industrie aan aan de karakteristieken van de papierindustrie. De resultaten van het gevalideerde model geven aan dat de endogene causaliteit van cycliciteit plausibel is. Uiteraard spelen exogene factoren een rol, maar ceteris paribus kan de golfbeweging verklaard worden door de investeringsacties van de aanbieders binnen de industrie. Naast het zoeken van endogene verklaringen voor de 'boom-and-bust' cyclus van de papierindustrie, hebben we ook gekeken naar de invloed van twee parameters binnen het model: procestechniek en voorraadbeheer. Voor beiden zijn duidelijke trends waarneembaar. Processen blijken flexibeler te worden en de vooruitgang in techniek verkort de bouwduur van nieuwe machines en heeft dus invloed op de vertragingsstructuur binnen de industrie. Tegelijkertijd maakt voortschrijdende voorraadbeheersingtechnologie het steeds aanlokkelijker on voorraden te minimaliseren. Simulatie van het model met verschillende waarden voor deze twee parameters lat zien dat verbeterde proces- en productietechnologie een gunstig effect heeft 
op de amplitude en duur van de golfbeweging. Vermindering van de voorraden, daarentegen, versterkt de cyclus zowel in amplitude als tijd (korter). De conclusie van dit onderzoek opent de weg naar andere dan traditionelle oplossingen voor de cycliciteit in de papierindustrie. Zo zou het bijwoorbeeld voor de industrie weldadig kunnen zijn om grotere voorraden aan te houden om zo vraagfluctuaties op te vangen.

In hoofdstuk 4 wordt de invloed van cycli op het anpassingsgedrag van ondernemingen bekeken. Verschillende aggregatieniveaus van golfbewegingen zijn onder de loep genomen om het verband tussen cyclusfase en aanpassingsrichting (investeren en desinvesteren) te verklaren. Uit de verschillende tests blijkt dat ondernemingen de neiging hebben zich symmetrisch te gedragen ten opzichte van de cyclus. Dat wil zeggen, in opgaande cyclusbeweging investeren en in meergaande beweging desinvesteren. Het gevonden verband voor de productiefactor kapitaal wordt echter sterk gemodereerd door in het verleden behaalde winsten. Interessant genoeg werd dit effect niet gevonden bij de productiefactor arbeid. Hoewel de resultaten aangeven dat bedrijven over het algemeen de neiging hebben zich symmetrisch aan te passen -en dus op zoek zijn naar 'strategic fit'-, zwiggen ze over de invloed van deze reactie op de winstgevendheid.

Hoofdstuk 5 behandelt de vraag of bovenvermelde symmetrische acties uiteindelijk tot een beter bedrijfsresultaat leiden. Daartoe hebben we de symmetrische reacties van ondernemingen over de gehele periode bekeken. Op basis van deze informatie, hebben we drie downsizing routines gedefinieerd. Als eerste noemen we de terughoudende routine. Bedrijven die deze routine hanteren laten zich niet snel verleiden ten opzichte van de andere bedrijven in de dataset tot het nemen van negatieve correcties van hun productiefactoren. Aan de andere kant van het spectrum hebben we de snelle aanpassers gedefinieerd. Vervolgens hebben we het bedrijfsresultaat van deze twee groepen afgezet tegen een derde groep: inconsistente aanpassers. Het blijkt dat de terughoudende dowonsizers beter presteren, zowel financieel als qua marktpositie, dan de inconsistente of de snelle aanpassers.

In hoofdstuk 6 tenslotte, worden de voornaamste conclusies uit de voorgaande hoofdstukken samengevat. Naast een aantal 
methodologische overwegingen geven we de aanzet tot verder onderzoek.

Dit proefschrift draagt op verschillende manieren bij aan het denken over bedriffsprestaties binnen het organisatievalsgebied. Allereerst hebben we een serie factoren bestudeerd die bepalend kunnen zijn voor bedrijfsresultaten binnen de papierindustrie voor een periode van 24 jaar. Industriestudies van deze orde stellen de onderzoeker in staat om patronen van dynamische interactie te bekijken. Ten tweede wordt in dit proefschrift gekeken naar reacties van bedrijven op golfbewegingen in hun omgeving en draagt daarmee bij aan de discussie over symmetrisch dan wel asymmetrisch reageren op deze fenomenen. Daarnaast hebben we theorie ontwikkeld waarin we een verband leggen tussen de aard van de aanpassingsroutine en het lange termijn bedrijfsresultaat. Ten vierde dragen de bevindingen bij aan het klassieke structuur-gedrag-prestatieparadigma door te beargumenteren dat endogene cycliciteit belangrijk is voor het verklaren van industriebrede verschijnselen. Ten slotte draagt iedere individuele empirische studie bij aan de literatuur waarin deze ingebed is. 
: 


\section{CURRICULUM VITAE}

Pieter A.J. Berends was born on 6 November 1968. He holds a Bachelor's degree in Business Administration from Nijenrode University and a Master's degree in Economics and Business Administration of Universiteit Maastricht. His work experience includes having held a managerial position in the Dutch Royal Navy, a directorship of a foundation seeking to bridge the university and society and having been a management trainer for executives. Since November 2000, he is employed as an assistant professor in the Organization Studies Group.

Pieter A.J. Berends werd geboren op 6 november 1968. Na het Gymnasium heeft hij bedrijfskunde aan Nijenrode gestudeerd waarna hij verschillende banen heeft gehad. Zo heeft hij als officier gediend op de HMS Naarden, werkte hij als bestuurder voor een nationale stichting en heeft hij voor het RBA in Venlo verkoopsystemen opgezet. Daarnaast was hij actief als managementtrainer in thet zuiden van het land. In 1994 is hij opnieuw gaan studeren aan de Universiteit Maastricht waar hij in 1996 afstudeerde. Sinds april 1996 is hij in dienst van de universiteit, eerst als docent, daarna 4 jaar als AIO en sinds 1 november 2000 als universitair docent. 